\title{
Allocating Health Care Morally
}

\author{
Einer Elhauge
}

TABLE OF CONTENTS

Introduction $\ldots \ldots \ldots \ldots \ldots \ldots \ldots \ldots \ldots \ldots \ldots \ldots \ldots \ldots \ldots \ldots \ldots, 1452$

I. The Absolutist Position......................... 1457

A. Moral Absolutism v. Professional Ethics............. 1457

B. Why the Absolutist Position Is Untenable ............ 1459

C. Denial Devices ............................... 1461

D. Lessons ...................................... 1464

II. Equal Access to Adequate Care .................... 1465

A. Difficulties in Defining the Right to Adequate Health

Care .................................... 1465

1. Physician-Prescribed Care, Reasonable-Cost Care, and Care Received by Others ...................... 1466

2. "Necessary" Health Care .................... 1467

3. Care that Restores "Normal Species Functioning" ... 1468

4. List-of-Services Approach ..................... 1470

5. Case-by-Case Determinations ................. 1471

6. Concluding Observations ................... 1471

B. The Underlying Redistributional Claim and Its

Traditional Justifications ......................... 1473

1. The Special Importance of Health Care .......... 1476

2. Undeserved Misfortune...................... 1479

3. Unpredictable Need for Health Care ............. 1479

4. Paternalism .............................. 1480

5. Externalities ............................. 1480

C. A Negative Justification for Targeting Health Care ..... 1486

D. The Purely Redistributive Conclusion .............. 1492

III. Health Tradeoffs Within a Fixed Overall Budget........... 1493

A. Medical Measures .............................. 1494

B. Moral Measures of Group Health Maximization ........ 1496

1. Total Lives Saved .......................... 1497

a. More on Random Choice .................. 1500

b. Resources Required and Likelihood of Benefit ... 1502

2. Life Years Saved .......................... 1504

a. Life Years Simpliciter ................... 1504

b. When Maximization of Life Years Conflicts with Total Lives Saved ..................... 1505 
3. Quality-Adjusted Life Years ................. 1508

C. Discrimination, Equitable Baselines, and the Status Quo. 1511

D. Allocations Based on Personal Characteristics......... 1518

1. Uncontrollable Characteristics .................. 1519

2. Improper Conduct ......................... 1521

3. Self-Inflicted Illness........................ 1521

E. Coping with Moral Diversity ................... 1524

IV. Actual or Presumed Prior Consent ................. 1526

A. Timing and Frequency of Consent............... 1527

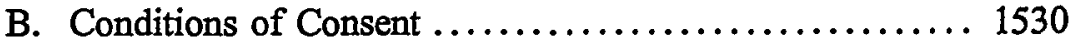

C. When to Presume Consent ..................... 1535

D. What Consent to Presume .................... 1538

E. The Limited Implications of Consent-Based Theory ..... 1541

Concluding Reinarks................................. 1541 


\title{
Allocating Health Care Morally
}

\author{
Einer Elhauge $\uparrow$
}

This Article examines the promise and limits of a moral paradigm for allocating resources both to health care and among competing health care needs, and derives the essential attributes of a moral health care system. The author concludes that, given society's limited resources, the absolutist position that no beneficial health care should ever be denied is untenable. Nonetheless, no health care system can survive unless it avoids ongoing tradeoffs between health needs and monetary costs by imposing a budgetary constraint derived outside the moral paradigm. The author also concludes that the principle that everyone should receive a minimum of adequate care lacks a concrete affirmative meaning sufficient to guide health care allocations. However, the absence in the health care context of important negative reasons for refraining from an equal distribution of societal resources supports defining adequate care roughly as the level of health care enjoyed by the middle class. The author then addresses how to allocate morally a limited budget among the different health care needs of a group. He rejects arguments that certain health maximization standards are discriminatory or in tension with equity, showing that these arguments generally assume without justification that the status quo is the proper baseline for measuring discrimination. Upon examination, each maximization standard simply reflects a different baseline of what an equitable distribution of health care would look like. Although moral analysis provides various useful criteria for making health care tradeoffs within a fixed budget, in the end it cannot dictate any particular measure of group health maximization. Accordingly, individuals should have a diversity of moral choice by being able to choose - among an array of health plans-the plan that allocates resources according to the policy they prefer. Finally, the author examines consent-based theories of moral justice and concludes they cannot alone resolve allocation questions. The reason is that one must go outside the consent-based framework both to determine the timing and con-

Copyright @ 1994 California Law Review, Inc., and Einer Elhauge.

$\dagger$ I am grateful for financial support from the John M. Olin Foundation, the Boalt Hall Dean's Fund, and the Center for European and German Studies. I also thank the University of Florence Law School, the European University Institute, Wolfson College, Cambridge University, the Rockefeller Foundation's Bellagio Center, the Centre for Health Economics at York University, the Karolinska Institute, the Statens Institut for Psykosocial Miljonediein in Stockholm, Yale Law School, Harvard Law Sclool, and University of Chicago Law School for their research support and warm hospitality while I worked there on this Article. Finally, I have had the benefit of helpful comments from Bruce Ackerman, Richard Craswell, Mark Hall, Ed McCaffrey, Eric Rakowski, Peter Schuck, Steve Sugarman, Alan Sykes and the participants in the Yale, Harvard, and University of Chicago Law School Workshops. 
ditions for valid actual consent and, where meaningful actual consent is unfeasible, to determine when and to what individuals should be presumed to have consented. Nonetheless, when coupled with the other propositions derived in this Article, consensual theories can help legitimate binding individuals to their choices among group health maximization policies and can exclude some allocations that we can presume no one would have consented to ex ante. This Article thus provides a morally and practically tenable framework-grounded in a specific proposal-within which individuals can consent to particular health care allocation schemes.

\section{INTRODUCTION}

Health law policy suffers from an identifiable pathology. The pathology is not that it employs four different paradigms for how decisions to allocate resources should be made: the market paradigm, the professional paradigm, the moral paradigm, and the political paradigm. The pathology is that, rather than coordinate these decisionmaking paradigms, health law policy employs them inconsistently, such that the combination operates at cross-purposes.

This imconsistency results in part because, intellectually, health care law borrows haphazardly from other fields of law, each of which has its own imternally coherent conceptual logic, but which in combination results im an imcoherent legal framework and perverse mcentive structures. In other words, health care law has not-at least not yet-established itself to be a field of law with its own coherent conceptual logic, as opposed to a collection of issues and cases from other legal fields connected only by the happenstance that they all involve patients and health care providers.

In other part, the pathology results because the various scholarly disciplines focus excessively on their favorite paradigms. Scholars operating in the disciplines of economics, medicme, political science, and philosophy eacli tend to assume that their discipline offers a privileged perspective. This leads them either to press their favored paradigm too far or to conceptualize policy issues solely im terms of what their paradigm can and cannot solve.

Instead, health law policy issues should be conceived in terms of comparative paradigm analysis. Such analysis focuses on the strengths and weaknesses of the various dccisionmaking paradigms, determining which is relatively better suited to resolving various decisions, and then assigning each paradigm to the roles for which it is best suited. It is front this comparative perspective that this Article analyzes the promise and limits of the moral paradigm for allocating health care resources.

The moral paradigm demies that the questions of what resources should be devoted to and within health care are matters that sliould be resolved by the market, professional judgment, or political forces. Instead, decisions about when health care should be provided call for moral inquiry because 
they affect profound matters of life, death, and health. As we will see, the principles guiding this moral inquiry are varied, including the immorality of allowing death and suffering, the obligation to treat everyone as equals, and the importance of respecting individual autonomy. Often these principles conflict. Moreover, different moral philosophers emphasize different principles and reach different conclusions about their interpretation. One thus cannot speak of $a$ moral paradigm in the sense of one monolithic set of universally agreed moral principles for guiding medical resource allocation. What unites the various positions I will group under the inoral paradigm is not their uniformity but their imsistence that allocation decisions should be derived from moral analysis, rather than dictated by market forces, professional judgment, or political accountability.

What role should such a moral paradigm have in allocating health care resources? Conclusions on such questions can often be hopelessly abstract and slippery. To ground iny analysis, let me assert up front a concrete proposal, one toward which I believe the national health care systems of the world are (from different directions) slowly converging. ${ }^{1}$ The analysis of the moral paradigm offered here supports, when coupled with the strengths and weaknesses of the other paradigms, a health care system having the following elements.

(1) A politically set annual health care budget with an associated tax not linked to employment.

(2) Free access for all individuals to a care-allocating plan.

(3) Individual choice about which plan they wish to join for some significant period (I suggest three years).

(4) Competition among care-allocating plans that each receive a share of the government budget based on the number of individuals they enroll, adjusted for each person's health risk, and that cannot retain profits from their budget (other than a possible bonus linked to total number of enrollees) but must instead spend it on those enrollees. Plans must accept all who wish to enroll.

(5) Management of those care-allocating plans by professionals who have the range of diagnostic expertise to evaluate the health care needs of plan enrollees, who have salaries unaffected by spending decisions (other than a possible bonus per enrollee), and who have a duty to decide how to allocate each plan's budget to purchase those health services that maximize health benefits for the unit's

1. The direction of United States health care reform is well-known. Receiving somewhat less attention in this country is the fact that countries that begin from the opposite extreme of national health care systems, such as Britain and Sweden, are introducing market reforms that move those countries in the opposite direction, but toward what looks like a common destination. See HER MAJESTY's Stationery Office, Working for Pattents (1989) (describing British reforms); Goran BerLeEN et aL., The Reform of Health Care In Sweden: National Report to OECD 29-31 (1992) (describing Swedish reforms). 
enrollees. Their sole incentive should thus be to do a good enough job at rationing to keep and attract enrollees.

(6) Maintenance of the vast majority of health care providers as private suppliers of procedures, tests, and technologies that compete with each other to sell to the care-allocating plans. This should create incentives for cost-effective innovation because suppliers will now face purchasers who have both the knowledge and incentives to trade off the costs and benefits of care.

(7) A politically appointed agency, the members of which are insulated from removal, that has only two tasks: setting risk adjustinents and licensing care-allocating plans by verifying their diagnostic expertise and fiscal soundness. In particular, this agency would not dictate a uniform schedule of covered services because that would be up to each care-allocating plan.

(8) The individual right to purchase additional care outside these plans on the open market.

A full analysis of why the market, professional, and political paradigms support these conclusions is beyond the scope of this Article. ${ }^{2}$ Our present task is more modest, but hardly minor. Does moral analysis support this sort of allocative system? I begin by exploring two versions of what it might mean to have a moral belief im a societal obligation to provide, or an mdividual right to receive, health care. ${ }^{3}$

The first is the absolutist position that health care must be provided whenever it has any positive health benefit. As Part I discusses, this position is obviously untenable: at some point tradeoffs must be inade betwcen health care and other social goods even if health were our only or ultimate goal. While this may seem obvious to many, the point requires some elaboration because this is by far the moral norm most pervasive im actual health law policy debate and most commonly invoked in actual allocative decisionmaking. Thus, one lesson of the analysis in Part $\mathrm{I}$ is that the moral paradigm cannot succeed unless it incorporates, or is limited by the external imposition of, some tradeoff between health care and other goods in life. Another lesson, no less important, is that any system that frames ongoing allocation decisions as a choice between individual health care needs and the monetary cost of that care will inevitably prove unstable.

The second version of the belief im a moral obligation to provide, or a right to receive, health care is the more modest clain that society must provide everyone with at least a minimum of adequate (or decent) health care. Part II examines this clain, concluding that the concept of "adequate

2. Such a full analysis will appear in a forthcoming book on which I am working.

3. A substantial hiterature debates whether this moral question is better conceived of as a societal obligation or an individual right. See DaNiel CaILAHAN, What KIND of LifE: The Limits of MEdical Progress $58 \mathrm{n} .28$ (1990) (collecting sources). Because it does not affect my analysis, I do not take this distinction up here. 
care" has no coherent affirmative meaning capable of guiding decisions about what to allocate either to health care generally or among different health care needs. Rather, at bottom this moral claim reflects a belief that one particular factor-ability to pay-should not significantly affect the health care received.

While this belief seems perfectly consistent with moral claims to distributive justice generally, the oddity is why the redistributive claim is limited to in-kind provisions of health care. After reviewing and rejecting the traditional arguments for targeting health care, Part II concludes that such targeting has less to do with the special positive characteristics of health care than with the absence of some potent negative reasons for pragniatically refraining from the redistribution generally supported by the aims of distributive justice.

This analysis has various implications. An individual's ability to pay should indeed be irrelevant to determining that individual's access to the minimum of adequate care. Moreover, the redistributive nature of this claim allows us to provide rough content to the "adequate care" standard: it means approximately the same level of care as that obtained by the middle class in their society. The right to adequate care, in other words, is the right of equal access to middle-class health care. This does not, however, help us in deciding what level of care the middle class should obtain; the adequate care standard does not determine any particular level of aggregate health care spending or otherwise make the tradeoff between health care and other social goods. Nor does the adequate care standard help us decide how to allocate the aggregate spending among health care needs-other than foreclosing allocative criteria based on ability to pay.

Part III addresses the latter of the questions left open by these adequate care standard: how to allocate, using the inoral paradigm, resources budgeted for health care among different health needs. One imight think that the basic standard should essentially be medical: resources should be allocated so as to maximize the health of the covered population. However, as Part III explores, "group health maximization" has no inherent medical meaning. Group health maximization can be measured in various ways, and the choice among them requires a moral, not medical, judgment. Moreover, as we shall see, each of the major measures of group health maximization reflects a particular notion of what constitutes an equitable distribution of health care among liealth needs.

This helps reveal the flaw in arguments that health maximization standards are discriminatory. Such arguments generally presume without justification that the status quo is the proper baseline for measuring discrimination. One must instead measure discrimination from a baseline of what one regards - on independent moral grounds-as an equitable distribution of health care. Simce each health maximization standard reflects a different baseline, here maximization standards and equity goals are not im 
tension with each other but are alternative manifestations of the same choice of priorities.

Moral and philosophic analysis is thus enormously helpful in structuring allocation decisions within health care. However, this moral analysis has not produced, nor is it capable of producing, any clear winners among the leading measures of group health maximization. Rathcr than suppress this justifiable variety of moral positions by imposing (via elite judgment or public polling) one single maximization measure on all, Part III concludes that society should provide, to the extent possible, ${ }^{4}$ a diversity of inoral choice by allowing individuals to sign up with the care-allocating plan that offers the health maximization policy they most prefer.

Finally, Part IV examines theories of moral justice based on autonoiny and actual or presumed consent. Although often illuminating, prior-consent theories offer no panacea for dissolving the underlying inoral difficulty of determining how to allocate resources. This is because their implications turn radically on four factors: the timing (including frequency) of consent, the conditions under which consent is considered valid, when consent inay be presumed, and to what individuals may be presumed to have consented. Because we must ultimately go outside the consent-based franiework to determine these factors, consensual theories cannot offer a completc inoral justification for health care allocations.

Nevertheless, while unable to provide a complete solution, consensual theories can still offer useful inoral guidance. If we can establish the foregoing parameters for consent through soine other means, consent to a particular method of group health maximization from limited resources can both help establish a diversity of inoral choice and help legitimate binding individuals to the choices they have made. In particular, the analysis in Parts I-III suggests that individual consent should be solicited under conditions where ability and willingness to pay is irrelevant, and where the tiining forces individuals to make soine tradeoff between the benefits and opportunity costs (in foregone health care) of various allocation inethods. Furthermore, although actual consent to specific health care allocation decisions is unfeasible given the information and transaction costs involved, structuring consent as a choice among group health maximization measures can make actual consent more meaningful, and thus uninimize the need to presume consent. And while presumed-consent analysis is far from determinate, it does seein sufficient to exclude some care allocation schemes, including those that are random, discriminatory, or fail to inake risk adjustments. The moral paradigm developed in this Article can thus provide a

4. Self-selection may make some moral norms hard to sustain in a system permitting choice among allocating plans even if a majority agrees with those norms. Risk adjustments will thus be neeessary and, to some degree, the amounts of those risk adjustments will necessarily require a central body to unilaterally impose some allocation choice. See infra text accompanying notes 261-64. 
framework for morally and practically tenable consent to specific allocation schemes.

\section{I}

\section{The Absolutist Position}

At the extreme, the moral paradigm insists that health care should be provided whenever it has any positive health benefit, denouncing as immoral any attempt to weigh health against mere monetary costs. ${ }^{5}$ One method of deriving this absolutist position begins by denying that there is any moral significance to the distinction between action and maction, or between acts and omissions. ${ }^{6}$ Accordingly, if it is immoral to commit acts that kill or injure a human, it is also immoral to allow death or mjury to befall a human through inaction. The person who chooses to act or not act is, in either case, responsible for the death or injury. Failing to provide medical care that could postpone death or alleviate illness is simply one sort of inaction that immorally causes death or imjury. ${ }^{7}$

Other moral absolutists do not rely on a denial of the act/omission distinction, but draw on the basic moral intuition that it remains morally unacceptable not to exert effort that could save lives and alleviate suffering, even if such failure to act is not tantamount to niurder or beating. Some draw on religious beliefs in the sanctity of the hife endowed in us by God. Other times the impulse toward absolutism flows from the charge that any failure to provide beneficial care reflects a cold-hearted indifference toward hunian suffering or conflicts with the moral belief that life and health have priceless value. $^{8}$

This version of the moral paradigm verges on the professional paradigm, which defines the ethical commitment of professionals in much the same way. But, even in this extreme form, the moral paradigm differs from the professional paradigm in several ways. I begin by sorting out these distinctions before analyzing the moral absolutist claim itself.

\section{A. Moral Absolutism v. Professional Ethics}

The nost important difference between moral absolutism and the professional ethical commitment to patient health hes in their different foundations. Specifically, the absolutist position rests on moral claims about patients' entitlements to health care, not a (somewhat noblesse oblige) sense of what obligations professionals should inipose upon themselves.

5. Paul T. Menzei, Strong Medicine: The Ethical Rationing of Health Care 5 (1990).

6. See Jonathan Glover, Causing Death and Saving Lives 92-112 (1977); John Harris, The VALUE OF LIFE 28-33 (1985).

7. HARRUS, supra note 6 , at $48-63$.

8. See Guido Calabrest \& Philit Bobbitt, Tragic Chotces 32, 39, 49 (1978); Callahan, supra note 3 , at 213. 
One implication of this distinction is that the moral paradigm does not limit the obligation to physicians, but imposes the obligation on society at large. Another implication is that, unlike the professional paradigm, the moral paradigm does not necessarily vest decisionmaking power in selfregulating professionals protected from competition and lay control. Because the obligation to provide health care is part of a more general moral obligation to preserve life, "professionals have no special prerogatives in the interpretation of that obligation." Such interpretation is instead performed either by moral philosophers, ethical consultants, or the relevant moral community. In contrast, the American Medical Association Code "assumes that the moral standards which should apply to physicians are essentially a creation of the profession itself.", 10

These foundational differences result in more specific differences between professional ethics and the moral absolutist claim. First, the professional paradigm defines the physician's obligation as one to provide all beneficial care to those patients the physician has agreed to take on: the physician may not abandon patients, but has no affirmative obligation to accept them as patients in the first place. ${ }^{11}$ Moral absolutism, on the other hand, msists that physicians have a moral obligation to take on all patients who have health care needs that would otherwise go untreated. ${ }^{12}$

Second, while the professional paradigm might allow limits on the number of professionals or equipinent as a rough cost constraint, such limits would be rejected by moral absolutism. Any demal of health care produced by a limit on the number of professionals or equipment would be the inoral responsibility of those who imposed the limit.

Third, and relatedly, under moral absolutism society has an affirmative duty to provide the resources necessary to elimmate any scarcity that prevents the provision of beneficial health care. ${ }^{13}$ Nonphysicians must exert just as much effort as physicians to fulfill this societal obligation, which all of us can carry out by funding the training and hiring of as many medical professionals, and the purchase and use of as many pieces of medical equipinent, as are necessary to provide all health care that has any health bene-

9. HARRIS, supra note 6, at 56 (emphasis omitted). This also holds for less extreme versions of moral obligations under the moral paradigm. See, e.g., Robert M. Veatch, DRGs and the Ethical Reallocation of Resources, 16 HASTINGS CENTER REP. 32, 38 (1986) (arguing that social decisions about ethics should not be made by health professionals in their clinical capacity).

10. Larry R. Churchill, Rationing Health Care in america 28-29 (1987).

11. See, e.g., id. at 29-30 (discussing the AMA's 1957 "Principles of Mcdical Ethics").

12. HARRis, supra note 6, at 50-54. If this requires physicians to exert more effort than nonphysicians, then physicians will have a moral claim to additional support from nonphysicians. See infra text accompanying notes 13-14. But, under the absolutist claim, that does not alter physicians' obligations to exert all the effort necessary.

13. HARRIs, supra note 6 , at $62-63$. 
fit. ${ }^{14}$ The moral absolutist position accordingly does not allow the rough mechanisms of coping with scarcity that could be (and at times have been) consistent with the professional paradigm.

\section{B. Why the Absolutist Position Is Untenable}

Moral absolutism has powerful emotive appeal. Easy as it may be to reject in the abstract, moral absolutism remains difficult to reject in practice. Indeed, the persistent power of absolutist beliefs in the face of unending escalation of health care costs is the most striking moral phenomenon of health law policy in the past quarter-century.

Nonetheless, moral absolutism is wholly untenable as a societal system of resource allocation. Most knowledgeable observers believe we could today easily spend $100 \%$ of our GNP on health care without running out of services that would provide some positive health benefit to some patient. ${ }^{15}$ Surely, the most committed moralist must concede that, if these observers are enipirically correct, some health care unust be denied even though it has a beneficial effect. Otherwise, the extreme moral position would require that we fund health care even if that means starving ourselves to death. And once the moralist makes this concession, she acknowledges that at some point tradeoffs must be made and that thus the moral principle is not in fact absolute. The moral question then becomes where, rather than whether, tradeoffs are appropriate.

Even if one denies this empirical assertion about the present, the longrun dynamics set in motion by a commitment to moral absolutism also indicate that the commitment is not sustainable. Consider, to begin with, the implications for research and innovation. Suppose our health care system must choose between a 98\%-effective drug currently used in cardiovascular treatment and a new drug that is $99 \%$-effective but costs ten times as much. The absolutist position seems to require use of the $99 \%$-effective drug despite its additional cost.

14. Indeed, because the moral obligation not to kill or cause injury transcends international borders, the absolutist's claim lcads to the conclusion that a rich country has an obligation to fund health care for the entire world until the country is as impoverished as other countries. See id. at 63 .

15. See, e.g., Callahan, supra note 3, at 53; David Gauthier, Unequal Need: A Problem of Equity in Access to Health Care, in 2 Prestdent's Comm'n for the Study of Ethical Problems IN Medicine and Biomedical and Behavioral Research, Securnng Access to Health Care: A Report on the Ethical Implications of Differences in the Availablity of Health Services app. $\mathrm{H}$ at 179, 204 (1983) [hereinafter President's Comm'N, Securing ACCESS to HeAlth CARE] (stating that there is no limit to the resources a society could pour into costly medical services); John M. Stanley, The Appleton Consensus: Suggested International Guidelines for Decisions to Forego Medical Treatment, 15 J. MED. ETHICs 129, 133 (1989) (discussing the consensus at a conference on biomedical ethics that "it is not feasible to offer all beneficial treatments that are medically possible to all patients"); Alan Williams, Priority Setting in Public and Private Health Care, 7 J. HEALTH EcoN. 173, 173 (1988) (" $[N]$ o country (not even the richest) can afford to carry out all the potentially beneficial procedures that are now available, on all the people who might possibly benefit from them."). 
But, like Sherlock Holmes' dog that did not bark, the item of real interest is what we do not observe: the development of a new drug that is $97 \%$ effective but costs one-tenth the current drug. As long as moral absolutism holds sway, no one will develop such a drug; private firms will not because they could not sell it, and even public research institutions will not because no one would use it. Instead, resources will continue to get channeled into producing any drug marginally more effective than that in current use, no matter what the cost. ${ }^{16}$ This is the principal reason why innovation in health care-unlike, say, the computer industry-is associated witl costescalation instead of cost-cutting.

Consider next a reality forcibly brought home by Daniel Callahan in his celebrated book, What Kind of Life: for all of us, physical decay and death is, in the end, inevitable. ${ }^{17}$ As Callahan stresses, an implication of this unpleasant reality is that medicine cannot really "save" lives or "cure" poor health-it can merely postpone deatl and delay illness. We may decide it is worth one million dollars to save a life (as $71 \%$ of Americans concluded in one poll), ${ }^{18}$ but we must take into account the reality that many of those saved today will need to be saved again next year or next month. Moreover, in the interim they are also likely to have other severe health problems that are not life threatening. The result is perversely iromic: the more successful medicine is in pushing off death, the greater the health probleins created down the lime. As Callahan puts it, medicine can-for individuals-put off facing the "ragged edge" between life and death, health and ilhress, but medicine probably cannot reduce, and will likely increase, the proportion of the population that is at that "ragged edge" and in need of medical treatment. ${ }^{19}$

The need for making tradeoffs is further underscored by studies showing that income, environment, sanitary housing, and good nutrition result in larger health improvements per expenditure than health care does. ${ }^{20}$ Indeed, even education is more highly correlated with good health than health care: individuals with advanced degrees have fewer health problems than less educated individuals even if both have the sanie insurance coverage. $^{21}$ Thus, we could accept the proposition that the greatest good in life is health, but still conclude that purchasing more health care is less effective than funding nutritious food, safe housing, environmental protection, col-

16. Of course, sometimes more effective drugs or technological innovations might turn out to be less costly to make. But that is almost entirely a matter of happenstance, since reducing cost is largcly irrelevant to increasing sales or use. The actual course of medical innovation provides little assurance that cost-reducing innovations occur with sufficient frequency to outweigh this cost-inflating tendency.

17. Caliahan, supra note 3 , at 23, 94-96, 100-02.

18. Id. at 84 .

19. Id. at $63-65,120,221-22$.

20. See VICTOR R. Fuchs, Who ShaIr Lrve? 6, 15-17, 30-55 (1974); see also Paul Starr, The Politics of Therapeutic Nihilism, 6 HAstrngs CENTER REP. 24, 27-29 (1976) (discussing studies of the effects of sociocconomic differences on health).

21. Clark C. Havighurst, Health Care Law and Policy 23 (1988). 
lege tuition, or even simply distributing cash. In promoting health, there are substitutes for health care, and at some poimt they are more effective..$^{22}$

Furthermore, we value many things besides health. For most of us, good health is a means to an end: the enjoyment of life. If health were all we valued, we would not risk injury by crossing the street or risk disease by having contact with other persons. From a societal perspective, we could not have art, entertainment, poetry, baseball, philosophy, or any of the other things unrelated to health that we value and enjoy unless we devoted some resources to those activities instead of health care.

The "cost" of devoting resources to health care is often expressed monetarily, but we must recognize that sucl monetary expressions are merely a shorthand for the value we could derive from alternative uses of those resources. It would make no sense to spend money to live longer at the sacrifice of those things that make life worth living. In the end we all will die; the question is which allocation of resources will allow the best living of life.

\section{Denial Devices}

Actors in health care systems tend to use various devices of denial or self-delusion to avoid confronting the implications this fundamental scarcity has for moral absolutism. One device is to divert attention to how much we "waste" on other matters. A common refrain is that if we can afford to waste hundreds of billions of dollars a year in military spending, we can surely afford to provide as much health care as people need. ${ }^{23}$ This argument implicitly presumes not only that the military budget has zero value but also that the opportunity cost of spending more on liealth care is zero because it would just come out of the military budget.

To my mind, the first premise is untenable given the unstable state of world affairs. But even if we accept the first premise, the argument falters on the second. The fact that you and I may agree that some significant portion of current military spending has zero value does not mean that increased health care expenditures would come out of the defense budget. A political process that spends those billions on defense must, justifiably or not, value it differently than we do; and we have no reason to believe that

22. At the extreme, some argue that health care is, on balance, harmful to health, see IvaN ILIICH, Medical Nemesis: The Expropriation of Health 3 (1976), or at least of dubious effectiveness, see Brian Inglis, The Diseases of Civilisation (1981); Thomas McKeown, The Role of Medicine: DREAM, MIRage OR Nemesis? (1979); Start, supra note 20, at $29 \mathrm{n} .1$ (citing sources discussing this issue). The plausibility of this claim is enhanced if one excludes the clear benefits of certain drugs, such as antibiotics or vaccinations, on the ground that those benefits could be garnered without physicians if they were not given a legal monopoly on prescriptions. For a thoughtful and critical evaluation of these claims, see id. at 24-30.

23. See, e.g., Marcia Angell, Cost Containment and the Physician, 254 JAMA 1203, 1207 (1985); William B. Blythe, Changing Perceptions of the End-Stage Renal Disease Program, N.C. MED. J. 403, 404 (June 1984); John Harris, QALYfying the Value of Life, 13 J. MED. ETHCs 117, 122 (1987). 
increasing health expenditures will alter the political process' valuation of military spending. ${ }^{24}$ Whatever leads the political process to waste resourccs on zero-value military spending will continue to do so. Indeed, the fact that we "waste" billions on military spending does not eliminate our scarcity problem but rather worsens it by leaving us with that mucli less to allocate to real needs. It thus makes it all the more important that we allocate those reinaining resources wisely.

In any event, the objection about waste in military (or other) spending may delay the ultimate tradeoff but cannot avoid it. For even if we transfer most or all of the defense budget (and the budget of all other "wasteful" activities) to health care, we will still not have exhausted all the possibilities for expending resources on beneficial health care. The question we must ultimately answer is how to trade off the benefits of sucli liealth care against the benefits of otlier nonwasteful activities. Moral absolutism cannot help answer this question.

A related denial device is to argue that eliminating waste and inefficiency within health care can produce sucl large savings that we need not face the question of denying marginally beneficial care. ${ }^{25}$ The history of liealth care reform designed to reduce waste and inefficiency is not especially promising. ${ }^{26}$ But it is nonetheless true that the current U.S. liealth care system has such enormous waste and inefficiency, and such perverse incentives to provide unnecessary or harmful care, that well-designed changes could probably save tens and perhaps lundreds of billions of dollars. Given the time it necessarily takes for any economic expansion, the reallocation of these billions could well mean that in the slort run we could fund all the positive value health care the medical industry has the capacity to provide. Any denials of care would be due to a lack of traimed providers, equipment, facilities, and so forth, rather than a lack of funds. But, in the long run, there is practically no limit to the expandability of the medical industry. And once this expansion has eaten up all the savings fron reduced waste and inefficiency, we will still need to face the question of just what proportion of our labor and capital we want to devote to health care.

Another cominon means of denying the scarcity problem is to argue that future bionedical research could produce large cost savings. Even though cutting edge technology and pharmaceuticals are expensive at pres-

24. Indeed, U.S. military spending remained largely static at six percent for decades before the fall of communism in 1989, even though medical spending was doubling. Callahan, supra note 3, at 117. Thus, whatever las been crowded out by increased liealth care spending, it does not appear to be military spending. See also id. at 19,118-19 (suggesting lealth care has crowded out spending on education and perhaps on housing, infrastructure, and industrial research).

25. See, e.g.; Alain C. Enthoven, Health Plan: The Only Practical Solution to the SoARING Cost OF Medical CARE 15-16, 37-54 (1980). The Clinton Administration stressed this sort of argument in promoting its proposed Hcalth Security Act.

26. See, e.g., Callahan, supra note 3, at 75-79 (revicwing reform attempts). 
ent, their costs may go down in the future. Moreover, in the past, many medical innovations (such as antibiotics and immunizations) have been quite imexpensive. Yet although isolated examples can be cited, the available evidence suggests that increased spending on medical research and developinent is directly correlated with increases-not decreases-in total health care costs. ${ }^{27}$ And the incentive structure for research noted above gives us little reason to expect this pattern to change as long as we are committed to purchasing any and all inarginally beneficial care. ${ }^{28}$

A final related demial device is to stress how much we could save with more preventive medicine. ${ }^{29}$ The inodest version of this clain argues that we can expand spending on preventive medicine without worry. The less modest version argues that more preventive medicine will produce costsavings large enough to avoid any tradeoff question.

These claims generally rely on evidence that preventive medicine can significantly reduce the incidence of certain illnesses at relatively low cost. The evidence is indeed impressive. But the problem lies with the clain that the amount it would have cost to treat those illnesses has been "saved." As discussed above, given the inevitable degeneration of the human body, those saved from one illness almost always go on to experience another. And the illness they go on to experience is generally (though not always) more expensive to treat. It is thus not at all clear that preventive medicine actually reduces long-run financial costs. ${ }^{30}$

This does not, of course, mean that we should not spend more on preventive medicine. Reallocating resources from curative medicine to preventive medicine is undoubtedly worthwhile because it provides far greater healtil benefits per resources spent. But the reason to spend more on preventive medicine is the intrinsic value we place on the health it confers. We should be under no illusion that spending on preventive medicine is likely to save us resources in the long run, let alone produce enough savings to fund all the beneficial curative care we want.

27. See id. at $96,266,276$.

28. See supra text accompanying note 16.

29. Again, the Clinton Administration often utilized this argument when lobbying for the Health Security Act.

30. See, e.g., MENzEL, supra note 5, at 59 (concluding that influenza immunizations of the elderly or screening for cervical cancer may not reduce long-term costs); Comment, Blowing Smoke, NEw YORKER, June 13, 1994, at 6, 7 (noting findings by Louise Russell that treating high blood pressure, providing flu vaccinations, and screening for cervical cancer probably increase medical costs); $c f$. infra note 225 (noting evidence that smoking actually reduces lifetime medical expenses). See generally MENZEE, supra note 5, at 57-75 (reviewing empirical controversy over whether preventive medicine reduces long-term financial costs); Louise B. Russeli, Is Prevention Betrer Than Cure? (1986) (discussing policy debate about preventive medicine and evidence showing that prevention is not the answer to rising health care costs). 


\section{Lessons}

Although moral absolutism is unjustifiable, it cannot be gainsaid as a phenomenological matter. It is one thing to reject the absolutist claim in the abstract; it is quite another to face a real flesh and blood person who would benefit from health care and deny it to him or her because it costs too much. The poimt is not one of mere public relations, but of the predictable problems that befall such a legal or institutional framing of resource allocation. Actual human beings, forced to make actual decisions framed as health versus money, find themselves seeming and feeling inhumane. And they resort to just about any mechamism of demal or short-term spending ineasure to avoid or postpone facing the reality of scarcity.

This morally founded demal of scarcity has played such a pervasive role that Damiel Callahan argues that escaping such absolutist beliefs and desires is a necessary prerequisite to serious and enduring health care reform. ${ }^{31} \mathrm{He}$ eloquently exhorts us to rethink our moral intuitions about health, to reconceive of health as just a means to living rather than an end in itself, and to focus on living a full life with the time we naturally have rather than clinging to life for the mere sake of being ahive. ${ }^{32}$ Cost-containment cannot work, he argues, until we first change our moral values. ${ }^{33}$

Such a change in moral discourse inay well be beneficial. But I doubt it is a sufficient strategy for grappling with the health care problems raised by moral absolutisin. Experience gives us little reason to believe that humans are likely to experience the sort of coinplete inoral transformation Callahan advocates. Humans faced with death or illness will want to be treated - will plead to be treated-as long as that treatment reduces their chances of dying or staying ill. And as long as decisions are framed as the health care needs of identifiable individuals versus mere inonetary costs, decisionmakers will have a hard time distinguishing inorally between a decision to deny an imdividual life-saving or injury-treating care because of costs and a decision to murder or mjure that individual for financial gain. They will be accused of, and feel they are, failing to respect the sanctity of human life. ${ }^{34}$ This will cause them to feel a natural revulsion toward such decisions and a strong compulsion to avoid them through spending mcreases that cannot be sustained by the system as a whole. Moreover, even if they were willing to make such tradeoffs, they would lack any standards for deciding what tradeoffs were appropriate.

31. Callahan, supra note 3, at 11-12, 23-29.

32. See id. at 22-23.

33. Id. at 80 .

34. See James F. Blumstein, Rationing Medical Resources: $A$ Constitutional, Legal, and Policy Analysis, in 3 President's Comm'N, Securino Access to Health CARE, supra note 15, app. Y at 349, 355-56 (arguing that, when focusing on the life of an identifiable person, government is likely to spend large amounts of money on health care to preserve the myth that life is priceless); James F. Blumstein, Constitutional Perspectives on Governmental Decisions Affecting Human Life and Health, 40 LAW \& Contemp. Probs. 231, 233, 250-51 (1976) (same). 
However, a more modest change in moral perspective may well be possible. While individuals inay not be morally comfortable with making tradeoffs between health care and mere monetary costs, perhaps if that tradeoff could otherwise be established, they might be able to live with making - and being subject to - tradeoffs between meeting the health care needs of soine versus those of others out of a fixed total budget. ${ }^{35}$ Telling someone she will not receive care because someone else has greater health care needs seems less likely to be experienced as a denial of her humanity than telling her the reason is that addressing her health problem is not worth the money. To be sure, this too requires morally painful choices, and would no doubt require a substantial change in moral discourse. But at least it avoids a commodification of human life that seems likely to doom any serious restraimt on health care spending.

This way of framing the allocative decision will also require changes in professional norms. Recently, great efforts have been made to try to convince medical professionals to abstain from care where the monetary costs seem excessive compared to its benefits. This has proven difficult, however, partly because it leaves physicians with no objective scientific function to fulfill and partly because it compromises their duty of loyalty to their individual patients. A more promising tack, which dovetails with the analysis here, would be to reconceptualize the professional duty as loyalty to a group of patients, whose aggregate health physicians must maximize out of a fixed budget. But before we address the question of whether it is possible to devise a morally satisfactory objective function for maximizing the health of a group, ${ }^{36}$ we need first to address a more modest moral claim to individual health care entitlement that aims to avoid the pitfalls of the absolutist claim.

II

Equal Access to Adequate Care

\section{A. Difficulties in Defining the Right to Adequate Health Care}

A popular moral alternative to absolutism concedes that there are limits on society's obligation to spend on health care, but asserts that everyone has a right to a minimum of "decent," "reasonable," "basic," "essential," or "adequate" health care. ${ }^{37}$ This position commands a widespread (though

35. The experience in Great Britain provides some evidence to this effect. See Callahan, supra note 3, at 88. Some, however, attribute this to a difference in British and American culture.

36. See infra Part III (describing various possible measures of what it might mean to maximize the health of a group).

37. See, e.g., 1 Prestdent's Comm'n, Securing Access to Health Care, supra note 15, at 1-6; Catlahan, supra note 3, at 57; Lu A. Aday \& Ronald M. Andersen, Equity of Access to Medical Care: A Conceptual and Empirical Overview, in 3 President's Comm'n, Securnno Access to Health CAre, supra note 15, app. N at 20; James F. Blumstein \& Michael Zubkoff, Public Choice in Health: Problems, Politics and Perspectives on Formulating National Health Policy, $4 \mathrm{~J}$. HEALTH Por. Por'Y \& L. 382, 385, 403-05 (1979); Allen Buchanan, The Right to a Decent Minimum of Health Care, in 2 
not universal) consensus. And it has the considerable advantage of avoiding a commitment to open-ended financing of health care. The problem is that all the above terms are so inalleable that they beg the question. One can reach just about any conclusion one wishes about what health care should be provided by asserting that the particular care is, or is not, necessary to make the overall care provided "decent" or "adequate." The apparent consensus inay thus be illusory. We can all agree that decent or adequate care should be provided only because we each harbor our own notion of what that means. This Part evaluates the various attempts at giving content to the "adequate health care" standard.

\section{Physician-Prescribed Care, Reasonable-Cost Care, and Care Received by Others}

Such phrases as "decent" or "adequate" are often used as if the denial of any health care that a physician would prescribe is proof of indecency or inadequacy. The Italian constitutional court, for example, has held that the state's constitutional obligation to provide health care to its citizens makes it unconstitutional to deny reinbursement for any health care unavailable through the public system that a physician prescribes as necessary. ${ }^{38}$ But such definitions inerely smuggle in the absolutist position under different terminology, for in the end, physicians are ethically committed to-and, under such a systein, financially interested in-providing any health care that has a positive health benefit.

Other advocates of an adequate-care standard do sometines conclude that, at the extreme, medical services need not be provided when they cost "too mucl." much is too much. That judgment comes not as a deduction from moral primciples but from the gut intuition of the advocate. Needless to say, without any guiding moral primciples, it is far from clear that one advocate's intuition should have more sway than anyone else's.

President's Comm'n, Securing Access to Health Care, supra note 15, app. I at 207, 236-38; Charles Fried, Equality and Rights in Medical Care, 6 HAstings Center Rep. 29, 32 (1976); Emily Friedman, Can 'Essential Services' Be Defined?, 58 Hosprtals 105, 105-06 (1984); Allan Gibbard, The Prospective Pareto Principle and Equity of Access to Health Care, in 2 President's Comm'N, Securing Access to Health CARE, supra note 15, app. G at 153, 171-74; Stanley, supra note 15, at 133.

38. See Decisioni della Corte Constituzionale, No. 992 (October 12, 1988). A subscqucnt decision concluded that the amount of the reimbursement was judicially unreviewable, but did not overturn the basic holding that some reimbursement was required for physician-prescribed care. See Decisioni della Corte Constituzionale, No. 247 (June 3, 1992).

39. See Gauthier, supra note 15 , at 204 (stating that society need not provide "health care services that offer relatively small benefits in relation to costs'); Gibbard, supra note 37, at 158, 169 (arguing that "if a treatment is sufficiently expensive, it should be withheld" and that even "the best known treatment for a serious ailment might not be worth the cost"); see also CHURCHIL, supra note 10, at 9596 (arguing that the right to health care embodies only what society can "reasonably afford"); Eruc RAKOwSK, EQUAL JUSTICE 318-19 (1991) (positing that individuals bcgin with a (waivable) right to medical treatment as long as it does not impose "excessive or unreasonable" burdens on others). 
Another possible definition is that everyone should be entitled to any care received by others with similar health conditions. ${ }^{40}$ However, this position is not fiscally feasible unless we restrict health care spending by the rich. And the ethical justification for preventing the rich from buying health care that can (however marginally) improve their health is far from clear, especially when the rich can instead expend those funds on other less essential items like expensive meals and vacations. ${ }^{41}$ The right to a decent or adequate minimum thus is usually understood to avoid any such demand for absolute equality. ${ }^{42}$ In any event, imposing an equal-expenditure requirennent would not answer the question of how much should be spent on health care, let alone on a given health condition.

\section{2. "Necessary" Health Care}

Similar probleins result if one defines the minimum of decent or adequate care as that care which meets all health care "needs." "need" is susceptible of many meanings. If it encompasses any service that a patient desires, that a physician prescribes, or that has a positive likelihood of helping to postpone death, correct disabilities, or alleviate suffering, ${ }^{44}$ then the definition embraces moral absolutism. If it encompasses something less, then the term has little obvious meaning because medical services can provide an almost infinite gradation of health benefits without any sharp cut-off poimt. ${ }^{45}$

This problem is most acute for new cutting-edge medical technology. For example, it is now possible, for a cost of roughly $\$ 20,000$, to implant in imdividuals an AICD (Automatic Implantable Cardioverter Defibrillator) that can sense a heart attack and help prevent fibrillation. It seems logical to inplant these in individuals who have had a history of heart failures. But should they also be implanted in individuals who have no history of heart trouble but whose age, sex, and hfestyle make their risk of heart trouble

40. See Amy Gutmann, For and Against Equal Access to Health Care, in IN SEARCH of EQuTrY: Health Needs and the Health Care System 43, 46-47 (Ronald Bayer et al. eds., 1983).

41. See id.; see also Buchanan, supra note 37, at 212; Dan W. Brock, Distribution of Health Care and Individual Liberty, in 2 Prestdent's Comm'N, Securang Access to Health Care, supra note 15, app. J at 239, 261-62.

42. Buchanan, supra note 37 , at 212; Fried, supra note 37 , at 32.

43. See, e.g., ChurchILL, supra note 10, at 90-99 (proposing a need-based test for rationing health care).

44. See Alan Williams, 'Need' as a Demand Concept (with Special Reference to Health), in ECONOMTC Policies AND Soctal Goals 60, 60-61 (A.J. Culyer ed., 1974) (arguing that the most plausible interpretation of what people mean by "needing" medieal treatment is that the person would be better off with the treatment than without it). See generally A. Williams, Priorities-Not Needs!, in Meeting Needs in AN Afrluent Society (Anne Corden et al. eds., 1992).

45. Larry Churchill, for example, proposes a right to health care based on need and defines it as a right "to all effective eare society can reasonably afford." ChuRchill, supra note 10, at 94 (emphasis omitted). "Effective care" excludes "marginally useful" care, and "reasonably afford" means individuals do not have the right to "the very best available." Id. at 95 . But while these caveats exclude the absolutist position, what they mean short of that is left unresolved. 
higher than normal? In everyone, because even normal healthy individuals have some nonzero risk of heart trouble? At which level of health risk do individuals "need" an AICD?

Or consider again the example involving the $99 \%$-effective drug that costs ten times what the $98 \%$-effective drug costs. Do people "need" the $99 \%$-effective drug or just the $98 \%$-effective one? Would they also "need" a $99.5 \%$-effective drug even if it cost 1000 times the $98 \%$-effective drug? These are the sort of issues that not only are already being raised in medicine, but are likely to be increasingly raised by any system committed to funding any marginal benefit $\cdot \mathrm{m}$ health care. For as discussed above, such a funding commitment encourages innovation despite smaller and smaller improvements over existing technology.

We can also illustrate the problem with a less high-tech example. Consider a cancer for which the odds of remission are higher the earlier it is detected and treated. We could thus achieve a certain level of health risk with yearly screening tests, a somewhat lower level of risk with monthly tests, and an even lower level with weekly tests. What does it mean to say that a person "needs" a particular frequency of tests when the risk of dying from cancer could be lowered or raised by changing that frequency? It does no good to dismiss low risks as of concern only to hypochondriacs, for even risk changes as small as $.02 \%$, when applied to ten thousand cases, mean two human beings will have died without the extra care. Specific conclusions about whether a particular type or frequency of service is "needed" will simply refiect judgments about whether the level of health care benefits conferred by the service outweighs its costs. The term "need" is a placeholder for such judgments, but does not help generate thein.

\section{Care that Restores "Normal Species Functioning"}

Norman Daniels argues that the vagueness problems created by adequate or basic minimum standards can be avoided by recogmizing a umversal right to that health care which protects or restores the "normal species functioning" needed for individuals to attain the "normal opportunity range" for their society. ${ }^{46}$ This, Daniels clains, provides a coherent method for defining the health care needs that society should satisfy. For example, he argues, certain cosmetic surgery can be excluded as unnecessary to achieve a normal opportunity range. ${ }^{47}$

Daniels' test usefully focuses attention on an important inoral consideration: that we value the improved health provided by health care not prin-

46. Norman Daniels, Health-Care Needs and Distributive Justice, 10 PhrL. \& PUB. Afr. 146, 15860 (1981); see also Norman Dantels, Am I My Parents' KeEper? $68-73$ (1988); Norman Dantels, Just HeAItH CARE 26-35 (1985); Norman Daniels, Equity of Access to Health Care: Some Conceptual and Ethical Issues, in 2 President's Comm'N, Securng AcCess to HeAlth CARE, supra note 15, app. B at $23,41-43$. at 41 .

47. Daniels, Equity of Access to Health Care: Some Conceptual and Ethical Issues, supra note 46, 
cipally as an end in itself but as a means to a larger end-in Daniels' view, improved opportunity. ${ }^{48}$ But surely that is not the whole story. A person who has an injury that causes pain but does not in any way impede her physical mobility or opportunities to achieve life goals would often seem deserving of care. ${ }^{49}$

Moreover, like the decent- or adequate-care standards, Daniels relies on a question-begging word: here, "normal." Take what he regards as an easy case, plastic surgery. If better looking persons have more opportunities to enter careers in modelling or acting, or a better chance of attracting and keeping a desirable inate, why should we exclude those opportunities from the "normal" range and thus deny funding for face lifts and nose jobs? $?^{50}$ We need some normative theory to explain which opportunities should be regarded as normal - a theory which Daniels does not provide. ${ }^{51}$

Nor does Daniels' theory provide any effective cap on costs. Everyone would, for exaniple, agree that life itself is necessary to attain a normal opportunity range. But, as pointed out above, we could probably spend an infinite amount of resources trying to bring the risk of death down to the lowest possible percentage. A decision not to use a $99.5 \%$-effective drug because it would cost a billion dollars does statistically deny some individuals their lives and thus a fortiori demies thein their normal species functioning and opportunities. ${ }^{52}$ Further, restoring everyone to normal species functioning, even persons with severe illnesses or disabilities, may not be medically possible or may require an expenditure of resources so high that we would have to seriously diminish the range of opportunities it is normal for most healthy people to enjoy in the society.

48. See also CALLAHAN, supra note 3, at 107 (making a similar point).

49. See G.A. Cohen, On the Currency of Egalitarian Justice, 99 ETrics 906, 919 (1989) (arguing that it is not "coherently egalitarian" to consider the difficulty in mobility as separate from the pain that accompanies it).

50. See, e.g., RaKowskr, supra note 39 , at 54 (concluding that a person born homibly ugly should be entitled to plastic surgery even though it does not alter his or her ability to earn an average wage).

51. See generally Buchanan, supra note 37 , at 228 (arguing that if the normal opportunity range includes only opportunities that everyone can pursue, regardless of one's talents, then it is probably too narrow to justify a universal right to health care, and that if it includes opportunities that would be reasonable for someone to pursue, it would require extraordinary expenditures).

52. At some age, one might say that a person who has lived so long has enjoyed the opportunities of a normal life span and thus does not merit further medical attention. But although Daniels does in later writing conclude that the normal opportunity range should be "age-relative," and that some agebased rationing may thus be appropriate, DANIEIS, AM I MY PARENTs' KeEPER?, supra note 46, at 74, he does not go quite so far. Rather, he bases his new principle on the somewhat different grounds of a prudential lifetime consent argument. See infra Part IV. In any event, this does not quite avoid the problem since the history of medical progress is precisely to redefine what a "normal" life span means. CALlaHAN, supra note 3, at 49. Nor would such an exception solve the problem of what to do with younger persons in cases where the risks are real but low, or substantial but highly expensive to lower. 


\section{List-of-Services Approach}

An alternative approach is to define the required minimum of care by listing the specific medical services included within the minimum. For example, Alaim Enthoven proposed a plan that would ensure umiversal coverage, at a minimum, of all the services specified in the Health Maintenance Organization Act of 1973. This "mcludes physician services, inpatient and outpatient hospital services, emergency health serviccs, short-term outpatient mental health serviccs (up to twenty visits), treatment and referral for drug and alcohol abuse, laboratory, and X-ray, home health services, and certaim preventive health services."53 The Clinton Plan took the same approach: defining eighteen categories of covered services with various limits (such as thirty psychotherapy visits) and exclusions (such as adult non-emergency dental care). ${ }^{54}$

However, the hist-of-services approach is unsatisfactory in three senses. First, it assumes, rather than justifies, the relevant moral conclusions: why should these particular services be covered and not others? Enthoven seems to rely on the fact that his adopted list was enacted into legislation. But there are other government-approved lists from which to choose. And if political adoption is the appropriate litmus test, then the pohtical process would also seem free to refuse to provide a mimimum of care at all.

Second, there is a certain irrationality im choosing when to provide health care by the category of medical services. Such a system funds any liealth care within the favored categories, even if the potential benefits in the actual case are minuscule, but provides no funding for care outside the favored categories, even if the benefits would be great in the particular case. Why, for example, sliould someone who would benefit greatly from dental care, or the twenty-first (or thirty-first) mental lealth visit, be denied coverage when others receive unlimited laboratory tests, no matter how sinall the medical benefit is?

Third, and most miportant, the approach does not offer an effective means of cost containment. A cominitment to provide all the types of ser-

53. ENTHOVEN, supra note 25 , at 128.

54. See Proposed Health Sccurity Act, H.R. 3600/S. 1757, 103d Cong., 1st Sess. $§ \S 1101-1128$ (1993). Within the covered categories, the Clinton Plan would have required insurance coverage of all "medically necessary" and "appropriate" care, and authorized a National Health Board to issue regulations defining what this term would have included and excluded. Id. $\S \S 1141,1151,1154$. The Board might potentially have exercised this authority to deny some health care with positive hcalth benefits within these categories. If so, the Act invited the making of some tradeoff without giving any guidance about how to do it. But the use of the modifier "medically" suggests that exclusions of care under this provision would have to be made purely on medical grounds. $C f$. infra note 264 (noting the technically defined nature of quahifications for serving on risk adjustment advisory committee). Indeed, in health insurance law, the term "medically necessary and appropriate care" has tended to be interpreted in a way that does not permit cost/benefit tradcoffs, in part because no administrable legal standards exist for making such tradeoffs. At most, the term pcrmits the exclusion of expcrimental treatments with ambiguous benefits. But that will hardly suffice to stop health care cost escalation. 
vices included in either Enthoven's or Clinton's broad list whenever they are potentially beneficial to anyone could easily exhaust our national wealth. But the problein goes beyond the iteins in these particular lists. The inore basic problen is that any list that simply limits the categories of services funded does nothing to limit expenditures on care within the funded categories. To be sure, in the short run we may run out of services to provide within those categories. But through the process described in Part I, a commitment to funding anything that confers positive health benefits coinpared to the alternatives will - even though limited to certain categories-inevitably encourage the innovation of new drugs, treatments, and technologies that confer marginally greater health benefits no inatter what the cost. One cannot underestimate the ability of technology to follow financing. In the long run, then, a commitment to fund any care within specified categories that confers a positive health benefit will simply exhaust all our societal resources within those specified categories rather than over the full range of inedical services.

\section{Case-by-Case Determinations}

Another common procedural strategy is to emphasize the need for discretion and careful judginent in particular cases. ${ }^{55}$ But this emphasis on ad hoc ethical judgment provides no guidance on how to actually make tradeoffs. The tradeoffs inust instead be made by whomever is ultimately left with the task of determining whether adequate care has been provided, whether it be the physician, ethical committee, judge, jury, or agency. Such decisionmakers will likely be influenced nore by the identifiable human being before them than by the more diffuse needs that would otherwise be served by the resources in question, in which case the standard again verges on absolutism. And even if the decisionmaker can avoid such a tendency, the fact remains that the ultimate decisions will be nade without any real guidance froin the inoral paradigm. Judginents are likely to be inconsistent, unduly influenced by the patient's powers of persuasion (or ability to hire someone persuasive), and perhaps biased toward the interests and values of the ad hoc decisionmakers. ${ }^{56}$

\section{Concluding Observations}

Usually such terms as decent or adequate health care are used with no specificity at all. Proposing a decent or adequate minimum is, rather, a way of conceding the need to trade off health care against other uses of societal

55. See Stanley, supra note 15, at 133-34; see also JohN F. KIINER, Who Lrves? Who Dres? 16 (1990) (collecting sources on the widespread use of ad hoc judgments in patient selection).

56. See CALABrest \& BoBBIT, supra note 8, at 60-64, 187; KInNER, supra note 55, at 16-17. Such standardless decisionmaking, even where physical constraints, such as a fixed number of organs, restrict expansion, has generally produced institutional failure. See CALABREST \& BoBBrTt, supra note 8, at 188; Callahan, supra note 3, at $45-47$. 
resources without actually specifying any principles for deciding how that should be done. ${ }^{57}$ Of course, one might say that this fundamental tradeoff must be resolved by the "political process,"58 or, more vaguely, by "society." 59 But that is hardly a satisfactory answer for a moral obligation propounded as "the standard against which proposals for legislation and regulation im this field ought to be measured."60

Because the adequate-care standard lacks real content, it effectively concedes that the moral paradigm cannot offer a complete answer to questions about when and how societal resources should be devoted to health care. What then is the moral belief driving so many to adopt this standard? It appears to be not so much that the adequate care standard supplies a moral principle that affirmatively determines when to provide resources to health care, but rather a moral belief that one factor traditionally employed by market societies-an mdividual's wealth-should not significantly affect the receipt of health care. ${ }^{61}$

57. See, e.g., 1 President's Comm'n, Securing Access to Health Care, supra note 15, at 3-5 (noting that the level of adequate care will depend on the "value of health care in relation to other important goods for which societal resources are needed," but not offering a means of making this tradeoff).

58. Fried, supra note 37 , at 32.

59. Callahan proposes a more eomplicated minimum level of adequate care standard that relies on the political process to define what to include within that standard beyond the provision of (1) caring services to stress our humanity toward the ill and (2) those minimal public health measures that are necessary for the society to funetion. CALLAHAN, supra note 3, at 66-68, 98, 123-24, 128-31, 138-41, $143-49,189-92$.

In addition to the problem noted in the text above, a further problem with the Callahan approach is that giving priority to caring services over curative services can lead to perverse results. Why, for example, should an individual who prefers certain curative services (not included in the standard package) over caring services carrying the same price not be able to substitute those additional curative services? Why should tbe caring services be preferred over any lifesaving ones? Moreover, what if the eurative service, say a hip replacement, eould avoid a lifetime of expense on caring services, such as helping the person with her wheelchair? Although Callahan in the end asserts the priority should not be rigid, id. at 150 , even a flexible priority has the flaw of overemphasizing the caregiver's desire to empathize at the expense of the patient's desire for better health.

Finally, Callahan bases the priority for caring services in part on the assumption that, unlike curative services, the amount we can spend on caring is inherently limited. Id. at 145, 149-50. I doubt that is true. It just appears so today because caring medicine has not yet been as much the focus of our open-ended funding commitment as curative medicine. The infinite possibilities for marginally lowering pain (a caring service in Callahan's account) suffice to make the point.

60. I Prestoent's Comm's, Securing Access to Health Care, supra note 15, at 1 . In subsequent writing, Fried does flesb out a deeent minimum standard that, while somewhat dependent on politieal results, is also capable of standing apart from them. His standard defines the dceent minimum as that level of essential goods enjoyed by unskilled unionized workers. Charles Fried, Is Liberty Possible?, in 3 Tanner Lectures on Human Values 91, 102, 104-06, $109-10$ (1982). Beeause that standard is avowedly redistributive and dependent on the level of societal wealth, 1 address it infra notes 123-27 and accompanying text.

61. More precisely, as we will sce in the next Section, hecause the right of equal access to adequate care is not predicated on a general equalization of individual wealth but rather makes a redistributive claim limited to health care, it excludes an individual's ability and willingness to pay for health care as an allocative factor. It is also conumonly said that a person's hcalth status should be irrêlevant; however, differences in health status signify differences in capacity to be helped by health care and thus naturally play important roles in health care allocations. What this claim usually means is, 


\section{B. The Underlying Redistributional Claim and Its Traditional Justifications}

The claimed right of equal access to adequate care is, in other words, at heart a redistributional claim: that societal wealth should be redistributed to offset the inability of the poor to purchase as inucli liealth care as other members of society. ${ }^{62}$ That is wly the empliasis is usually on the equal access part of such standards, and why the concrete illustrations offered regarding the standard's application generally concern the exclusion of various inequitable distributions of care. ${ }^{63}$ This understanding is further supported by the fact that advocates of an adequate care standard argue that the care regarded as adequate should depend on the level of societal wealth. ${ }^{64}$ If "adequate care" had an inherent medical or moral meaning, then societal affluence would be irrelevant. If, however, the claim is at root redistributional, then the level of societal wealth is precisely what determines the level of care that should be provided.

The general impetus behind redistributive policies is not hard to see. If we regard each individual as equally worthy of respect or of having her needs satisfied, then a redistribution of wealth will offset an inequality in resources and help assure that the intense needs of poor individuals are inet before the less intense needs of richer individuals. There are, to be sure, numerous coinpeting theories of distributive justice. Under a utilitarian the-

instead, that a person should not be denied care because she is unable or unwilling to pay the extra costs necessitated by treating a preexisting illness. See infra Part IV. Finally, we should note, various plainly iliegitimate factors, such as race, are also excluded as allocative factors. See, e.g., CHuRCHIL, supra note 10, at 96. Age, however, may not be. See infra Part III.C.

62. Of course, as Charles Fried has rightly stressed, moral rights include not only rights to health care but rights in health care that go beyond distributional rights: namely, rights not to be deliberately misled, denied information, or abandoned by a physician who has committed to treatment. Charles Fried, Rights and Health Care-Beyond Equity and Efficiency, 293 NEw ENG. J. MED. 241, 243-44 (1975). Respecting such rights in health care provides additional grounds, I believe, for preferring a system that openly describes the rationing being applied, see infra Part III, and that secures to the extent possible advance individual consent to that rationing, see infra Part IV, over a system that invites or requires physicians to make what are likely to be covert tradeoffs between the health benefits and financial costs of individual treatunents.

However, Fried suggests that these rights in health care require something more specific: allowing bureaucrats to fix the resources available to the physician, but forbidding the physician to deny any beneficial care to any patient he has (on a first-come, first-serve basis) accepted. Fried, supra, at 24344; see also Fried, Equality and Rights in Medical Care, supra note 37, at 33-34. This solution strikes me as both unwise and morally unnecessary for three reasons: (1) bureaucrats, being less knowiedgeable and further removed from the decisions, are less well-positioned than physicians to make the necessary tradeoffs; (2) first-come, first-served rationing is not just socially inefficient but morally anomalous, see infra notes 131-33 and accompanying text; and (3) there nced be no conflict with professional duty or patient expectations if the physician's duty is reconceived as a duty to a covered group out of fixed resources, see supra note 36 and accompanying text.

63. See, e.g., Churchil, supra note 10, at 96 (stating that although his health care needs standard allows many possible judgments about what society can afford, "we could not justifiably distribute care by race or by money").

64. See, e.g., 1 President's Comm'N, Securnng Access to Health CARE, supra note 15, at 4-5; Buchanan, supra note 37 , at 211; Fried, supra note 60 , at 103; Stanley, supra note 15 , at 133-34. 
ory of justice, we would say that because everyone spends his scarce resources on the items of highest utility first, money has dimimishing marginal utility. This suggests that the marginal utility of money is higher for the poor than for the rich, and that a redistribution of wealth would maximize social utility. ${ }^{65}$ Under other theories of distributive justice, however, the distribution of individual utility takes precedence over its societal maximization, ${ }^{66}$ an equitable distribution of opportunities to achieve utility takes precedence over actual utilities, ${ }^{67}$ or an equitable distribution of unearned resources takes precedence over the utility derived or derivable from those resources. ${ }^{68}$ And some argue that distributive justice requires just that level of redistribution that offsets human inisery ${ }^{69}$ or that maximizes the welfare of the worst-off economic class. ${ }^{70}$ We need not linger over this rich debate here, however, for all these theories justify some substantial redistribution of current wealth holdings. ${ }^{71}$

The puzzling feature about the specific redistributive claim here, however, is that it is targeted at health care. Why should this be? If we want to help the poor, would not it be better simply to give them more money and allow them to spend it on what they need most? ${ }^{72}$ To be sure, the poor may not have enough to purchase the health care that others might regard as basic. But the poor also suffer severe deficiencies in many other areas, including food, clothing, shelter, and education. Why target health care rather than allowing the poor to spend any redistributed funds on the needs they regard as most important? Or-to address the oft-raised fear that some people receiving such assistance will spend the redistributed money on booze, drugs, or gambling - why not provide vouchers whose only restric-

65. See, e.g., Richard B. Brandt, A Theory of the Good AND the Rioht 309-16 (1979).

66. See generally RAKowsK, supra note 39, at 39-43 (describing and critiquing egalitarian welfarism).

67. See Richard J. Ameson, Equality and Equal Opportunity for Welfare, 56 PHLl. STUD. 77 (1989).

68. See, e.g., Bruce A. Ackerman, Soctal Justice In the Liberal State 53-59 (1980); RakowsK, supra note 39, at 43-72; Cohen, supra note 49; Ronald Dworkin, What is Equality? Part 1: Equality of Welfare, 10 PHII. \& Pus. AfF. 185 (1981); Ronald Dworkin, What is Equality? Part 2: Equality of Resources, 10 PHIL. \& PUB. AfF. 283 (1981).

69. Fried, supra notc 60, at 96-110.

70. John RawLS, A Theory of Justice 83, 97-100 (1971).

71. Of eourse, there are thcorics of justice that do not countenance redistribution at all, concluding that each person is entitled to retain whatevcr wealth he lawfully acquired. See, e.g., RoBert Nozick, ANARCHY, STATE, AND UtOPIA 149-53 (1974). But such theories offer no plausible grounds for a right of equal access to some minimum level of adequate care. See, e.g., id. at 233-35 (arguing that distributing physieians according to need is no more justifiable than distributing barbers according to need). The argument here will thus only be persuasive to those who begin from philosophical premises counselling for some redistribution.

72. Paul T. Menzel, Medical Costs, Moral Chotces: a Philgsophy of Health Care ECONOMICS IN AMERICA 67-68 (1983); see also FuCHS, supra note 20, at 14, 22-23; Robert C. Clark, Does the Nonprofit Form Fit the Hospital Industry?, 93 HARV. L. Rev. 1416, 1429 (1980). 
tion is that they cannot be spent on defined goods (like drugs and alcohol) that are self-destructive ${ }^{73}$

One explanation that should be addressed up front is that the right of equal access to adequate care may be only one of many rights to equitable compensation that are justifiable. ${ }^{74}$ But that would be to admit what advocates of an adequate care standard are often at pams to deny: that equal access to adequate care implies a general redistribution of wealth. ${ }^{75}$ It would also suggest that the "equal access to adequate care" label is deceptive, masking the more general redistributive principle on which the claim really rehies. Of course, one might understand all this as purely strategic. To paraphrase what some candid advocates have told me in confidence: "Sure, what we really want is general redistribution to all the disadvantaged. But we can't get that from the electorate or the current set of judges. What we can get, perhaps because of some imisguided mystique attached to health care, is soine redistribution in health care to those disadvantaged by illness."

This does not, however, explain the moral mtuitions that might-or should-motivate the apparently decisive block of voters (or judges) unconvinced by the general redistributive argument. Nor are mass deceptions without their cost; a perceived right to health care uncoupled with general redistribution may only exacerbate a maldistribution of societal resources across human needs by contributing to excessive health care spending that tends to crowd out other social needs, like education. ${ }^{76} \mathrm{~A}$ strategically inspired misdescription of the right to health care is also bound to provide an unstable depiction of the ideals undergirding health care law. Judges looking for guidance from the legal ideals would be left with the conclusion either that the right as described could not be justified or that the right implicated general redistributive principles inconsistent with the ideals underlying the bulk of legal doctrine, which remains largely committed to

73. Obviously, such vouchers would free up some of the funds the poor now spend on such basics as housing and food, and those funds could, in turn, be spent on drugs and alcohol. But it is also true that the in-kind provision of health care frees up whatever funds the poor would have otherwise spent on health care.

74. Indeed, at least some advocates of a minimum level of adequate care have suggested society should sometimes compensate for unequal talent. See, e.g., DANIELs, AM I MY PARENTS' KeEPER?, supra note 46 , at 70 . In addition, general theories of distributive justice often advocate compensating for illness and injury as part of a general redistribution that also would redress inequalities in talent and other resources. See, e.g., RAKowsk, supra note 39, at 120-21, 138-48.

75. Compare Peter Singer, Freedoms and Utilities in the Distribution of Health Care, in ErHcs AND HEALTH PoLICY 175 (Robert M. Veatch \& Roy Branson eds., 1976) (arguing that because health care needs cannot be distinguished from other needs, there is no stopping point between the right to health care and Marxist socialism) with CiurCHIL, supra note 10, at 91-93 (denying this asserted equivalence) and Paul F. Camenisch, The Right to Health Care: A Contractual Approach, 62 Soundings 293, 307-08 (1979) (arguing that health care needs are unique).

76. See supra text accompanying notes 22-24 and note 24 . 
capitalist nonredistributive principles. ${ }^{77}$ Such a tension is hard to maintain and likely to produce schizophrenic legal results.

A number of arguments have been offered to justify recognizing an imdividual right to health care rather than a more general right to a redistribution of societal resources. The renuamder of this Section reviews these arguments, concluding that none of the currently offered arguments convincingly provides a justifiable explanation for the right to adequate care as it is generally understood. ${ }^{78}$ After rejecting these arguments, the subsequent Section offers ny own explanation for why liberal inarket societies are justifiably more willing to equitably distribute health care than other social goods.

\section{The Special Importance of Health Care}

The first, and most common, argument is that health care should be targeted because it has "special importance."79 There are a number of grounds for doubting this clain. Health care is far less special than con1noonly thought: studies suggest that much of the health care now provided does not promote good health, and for many other health care treatinents there is no rehable proof about their effectiveness one way or the other ${ }^{80}$ It is even less clear that health care has any clain to being special conipared to alternative uses of resources. As noted above, education, nutrition, environment, shelter, sanitation, and income often have larger per expenditure effects on health than health care does. ${ }^{81}$ Indeed, studies indicate that in Britain national health nisurance did not significantly improve health indices or reduce health inequahities. ${ }^{82}$ Thus, even if we agree that good health is the ultimate goal, the decision to finance only health care seen1s suspect. Finally, we are still left with the question why the poor should not be allowed to decide for themselves what they regard as special among their

77. To the extent the legalization of the right were accomplished through the political process, such general redistributive principles would also be inconsistent with the more limited political discourse and legislative history.

78. In asking whether the traditionally offered arguments provide a "justifiable explanation," I mean to test them against two standards: (1) whether they descriptively fit (explain) the right as currently understood; and (2) whether they normatively support (justify) that right. This focus implicitly excludes other sorts of inquiries that might be entertained, namely, whether freestanding philosophical arguments could be made for a right to health care divorced from commonly held moral belicfs, or whether individuals in actual society would generally offer the posited argument as the motive for thcir beliefs. My justification for this exclusion is that this is intended as a work neither of pure moral philosophy nor of pure cultural anthropology. Rather, my focus is on devising a practically sustainable system for allocating health care resources, and, it seems to me, such sustainability requires both a rationale plausibly able to resist moral analytic critique and a broad correspondence with commonly held moral conclusions.

79. I President's Comm'n, Securing Access to Health Care, supra note 15, at 4.

80. See, e.g., ENTHOVEN, supra note 25, at 1-8; Fuchs, supra note 20, at 6, 15-17, 30-55; ILLICH, supra note 22; Starr, supra note 20.

81. See supra note 20 and accompanying text.

82. See Tom L. Beauchamp \& James F. Childress, Principles of Biomedical Ethics 284 (3d ed. 1989). 
various needs, even if that means they make tradeoffs between their health and other goods. ${ }^{83}$

A specific form of the "special importance" argument stresses that a minimum level of health is a necessary condition for exercising basic civil and political rights. ${ }^{84}$ The fit between this justification and targeting health care is, however, dubious. Improving education would seem far more likely to produce the informed exercise of rights, and alleviating shortages in food, clothing, and shelter might be more likely to encourage political participation. Moreover, if the government must target something to improve the exercise of civil and pohtical rights, other targets would seem more cost-effective: sucl as subsidizing legal counsel or political participation. ${ }^{85}$ More fundamentally, this explanation seems implausibly indirect. As Allen Buchanan put it, "the primary reason I need relief from the excruciating pain in my abdomen is surely not that its presence may distract me from pulling the right lever in the voting booth." 86

Another form of the "special importance" argument is Norman Daniels' claim that health care is distinctive because it maimtains the "normal

83. Of course, individuals are likely to lack the information necessary to judge the value or quality of health care services. But this lack of information affects the poor and nonpoor alike. Nor, in any event, does it explain why on moral principle either should not be permitted to make a global tradeoff between health care and other life needs by opting out of any societally required minimum level of care and taking the cash equivalent instead.

To be sure, a market failure explanation - adverse selection - can be offered for requiring everyone to purchase a basic insurance package. The adverse selection problem results when insurance plans and insured persons have asymmetric information. To illustrate, suppose an insurance plan begins with the same mix of healthy and sick people as are in the population. The plan cannot, however, tell the healthy and sick apart, and thus sets a premium at the average cost of providing coverage. However, insured individuals are better able to judge their own general state of health. The healthy will be less likely to purchase the plan's insurance becausc, from their perspective, the premium is inflated by the cost of covering the sick and thus probably exceeds the benefit the lealthy receive. The sick will be more likely to purchase the insurance because from their perspective the premium is deflated by the lower cost of covering the healthy and is thus a relative bargain. Because the healthy are less likely to subscribe than the unhealthy, the insurance plan's pool of subscribers will have a sicker profile. The plan's average costs will increase and the premium will have to be adjusted upwards. This rise in the premium will drive out another group of relatively low-risk patients. Average costs will increase again, and so on, until only high-risk patients are left. In short, the adverse selection problem is that high-risk subscribers tend to drive the lower-risk subscribers out of the market.

But adverse selection is a market, not moral, explanation for mandatory health insurance. It could thus be consistent with, for example, requiring all to contribute equally or in proportion to their expected health costs. The morally founded right to equal access to health care, in contrast, normally contemplates societal funding that requires lower contributions from the poor and no difference in contribution because of health status. Alternatively, as Louis Kaplow has pointed out to me, one could solve the adverse selection problem within income brackets: requiring those with higher income to contribute more but giving them better health care as well. Again, this would solve the market problem but not fulfill the posited moral duty. Finally, the moral right would (unlike the market failure argument) apply even to the extent the adverse selection problem was not serious or was ameliorated either by the disclosure of asymmetric information or by the grouping of health risks in, for examplc, employer groups.

84. See Buchanan, supra note 37, at 214-16.

85. See id.

86. Id. at 216. 
species functioning" that is an important influence on whether individuals attain the "opportunity range" of life-plans that are "reasonable to pursue within the conditions obtaiming in a given society." 87 In Section II.A.3, I questioned whether this provides a tractable method of defining what minimum of health care society should provide. Here I wish to examine whether Damiels' argument justifies a conclusion that health care has special importance.

An initial probleen with Daniels' argument is its implication for individuals who have disabilities that will always prevent thein from attaining the normal opportunity range. Daniels' claim would seem to inply that, if such an individual contracted an unrelated illness, fewer (or no) health care resources should be devoted to treating that illness because it would not help him achieve a normal opportunity range. ${ }^{88}$

A inore serious problem is the poor fit between the justification and the right it purports to justify. As noted above, other goods and services seem to have a larger effect than health care on health and normal species functioning. And much health care provides benefits, such as relief from pain, that are important to patients whether or not they help the patient attain a normal range of opportunities to pursue. Nor is normal species functioning the only factor contributing to an imdividual's range of opportumities. Providing wealth, better education, and good neighborhoods would seen more likely to expand the range of opportunities than providing health care. And while the sick may have fewer opportunities than normal, so do the untalented and unintelligent. Why should the sick have a clain to societal resources prior to that of the latter ${ }^{89}$

More generally, the point of preserving opportunity is to permit the poor to fulfill their life goals. Health is undoubtedly important to reaching these goals. But so is money. The equal opportunity argument does not explain why it is not rational for the poor to forego whatever life goals would be furthered by spending on health care in order to pursue the life goals furthered by spending inoney in alternative ways. ${ }^{90}$ Instead, it assumes the question at hand: that the goals furthered by health care are,

87. Daniels, Equity of Access to Health Care: Some Conceptual and Ethical Issues, supra note 46, at 41; see also Dantels, JuST HeAlth CARE, supra note 46, at 26-28; Daniels, Health-Care Needs and Distributive Justice, supra note 46.

88. Cf. Amartya Sen, On ECONOMIC INequaltTy 16-18 (1973) (posing a similar objection to utilitarianism).

89. That the sick have such a priority under Daniels' theory is made clear by his reply to Buchanan, which states that his moral claim does not seek to assure everyone the normal opportunity range in society but only the normal range that the individual's particular skills and talents would ordinarily have made available to him without the disease or disability that health care can treat. See Norman Daniels, Fair Equality of Opportunity and Decent Minimums: A Reply to Buchanan, 14 PrIl. \& Pus. Afr. 106, 107-09 (1985). What Daniels docs not explain is why society should be passive about compensating for poor skills and talents that deprive individuals of the normal opportunity range but active in treating diseases and disabilities.

90. MENZEL, supra note 5, at 124. 
despite some poor individuals' contrary views, more important than competing goals.

\section{Undeserved Misfortune}

A second argument for targeting health care is that sickness is an undeserved misfortune. ${ }^{91}$ This argument is soinewhat undermined by the growing evidence that health is more influenced by behavior (such as diet or smoking) than by health care. ${ }^{92}$ But the more fundanental problem is this: can the poor really be said to deserve all their other misfortunes? To some extent for some persons, poverty is doubtless due to lack of effort. But one cannot deny that, for any given level of effort, persons with more mitial capital, greater talent or aptitude, more advanced education, and better luck will end up richer than others. Is it the fault of the poor that they lack the resources, talent, aptitude, education, or luck necessary to earn enough income to afford good housing, food, clothing, and further education for themselves and their children? If not, then we cannot use this argument to justify targeting health care, for the poor's inability to meet all their needs seems in large part due to undeserved misfortune. Indeed, one might even conclude that, if anything, the existence of unmet health care needs is less a Inatter of undeserved misfortune justifying societal distribution than lack of talent or intelligence, because the former can more easily be insured against. ${ }^{93}$

Moreover, what about those who suffer the undeserved misfortune of contracting an untreatable illness? Why do they not deserve as much-if not inore-compensation than those whose illnesses or conditions we can treat with health care?

\section{Unpredictable Need for Health Care}

A third argument differentiates health care because, in contrast to other needs, the need for health care is unpredictable. ${ }^{94}$ Ill health, unlike hunger, is a inatter of chance. This is largely true, but we have a ready inarket mechanism for dealing with uncertainty: insurance. If the poor feel that the value of health care insurance exceeds the value of alternative uses of their resources (as supplemented by redistributive subsidies), they can always

91. 1 Prestennt's Comm'n, Securing Access to Health Care, supra note 15, at 22-25; Churchill, supra note 10 , at 91 .

92. See Fuchs, supra note 20, at 54-55; see also ENTHOVEn, supra note 25, at xvi.

93. See Dworkin, What is Equality? Part 2, supra note 68, at 293-301 (arguing that an adult's failure, at least under conditions of equal resources, to buy insurance against illness makes his illness bad "option luck" rather than bad "brute luck" and thus does not require societal compensation); RAKowskr, supra note 39, at 88-106, 313-24 (same). An alternative line of argument might be that our notions of what constitutes "undeserved misfortune" are, in the end, socially constructed. This line of argument is, 1 contend, consistent with the negative justification for providing health care that 1 present below. See infra text accompanying notes 120-21.

94. I President's Comm'n, Securing Access to Hearth Care, supra note 15, at 23; Gauthier, supra note 15 , at 203. 
purchase it. The argument about uncertainty thus seems to devolve to the paternalistic argument that the poor will fail to purchase insurance, even though they should.

\section{Paternalism}

This fourth argument, paternalism, perhaps most accurately explaims what actually motivates policymakers to refuse to simply redistribute cash: the poor, many believe, would irrationally spend money on the wrong things. ${ }^{95}$ But to say that paternalism often explains our targeting of health care is not to say that it justifies it. Paternalism depends on the premise that those making decisions for the poor are better at it than the poor would be themselves. This requires an embrace of elitism that is somewhat mconsistent with the egalitarian impulse underlying the right to equal access to adequate health care. If the poor are as equally worthy of having their needs met as others, why should they not also be regarded as equally worthy of making up their own minds and determining their own ends im life?

Moreover, the empirical premise seems questionable on both ends. The elite, who enjoy more wealtli than the poor, may suffer from a bias in judgment; because their needs outside of health care are better met, they are likely to judge it sensible to purchase a relatively higl level of health care. But it is nothing more than class parochialism to impose this judgment on the poor. More to the point, given the evidence mentioned above, it seems perfectly rational for the poor to decline to spend mucli on healtl care. A lot of health care simply is not that effective, and other things the poor might purchase would have a more positive effect on their liealth. Further, those who are not poor trade off their health agamst other goods all the time. ${ }^{96}$ We drive at the speed limit when driving more slowly would reduce our risk of dying; we mgest food or drinks that are less healthy than others we could ingest; we work in stressful or distant jobs when less demanding or closer jobs would lengthen our life-span. If it is rational for others to trade off health against nonhealth benefits, why would it be irrational for the poor to do the same?

\section{Externalities}

The final argument for targeting healtli care stresses the "externalities" imposed when liealth care is not bought. The classic example is immunization against contagious diseases. If the poor were given cash, the argument goes, they would forgo iminunizations whenever the cost of purchasing the iminunization outweigled the expected benefit to their liealth. But immunizations have a health benefit "external" to the purchaser: they protect other

95. See Brock, supra note 41, at 262 (adopting the patcrnalistic argument); see also Clark, supra note 72 , at 1429 .

96. Fuchs, supra note 20, at 17-19; see also Blumstein, Rationing Medical Resources: A Constitutional, Legal, and Policy Analysis, supra note 34, at 355. 
persons against the spread of any contagious diseases that unimmunized persons might otherwise contract. If we assume that, when these external health benefits are considered, the immunization increases overall social welfare, then poor persons who receive unrestricted subsidies will fail to purchase all the health care that they societally should.

This argument provides a better rationale for providing (or requiring) immunizations than it does for redistributions that target health care generally. To begin with, the argument about health externalities hardly explains the full panoply of health care funded by targeted subsidies. Most health probleins are not contagious, meaning that the only one who will suffer worse health as a result of failing to purchase the health care is the patient herself. ${ }^{97}$ Further, the externality problen with immunizations is not limited to the poor. The root problem is that the chances of catching a disease are low if others have been immunized, and that everyone, rich or poor, therefore has an incentive to free ride off of the immunizations of others. Accordingly, governments generally provide free immunizations to everyone, whether or not they are poor, and often coinpel (or at least exhort) individuals to accept the free immunizations, whether they want them or not. In short, the health externality argument demonstrates that eliminating contagious diseases through immunizations is a public good, not that subsidies given to the poor should be targeted for health care.

Another version of the externality argument focuses on the effects not on others' health, but on their pocketbooks. According to this argument, individuals who received an unrestricted subsidy would not spend it on health insurance (even if the expected health benefits to themselves exceeded the costs) because they know that, if they developed a serious health care need, society would feel obligated to provide them with care if they could not afford it. Care would be provided either by a public hospital, funded by taxpayers, or by a private hospital, which recovers the cost from paying patients. In any case, individuals will have an incentive to free ride by failing to purchase insurance because they do not experience the full cost of their decision. They will also have an incentive to forgo purchasing routine health care that might prevent serious illness because they incur the cost of the routine preventive care but not of the curative care necessary to treat serious illnesses. Providing health care, rather than unrestricted subsidies, prevents such free riding. And providing routine preventive care forestalls the graver health care problems, and bigger medical bills, we would otherwise feel obligated to pay.

Although this argument is often mvoked by those who also make the paternalistic argument, the two are diametric opposites. Rather than assuming the poor are irrational, the argument here assumes they are hyper-

97. Cf. Buchanan, supra note 37 , at 210 (noting that right to decent minimum is generally understood to extend beyond traditional public health services, such as immunizations, to cover medical services that protect individual health independently of their beneficial effect on the health of others). 
rational. If given unrestricted subsidies, they would consider the likelihood of suffering a severe health problem but discount it by the probability that others would give them health care despite their failure to purchase insurance or preventive care.

Even if we assume this behavioral picture is correct, the factual predicate for this argument is shaky. The amount and quality of health care provided free of charge is far from generous. Generally, doctors have no legal obligation to take on patients, even in an emergency; their only obligation is not to abandon the patients they have taken on. ${ }^{98}$ Hospitals stand on somewhat different ground: although at common law their duty was much the same as doctors, statutes now nornally forbid hospitals from denying emergency care to those unable to pay. ${ }^{99}$ Yet there are many documented instances of hospitals domg just that. ${ }^{100}$ Moreover, hospitals can and often do deny nonpaying patients treatments for long-ternn illnesses such as cancer, however deadly those illnesses are, on the grounds that no emergency is present. ${ }^{101}$ The provision of free care is even less generous for nonfatal illnesses and disabilities. Indeed, studies have shown that the uninsured receive half as much health care as insured persons, despite perceiving themselves as being in worse health. ${ }^{102}$ And even where free care is provided, the quality is often decidedly lower: nonpaying patients inust expect overcrowded emergency rooms and treatment by harried professionals who often lack access to recent technology.

Accordingly, the hyper-rational mdividual who considers the chances that he will receive free health care is not heavily encouraged to forgo insurance. Other empirical problems beset the argument for preventive care. As we saw above, ${ }^{103}$ it is doubtful that more preventive care would save the government money. It may decrease the expected costs of those illnesses that are prevented, but it also means that individuals will survive to develop new illnesses that may be even more costly to treat.

98. HAVIGHuRst, supra note 21 , at 128.

99. Id. at 128-45.

100. KIINER, supra note 55 , at $176 \mathrm{n} .16$ (collecting sources).

101. See id. at 176 (citing sources on actual medical practice).

102. Churchell, supra note 10, at 11; see also Howard H. Hiatt, America's Health IN THE BALANCE: CHOICE OR CHANCE? 4 (1987) (citing statistics on the unavailability of health care to the uninsured); KIINER, supra note 55, at 175 (discussing widespread lack of adequate health insurance); Jack G. Copeland et al., Selection of Patients for Cardiac Transplantation, 75 Circuration 2, 8-9 (1987) (stating that there is little hope that individuals without some form of insurance can obtain cardiac transplants). Although hospitals often claim to provide large amounts of uncompensated care, the bulk of that reffects care for which the hospital actually tried to charge but did not receive payment, which would be treated as a bad debt write-off in any other business. See Frank A. Sloan et al., Identifying the Issues: A Statistical Profile, in Uncompensated Hospital Care: Rights and Responsibiltites 16, 19 (Frank A. Sloan et al., eds. 1986) (in for-profit hospitals, 97\% of uncompensated care is bad debt); see also Utah County v. Intermountain Health Care, Inc., 709 P.2d 265, 274 (Utah 1985) (finding that two nonprofit hospitals spent less than one percent of revenues on uncompensated care, and had tried to collect for that care first).

103. See supra notes $29-30$ and accompanying text. 
There is, however, an even more fundamental doubt about the premises of this argument. Namely, even if the current system provides some incentives to free ride, it is probably also true that, even without such incentives, it would often inake sense for the poor to gamble by buying far less health care than guaranteed under an adequate minimum standard. The competing needs of the poor are so great, and the cost/benefit ratios associated with health care so high, that declining to purchase current forms of health insurance with any redistributed dollars would likely be a sensible decision even without any prospect of free emergency care. ${ }^{104}$ If so, then the restriction to health care does far more than eliminate free riding: it actually forces the poor to spend nnore on health care than they rationally would even without distorted incentives.

In any event, the limited nature of the legal obligation to provide free care suggests that the fiscal externality argument extends at most to care that avoids the need for emergency care in the future. This cannot justify the full range of care generally included in the position that everyone is entitled to receive adequate health care. Rather, those employing this fiscal externality argument seeIn to be operating under the assumption that society should be obligated to provide care for any serious illness that would otherwise go untreated. But this is bootstrapping. While perhaps society should be obligated to provide care to those unable to afford it, one cannot derive such an obligation by using an argument that presupposes it.

This brings us to the third form of externality: intangibility. Anthony Culyer and Allen Buclianan, for example, have argued that we feel moral discomfort when our fellow man must do without health care. ${ }^{105}$ Thus, even if the poor felt the benefits of health care did not outweigh the costs, their judgment should not determine the inatter because they are not considering an intangible externality: the moral discomfort inposed on others when the poor go without medical treatment. To avoid this intangible externality, we restrict redistributions to health care.

Alternatively, as put more forcefully by Charles Fried, the issue is not merely moral discomfort, but one of a Kantian moral duty to alleviate serious misery suffered by our fellow man. ${ }^{106}$ Thus, we provide health care rather than redistributed cash because what we are obligated to alleviate is not the poor's lack of casl, but the misery suffered when health care needs are unmet. If the poor took redistributed cash and spent it on something other than health care, that obligation would remain. Ergo, the only way to be sure the obligation is satisfied is to restrict our redistribution to health care.

104. See supra note 96 and accompanying text.

105. A.J. CUlyer, Need and the National Heatth Service 89 (1976); Buchanan, supra note 37, at 232-36; see also Kenneth J. Arrow, Uncertainty and the Welfare Economics of Medical Care, 53 AM. ECON. REv. 941, 954 (1963); Clark, supra note 72, at 1428-29.

106. Fried, supra note 60 , at 99-101, 108-09. 
This argument strikes me as the strongest and most plausible contender to the theory I advocate. It also seems one that might well conform to what most imdividuals would actually say was their reason for supporting universal health care. Nor am I ultimately convinced by the most common objection to this theory: that individual philanthropy can resolve the problem because those who feel moral grief could pay to ease their feelings. As the theory is stated, it seems clear that maintaining the general health would be a type of public good. We feel morally comfortable if sick people have health care-and uncomfortable if they do not-whether or not we have paid to provide them with care. ${ }^{107}$ Private philanthropy will thus systematically underweigh the value of providimg for the general health. If so, we need collective philanthropy to eliminate moral free riding. ${ }^{108}$

107. See Culyer, supra note 105, at 89-91; Arrow, supra note 105, at 954; Lester C. Thurow, Government Expenditures: Cash or In-Kind Aid?, 5 PHIt. \& PuB. AFr. 361, 368-70 (1976). Robert Sugden disputes the premise of this theory. A philanthropist, he argues, does distinguish between ber gift and those of others and is concemed about how much she aids the charitable cause, not how much it is aided generally. Robert Sugden, Who Cares?: An Economic and Ethical Analysis of Private Chartiy and the Welfare State 28-30 (1983). The extent to whieh this is true is an empirical matter, but as long as donors to some extent are moved by the overall plight of donees, then some freeriding seems inevitable. See A.J. Culyer \& John Posnett, Would You Choose the Welfare State?, 5 ECON. AFF., Jan.-Mar. 1985, at 40, 42 (replying to Sugden's critique of their model).

The Kantian duty, on the other hand, does not seem to provide a free-riding explanation. Because the duty of each Kantian actor is to act as he would want everyone to act, his duty would be fulfilled by making a contribution large enough so that, if everyone made a similar contribution, the misery would be alleviated. The fact that others did not fulfill their Kantian duty would not make me in any the less compliance with $m y$ duty if I made a sufficient contribution, and the fact that others did fulfill their Kantian duty would not excuse me from failing to make the contribution necessary to fulfill mine. But the Kantian argument nced not rest on anything as indirect as a free-rider argument: involuntary philanthropy via government financing can be justified as necessary simply to enforce the Kantian duty everyone has.

108. Buchanan draws a similar conclusion, but denies that it is because a public good is at issue. Buchanan, supra note 37, at 233-34; see also Allen BuchaNAN, ETHICs, EFFICIENCY, AND THE MARKET 72-73 (1985) (distinguishing the free-rider argument from the argument that individuals will not contribute to a collective fund to aid the needy unless they have assurance that others will contribute as well). Rather, he argues that individuals will not contribute without collective action because the economies of scale for effective treatment and research programs are large enough that individual contributions cannot be effective unless others contribute. Individuals will instead, be argues, satisfy their moral obligations by funding action sufficiently small-scale that others' contributions are unnecessary, such as providing aspirin to a few arthritics, even though these contributions collectively result in a patchwork of ineffective small-scale actious. Buchanan, supra note 37, at 233-34.

Buchanan's argument is, however, unconvincing. There are already ongoing large-scale treatment and research institutions to which an individual can contribute. The economy-of-scale problem is solved as long as someone, typically the very wealthy or the government, provides the threshold capital necessary to achieve those scale economies. After that, individual contributions to the programs will be more effective than contributing to ineffective small-scale action.

Nor is Buchanan right that the situation lacks the essential public good characteristic that noncontributors cannot be excluded from partaking of the good. The only oddity is that here the public good is the moral comfort that comes when everyone's health care needs are met. That good is nonexclusive beeause noncontributors cannot be excluded from enjoying moral comfort if others have contributed enough to meet the poor's health care needs. This incentive to free-ride will undermine philanthropy both for small-scale projects and to ongoing large-scale programs. Bucbanan's contrary argument is apparently based on the assumption that donors bave a desire to be charitable rather than a 
A more serious problem with the intangible externalities theory is that it renders the analysis rather conclusory: expending nnoney on anything can be justified by the externalities resulting from the moral grief of not seeing that money expended. ${ }^{109}$ Nonetheless, I ain unpersuaded by this objection as well, for the moral discomfort at issue seems quite real, especially in dramatic cases where lealth care could save individuals from suffering severe pain or even death. ${ }^{110}$ It is indeed hard to see low one could face such human misery with indifference.

But dramatic cases with this strong visceral pull cannot explain the full panoply of health care included within the services commonly conceived to be covered by a commitment to provide all with a minimum of adequate care. Much of that care is routine and inundane, helping those who are not in a state quite as dire as misery. Of course, one reaction to this might be to conclude that this common conception is simply wrong: universal care should include only that minimum of care necessary to avoid true misery. But that would not satisfy iny aim of discovering a justifiable explanation for the actual scope of the inoral belief. ${ }^{111}$ Another strategy might use these core cases of powerful intangible externalities as the hook to tie the bootstrap necessary to get the fiscal externalities off the ground. But, as we just saw, that argument suffers froin serious empirical problems. Even if it did not, I doubt even the combination of the two arguments would suffice to justify all the healtl care generally imcluded within an adequate care standard. ${ }^{112}$

A bigger problem, lowever, is that neitler tangible nor intangible externalities persuasively explain why we slould not allow the poor instead to spend their scarce resources on housing, education, food, or clothing. It would be easy enough to conclude that the crime, illiteracy, social decay and unrest that result from deficiencies in those areas-let alone the resulting poor health-impose tangible externalities at least as great as the exter-

desire that charity he done. See Buchanan, supra at 74. See also supra note 106 (discussing similar assumption by Sugden). The latter desire, unlike the former, is nonexclusive.

109. Thurow, supra note 107, at 365; see also John S. Wiley, Jr., A Capture Theory of Antitrust Federalism, 99 HARv. L. Rev. 713, 761 (1986).

110. Fried, for example, raises the specter of the appendicitis that could readily he cured at an early stage, but if left untreated would lead to death. Fried, supra note 60, at 108-09.

111. Note that a consistent majority of Americans have opposed allowing ability to pay to be a criterion affecting the allocation of medical resources. See KILNER, supra note 55, at 180 (collecting sources).

112. Similar problems beset the argument, suggested to me by comments from Steve Sugarman and Mark Hall, that the full range of care provided within the adequate care standard can be explained by comhining the obligation to provide misery-alleviating care with the fact that practicahle systems of dehivering health care require a system of insurance. Thus, we can provide the core of miseryalleviating health care only as part of an insurance package, which must be relatively uniform. The weak point of this argument is the assumption that insurance benefits must be uniform. Assuming we would have to use an insurance system, it is far from clear why the government could not offer insurance that covers only the core of misery-alleviating care if providing such care were the limit of the societal obligation. 
nalities imposed by the failure of the poor to spend on health care. And if we mclude intangible externalities, is the moral grief of knowing there are homeless, hungry, illiterate poor people really less than the imtangible externalities of knowing the poor have chosen not to spend the supplement to their limited resources on health care? Is our sense of their overall misery really lessened by restricting the supplement to the provision of medical care? The public good argument for collective philanthropy, it would seem, justifies not just the financing of health care, but a general redistribution of mcome to the poor. ${ }^{113}$

Fimally, even if seemg the poor do without health care does impose greater intangible externalities on the nonpoor than seeing the poor have other needs unmet, is it really justifiable to prevent poor persons from spending their few (redistributed) dollars on needs that they regard as greater-thus effectively guaranteemg that those needs remain unmetbecause it would make others feel morally uncomfortable? Such a stance puts satisfying the nonpoor persons' desires for moral ease over satisfying the concrete needs and wishes of the poor. ${ }^{114}$ Or, if we instead frame the issue as fulfilling a duty to alleviate the poor's misery, we might phrase the objection as follows: why should the nonpoor be considered better judges than the poor of which deprivations make the poor more miserable and of low best to alleviate them?

\section{A Negative Justification for Targeting Health Care}

We must search for more himited and selective rationales if we are to explain why - even among societies and persons otherwise committed to free market policies-health care is justifiably regarded as a special case. The answer, I think, lies not so much in the presence of some special affirmative argument, but in the absence of some potent negative ones. What distinguishes health care is not that there are better reasons for distributing it without regard to ability to pay, but that there are fewer reasons to oppose such an egalitarian distribution because providing health care reliably identifies and meets a variable need with less harm to productive incentives than providing other goods.

At any given level of poverty, poor persons in need of health care are somewhat worse off than other poor persons: they are both poor and sick. In a sense, then, they are the poorest of their mcome bracket. Moreover, unlike needs for food, housing, shelter, and education, which are similar for

113. Cf. Mitton Friedman, Captralism and Freedom 191 (1962) (accepting the intangible externality argument as justifying governmental action to alleviate poverty).

114. To put the matter more formally, the explanation for restricted transfers requires, as Lester Thurow has cogently pointed out, that the donors' utility flows not from the donee's utility but from the donees' consumption of a particular good. Thurow, supra note 107, at 363-64. But even if this is empirically true, the question remains whether it is justiflably true. Why doesn't truc altruism require the donor to have the aim of maximizing the donee's utility rather than using the transfer as the excuse for making the poor consume what makes the donor happy? 
different individuals, needs for health care vary sharply among different individuals. Those who are sick will thus gain a higher marginal utility from extra resources than others who are healthy and have the same wealth and income. Or, as distributive theories that stress equality of resources might emphasize, their illness probably reflects additional bad "brute luck" for which they should be compensated. ${ }^{115}$ At first cut, this justifies redistributing solnewhat more to those who are sick than to others in their same wealth and incoine bracket.

This reasoning still does not explain, however, why we do not simply identify the poor who are sick and give them their extra redistribution in cash to spend how they would like. The explanation is that a regine that simply provided more money to the sick poor would face administrative costs, identification problems, and moral hazard incentives.

First, there are the administrative problems of identifying illness separately from the sinple provision of medical care. Rather than having the sickness diagnosed in the process of providing care, a separate bureaucracy of sickness verifiers would be required. Such a bureaucracy imcurs costs that may not be worth incurring, especially when one considers that most of the truly sick poor would likely spend much of their subsidies on having their illness treated.

Second, and more important, such a system would lose the element of reliable self-selection. Those without any medical need are unlikely to go to a doctor, where all they can get is help for medical needs. But if the system gives them money that they can use on other things, then there is an incentive to falsify or exaggerate illness.

Third, a system of cash distribution would create undesirable moral hazards. Individuals normally have no incentive to stay in a state of sickness (or get into one) because no one wants to be sick, and because receiving medical care is not (for most of us) intrinsically enjoyable. But if cash were paid for being sick, then individuals would have incentives not to take care of their health. This is particularly true for those who, by liypothesis, value the money (and the other things it can buy) more than they do the care. ${ }^{116}$ Indeed, a system that distributes cash instead of health care to those who are sick creates a special inoral hazard in the use of those funds. Nainely, if an individual under such a system does not spend the redistributed funds on health care, they will remain sick and thus eligible for another redistribution next week or month or at whatever interval eligibility for redistribution is determined. Thus, even those who would prefer the

115. The proposition stands unless they made a deliberate decision, under conditions of equal resources, to forego insurance against foreseeable illnesses. See Dworkin, What is Equality? Part 2, supra note 68, at 293-99; RAKowSK, supra note 39, at 88-106, 313-24.

116. I say "by hypothesis" because the objection to targeted redistributions is that individuals may prefer to spend the redistributed resources on other things. 
treatment to the cash equivalent would have incentives to reject treatınent in order to inultiply the cash payments.

While this gives us a justification for providing health care rather than giving more money to the sick poor, it still does not fully explain the tendency to stop redistribution at this point. Those who are poor and sick inay be worse off than others in their income bracket, but what about those who have lower incomes but no health problems? And even if the poor and sick are the neediest of the needy, why is that level of neediness the inagical cutoff? Why not subsidize people who are somewhat less needy but clearly needy enough that redistribution would increase utility or otherwise promote distributive justice? The answer lies in a final factor: this is the point at which productive incentives are least undermined.

Within a market economy, society must be concerned that general redistributions of wealth will decrease everyone's incentive to work and produce wealth by reducing the cost of not working and producing. ${ }^{117}$ Without some nonegalitarian economic incentives, there is likely to be no wealth to redistribute. The point is not that those without talent and initial capital deserve lower income than others; their economic status is justifable only as a byproduct of preserving incentives to work, developing talents fully, and deploying capital productively. Nor are the benefits of encouraging employment limited to the increase in goods and services produced. Employment is widely believed to have sociological importance in discouraging crime, drug abuse and other antisocial behavior.

An egalitarian distribution of health care is less likely to undermine productive incentives than an egalitarian distribution of cash, food, clothing, or shelter. People do not want to be sick, and (leaving aside hypochondriacs) have no desire for health care unless they are sick. Thcre is thus no incentive to stay sick im order to get health care. In fact, getting well eliminates the need. Nor does the distribution of health care greatly rcduce the incentive to work since working is still necessary to buy the basics in life. Moreover, the concern about work disincentives is weaker for sick individuals because illness often disables one from working anyway. In contrast, food, shelter, and clothing are valued and deinanded for their own sake, and those who need them-or would enjoy middle class levels of thein-may often be perfectly capable of working hard. ${ }^{118}$ Furthermore, egalitarian dis-

117. See generally Jerry A. Hausman, Labor Supply, in How TAXEs AfFect EcoNomic BrHAvior 27 (Henry J. Aaron \& Joseph A. Pechman eds., 1981) (presenting evidencc on the disincentive effccts of taxes); Jerry A. Hausman, Taxes and Labor Supply, in 1 HaNdBOoK of Public Economics 213 (Alan J. Auerbach \& Martin Feldstein eds., 1985) (same); Agnar Sandmo, The Effects of Taxation on Savings and Risk Taking, in 1 HaNDBOOK OF PUBLIC Economics, supra, at 265 (same). Lump-sum taxes coupled with redistributive subsidies to those with lower income do not solve this problem, not only because of enforcement problems but because, even if the lump-sum taxes themselves would not have disincentive effects, the redistributive subsidies would.

118. See Robert C. Ellickson, The Untenable Case for an Unconditional Right to Shelter, 15 Harv. J.L. \& PUB. PoL'Y 17, 33 (1992) (collecting data that American cities were foreed to abandon unqualified rights to emergency shelter because thcy became flooded with able-bodied entrants). 
tributions of such other goods may leave individuals with little incentive to work because with those other goods they can buy leisure-the one thing liealth care does not buy.

The difference in productive incentives does not result solely because those who would prefer cash or other goods to lealth care are, by definition, getting something they value less. Rather, it results because those who receive health care are-post-distribution-more able and eager to work. Suppose, for example, that I have a limp that costs $\$ 20,000$ to fix. If given a clioice of taking the operation or the $\$ 20,000$, I might take the money because I value the leisure of taking a year off and living on the money slightly inore than the $\$ 19,999$ value I put on having the limp fixed. If instead I have to take the operation, not only will I be left better able to work without the limp but also I would have to go out and work. The additional incentive to work is far more than the $\$ 1$ difference in marginal value. Thus, the fact that I inay value the $\$ 20,000$ and operation almost the same does not mean that distributing them to me leaves ine with equivalent post-distribution incentives to produce.

So although cash, food, shelter, and clothing may be more useful in terms of making people healthy, egalitarian distributions of such goods would more greatly disrupt the incentive structure undergirding our basic economic system. ${ }^{119}$ Accordingly, while capitalist societies do make some effort to provide the poor with more imcome and better food, shelter, and clothing than they could otherwise afford, the belief that everyone is entitled to egalitarian shares of these other goods is far less widespread than it is with health care. ${ }^{120}$ Most accept that the imiddle class will always have more inoney, eat better food, live in better loousing, and dress in better clothes than the poor. Not so with health care, where equivalent differences meet with outrage and condemnation as "two-tier inedicime." Complaints about "two-tier eating" or "two-tier housmg" are rare and would have far less impact.

This is lardly to say that providing free health care creates no dilution of incentives. Without sucl a right to minimum care, mdividuals might well work marginally harder, especially before they are sick or on behalf of sick family members, to be able to afford health insurance, or to get or keep a job that comes with it. Indeed, it is possible that residual concerns about incentive dilutions lielp explain why Medicaid has received nnuch more lostile treatınent than Medicare, since the latter covers persons wlio are disabled or beyond their working years, ${ }^{121}$ and why even Medicaid has generally been restricted to children (who cannot work) and those mainly occu-

119. See id. at 24-30, 33 (arguing and collecting evidence that guaranteed rights to housiug undermine work incentives).

120. ACCord, Menzer supra note 5, at 117, 121.

121. The relative political clout of Medicaid and Medicare beneficiaries may, however, be a more likely explanation. 
pied with taking care of those children. But my point is not that equitable distributions of health care create no incentive dilutions. The point is just that the mcentive dilution is far less than it would be if income were generally redistributed or if everyone were entitled to middle class levels of food, shelter, and clothing.

It is also true that productive incentives may well be undermined by the taxes necessary to raise the funds to provide health care. However, the argument here is not an affirmative argument about the general level of redistribution a society should undertake. Rather, it is an explanation why-out of the resources raised by any redistributive taxes a society cares to levy-health care proves an attractive target. Among the important needs one can fund out of any redistributed dollars, it makes sense to focus on those, such as health care, whose provision least undermines productive incentives instead of raising the funds for redistribution with income taxes, the government can use lump-sum taxes, externality taxes, or consumption taxes.

Note that the argument here differs sharply from the claim sometimes made that targeting health care is justified because it creates a more productive work force. ${ }^{122}$ That justification falters on the fact that the lion's share of health care is provided to the retired elderly and to other persons unlikely to work agam. We would not need to provide these persons with health care if enhancing worker productivity were our aim. Rather, the justification offered here is that providing health care on an egalitarian basis does not seriously undermine productive imcentives. The elderly inay not be likely to work again, but they do derive utility from health care and suffer (generally undeservedly) from their illnesses. Since the egalitarian distribution of health care does not significantly undermine their (and others') productive mcentives, there is little reason not to maximize utility and promote distributive justice by distributing health care equitably.

Note also that this theory explams why the social redress provided for illness does not contemplate complete compensation for the undeserved mjuries suffered because of ill health, but rather only the free provision of treatment-even if the treatment cannot cure the illness. Such complete compensation would seem necessary if undeserved misfortune were the true underlying theory. Non-health care expenditures might also make sense under an mtangible externatities theory if such expenditures would assuage our moral discomfort or make the unhealthy less miserable, in cases where health care alone falls short. But such cash compensation would conflict with the negative rationale laid out above.

In short, my claim is that what we experience as a strong moral sense that health care should be distributed without regard to ability to pay is, at root, the same moral sense we have that other needs should also be met

122. Callahan, supra note 3, at 111; Buchanan, supra note 37, at 210. 
equally and that other undeserved misfortunes should be compensated, but far less diluted by concerns about administrative problems and undermined productive incentives. Health care commands a greater commitment to equality because it is here that the reason for resisting equality vanishes, making any denial seem far more hard-hearted. What may be surprising, especially to those used to regarding market and egalitarian views toward health care as opposites, ${ }^{123}$ is that, far from being a sporadic aberration to liberal capitalist beliefs, our moral sense regarding equal access to medicine fits quite strongly within thein.

Another way of looking at this phenoinenon might be to say that judgments about what constitutes undeserved misfortune are in the end socially constructed. Because we can treat illness without generating serious conflict with the underpinnings of our market system, we have no trouble conceiving of it as undeserved misfortune meriting social redress through health care. On the other hand, because redressing the lack of talent, intelligence, or initial resources would raise serious administrative problems and undermine incentives in a narket society, the social construction of these deficiencies does not so readily admit that those misfortunes are undeserved. Instead, popular culture (at least in the United States) is replete with tales of rags-to-riches and examples of how people possessing little talent, intelligence, or education nuade it rich.

However interpreted, the above explanation helps provide some content to the "adequate" or "decent" or "reasonable" minimum care standards. These standards can be understood to encompass that level of health care that would be purchased by an average individual if wealth were redistributed in accord with principles of distributive justice, once those principles are freed from the shackles of fear about administrative probleins and productive incentives. ${ }^{124}$ Of course, the precise details would depend on the precise theory of distributive justice adopted, and we are far from a consensus on that. ${ }^{125}$ But, it is also true that the measurenents necessary to sort out these differences are likely to be unfeasible. In fashioning a workable standard, then, perhaps the best we can do is to say that, in rough approximation, the adequate care that society should endeavor to provide to the poor equals the level of health care actually purchased by the middle class of their society. ${ }^{126}$ Because the ricli would remain free to spend more

123. See, e.g., Williams, supra note 15 , at 174-76.

124. This assumes that the overall level of redistributive taxes suffices to fund middle class levels of health care for those unable to afford it, or at least could suffice by levying taxes that do not themselves excessively discourage productive incentives. This assumption has, obviously, become increasingly difficult to meet as health care has grown to consume an increasing share of the national Gross National Product. But part of the point of having a national health care system is to restrain the galloping increase in health care expenditures. Moreover, even today, current levels of redistributive taxes likely suffice to provide roughly middle class levels of health care to those unable to afford it.

125. See supra notes 65-71 and accompanying text.

126. Cf. Mary A. Baily, Rationing Medical Care: Processes for Defining Adequacy, in THE Price of Heattr: Cost-Beneftr Analysis and Effictency in Medicine 165, 168-73 (George J. Agich \& 
than this level, the standard remains a minimum, rather than a maximum. And because the middle class level of expenditures depends on societal wealth, so does the standard of adequate care.

Although the middle-class standard seems broadly congruent with the more thoroughly egalitarian standards of distributive justice, it might appear to conflict with those requiring less equalization. Rawls' maximin principle, for example, allows any unequal distribution of primary social goods that maximizes the level of such goods enjoyed by the worst-off class. ${ }^{127}$ But if I am right that redistributions targeted to health care do not significantly undermine productive mcentives, then an equal distribution of health care would seem to be the one fitting the maximin principle. After all, if incentives to create societal wealth were irrelevant, the distributional rule maximizing the welfare of the worst-off class would be to distribute all social goods equally.

Charles Fried's theory basing redistribution on the duty to avoid human misery poses a more direct challenge, because he expressly rejects a middle class standard, arguing that this duty can be satisfied by imstead guaranteemg each person the same level of essential goods (such as health care) as enjoyed by umonized unskilled workers. ${ }^{128}$ A convincing explanation of why I find this theory, while powerful, ultimately unpersuasive would take extensive analysis. ${ }^{129}$ Fortunately, a full-scale explanation is unnecessary because in health care the two standards actually converge. At least in the United States, unskilled unionized workers generally have at least as complete health insurance coverage as menibers of the middle class. $^{130}$ Thus, Fried's standard would, it turns out, imply roughly the same level of health care spending as that suggested here.

\section{The Purely Redistributive Conclusion}

While the analysis in this Part suggests another important lesson of the moral paradigm - that the distribution of health care should not disadvantage the poor-this far from constitutes a general theory for deciding when

Charles E. Begley eds., 1986) (reaching the same conclusion that middle-class care is the proper standard for the decent minimum, but relying mainly on the claim that providers fall into routines of what good, standard care means).

127. RawLs, supra note 70 , at 83 .

128. Fried, supra note 60 , at 99-103.

129. A brief sketch of my argument would be as follows. I doubt the level of goods consumed by unionized unskilled workers correlates that well with misery avoidance: such workers may remain miserable on several scores or enjoy goods in excess of that needed to avoid misery on other scores. Nor am I persuaded that, if we could truly put aside concerns about undermining productive incentivcs, we would be justified in only alleviating misery rather than accomplishing the fuller cqualization required by the alternative theories of distributive justice. In addition, I would raise my prior objections to a duty to avoid tbe misery of donees doing without those goods the donors fcel are essential. See supra text accompanying note 114 .

130. See, e.g., James Bennet, Auto Talks Hang on Health Costs But Workers Are Loath to Chip In, N.Y. TMMES, Sept. 6, 1993, at 1, 8 (noting that average unionized auto worker received over $\$ 1700$ a year more in health benefits than average employee). 
to provide health care. It does nothing to answer the question of what the aggregate spending on health care should be. Nor does it settle a host of issues that remain about how to distribute health care resources even after ability and willingness to pay are eliminated as criteria and equitable distribution is accepted as the goal. It is to this latter set of issues that we turn next.

III

Health Tradeoffs Within a Fixed Overall Budget

Despairing of deriving any systemic noral principles for trading off health care against other goods and services, inany academics focus on deriving principles for trading off different health care needs once an overall budget for health care has been fixed. Suppose we have a provider facing a limited health care budget: for example, the budget of the national health care system in Britain, the budget of the state Medicaid program in Oregon, or the budget of a county hospital in California. What moral principles should guide that provider in allocating its budget among the different health care needs of its community, recognizing that some needs must go unmet?

The basic goals, often seen to be in tension, are of maximizing the overall health benefits to the group and distributing those health benefits equitably among group members. ${ }^{131}$ These goals are, however, hardly selfdefining. As Section III.A discusses, inedical measures have no special claim to accuracy in measuring the health maximization of a group. In addition, as Section III.B discusses, moral analysis can generate many divergent ineasures of aggregate health that an allocative decisionmaker might endeavor to maximize, including: total lives saved, total life-years saved, total quality-adjusted life-years saved, the well-being of the worst-off individual, and the number of individuals living a normal life span.

Section III.C then examines the claims that soine of these maximization standards discriminate against the old (or the young), or against those with acute illnesses (or chromic ones). Such claims of discrimination, I conclude, depend on one's baselime understanding of what constitutes an equitable distribution of lealth care. Further, each nneasure of liealth maximization reflects a particular notion of equity. Accordingly, here the concepts of maximization and equity are not in tension, but are rather two sides of the same coin, separate mamifestations of the definition of a simgle set of priorities. Finally, Section III.D considers and rejects allocative mechanisms favoring those with desirable personal characteristics unrelated to their capacity to benefit from health care.

131. I assume throughout that the relevant patients actually want treatment, thus putting aside tricky issues about when to deny treatment on the grounds that the dying person prefers (or, if competent, would prefer) to die rather than remain alive in a condition of extreme pain and/or dysfunction that health care can provide. 


\section{A. Medical Measures}

One might think that one could just rely on medical judgment to determine how best to allocate a fixed set of resources to maximize the health of a group. ${ }^{132}$ But this has not actually been a traditional focus of medical attention. Physicians have generally regarded the lack of resources to provide care for all treatable illnesses as a temporary problem requiring a budget increase, not the development of sustamable principles of allocation. Indeed, the development of such principles has sometimes been shunned as tantamount to admitting defeat. The dominant forms of nonprice rationing practiced by the medical profession have thus tended to be makeshift and poorly-conceived.

Rationing at the bedside via ad hoc, seat-of-the-pants judgments is a common phenomenon, a "method" of allocation dubbed "ad hockery."133 Most medical rationing does not involve even this level of conscious thought. Absent emergencies, patients are usually treated on a first-come, first-served basis that may be regarded as a means of random allocation akin to using lotteries. ${ }^{134}$ But im fact, both the priority given to emergency cases and the use of waiting lists flow from the medical premise, no matter how unrealistic, that eventually all the patients will be treated. ${ }^{135}$

The resulting waiting lists (interrupted only by emergencies) often produce irrational allocations that effectively deny some persons care entirely and cause needless suffering and worse health outcomes because patients deteriorate during the wait. Indeed, because first-come, first-served treatment favors patients wlio have waited the longest, it tends to select the sickest patients for treatunent (as does einergency priority) even if they are the least able to benefit from it. ${ }^{136}$ But these facts either are studiously ignored to preserve the illusion that only the timing of care is being affected or are strategically highlighted in calls for greater funds. Some have even argued in favor of using random means of allocating health care in order to provoke a public outcry that might in turn produce greater funds. ${ }^{137}$ Rarely do the above problems provoke a conscious medical rcthinking of the allocation problem.

One partial exception to this refusal to allocate is the system used in time of war or natural disasters: medical triage. But triage does not really

132. For the view that medical judgment should suffice to make any rationing decision, see, e.g., Gerald R. Winslow, Triage and Justice 61 (1982); Cynthia B. Cohen, Ethical Problems of Intensive Care, 47 Anesthesiology 217, 224 (1977); Frederic B. Westervelt, Jr., A Reply to Childress: The Selection Process as Viewed from Within. 53 Soundings 356 (1970).

133. David Sanders \& Jesse Dukeminier, Jr., Medical Advance and Legal Lag: Hemodialysis and Kidney Transplantation, 15 UCLA L. REv. 357, 376-77 (1968).

134. See KIINER, supra note 55, at 192-207; RAKOWSKr, supra note 39, at 317, 323.

135. Cf. KIINER, supra note 55, at 129-30 (linking the priority given to cases of imminent death to the assumption that resources will grow).

136. Id. at 202.

137. See id. at 200, 203, 225; Jay Katz \& Alexander M. Capron, Catastrophic Disrases: Who DeCides What? 195 (1975). 
offer a means of systemic allocation. Traditionally, medical triage sorts individuals into three categories - those who will die regardless of treatment, those who will live regardless, and those for whom treatment makes the difference between life and death-and then treats the last group first. ${ }^{138}$ Such triage, however, is generally used merely to time the order of treatments where it is assumed that the health problems of those who will live without immediate treatment will be treated later. Medical triage thus has little implication for how to order priorities where treatment of those whose lives can be saved (albeit for a short time and in poor condition) means nontreatment of those whose health could be significantly improved. ${ }^{139}$

Hidden-and often quite dubious-allocative judgments are often imbedded in seemingly innocuous measures of medical effectiveness. For example, take a ineasure of effectiveness commonly used by the medical profession: two-year survival rates. Although employed as if it were merely a technical measure of effectiveness, in fact, as Alan Williams poimts out, the use of two-year survival rates to decide where to allocate health care resources implicitly makes three dubious value judgments:

(1) to survive less than two years is of no value;

(2) having survived two years, further survival is of no additional value; and

(3) it does not matter with what quality of life people survive to two years. ${ }^{140}$

One could also add a fourth dubious value judgment: it does not matter how many resources were needed to achieve a given survival rate. A treatment with an $80 \%$ survival rate, for example, might thus be used even if more lives could be saved by using the same resources to provide twice as many persons with a cheaper treatment having a $60 \%$ survival rate.

This problem is not unique to two-year survival rates. Beyond the threshold criterion of whether or not the treatment will confer a medical benefit at all, any measure of a treatment's degree of medical effectiveness implicates some value judgment that cannot be justified on purely medical or scientific grounds. Medical judgment necessarily plays an essential role in allocative decisionmaking by determining when that threshold criterion is fulfilled, and by accurately describing the prognosis if a given treatment is

138. Harrus, supra note 6, at 262 n.1; Bensen B. Roe, Treatment Decisions and Triage, in Dilemmas of Dyano 89, 93 (Cynthia Wong \& Judith Swazey eds., 1981); George P. Smith, II, Triage: Endgame Realities, 1 J. Contemp. Health L. \& Pol'y 143, 143 (1985); see also Beauchamp \& Chmoress, supra note 82, at 300; Douglas A. Rund \& Tondra S. Rausch, Triage (1981); Triage in Medicine AND SocteTy (George R. Lucas, Jr. ed., 1975).

139. Some forms of triage may also call for first treating, among those who will die without treatment, those who can be treated quickly on the theory that more total lives will be saved that way. See Roe, supra note 138, at 93 . This is consistent with the first health maximization measure discussed in Section III.B.1, but does not involve any conscious rejection of the alternative measures.

140. Alan Williams, Cost-Effectiveness Analysis: Is It Ethical?, 18 J. MEd. Etrics 7, 10 (1992). 
undertaken. But it can offer no scientific method to tell us how to value that prognosis and weigh it against other health benefits we could achieve with the saine resources. For that we need moral, not medical, judgment.

\section{B. Moral Measures of Group Health Maximization}

Health care can affect the health of individuals in many different ways. It may save their lives, or it may improve the quality of their lives by, for example, reducing paim or improving mobility. The improvement may last for a short or long time. The patient whose life is saved may have many years of life ahead of him, or just a few. The illness or disability that is cured may have been one that would have eventually healed on its own, or one that would have lasted for the rest of the person's life.

Once we abandon a commitment to fund every health benefit possibly achievable, we face difficult choices about which health improvements to fund out of a himited set of resources. These choices would be difficult enough to make if the various health improvements provided or demicd were experienced by one person. But they are rendered far more difficult because providing the health improvements to some people inevitably means denying them to others. Where we have various sorts of possible health improvements distributable anong different members of a group, it becomes far from obvious to say which distribution maximizes the health of the group.

In short, if we are to have a limited health care budget, we must confront the question of how to make tradeoffs between the lives and health of different individuals. Unfortunately, when faced with this issue, there is a tendency among some moral philosophers and ethicists to duck the issue by arguing that more money should be spent on health care. ${ }^{141}$ This tendency was illustrated by a bioethical consultant who, when asked to help a county health agency decide where to allocate its limited resources, concluded after three months of study that it was immoral to make a choice. ${ }^{142}$ The only ethical option, apparently, was to demand a budget increase.

This advice is obviously of no help to the health agency, which must ultimately make some decision about how to spend whatever budget it has. ${ }^{143}$ It does no good to tell a provider that it cannot deny some persons health care to serve other health care needs. That position is intellectually bankrupt because, however it spends its budget, the provider inust effectively do just that. The only question is whether the provider will make its choice knowingly and deliberately or through ignorance and happenstance.

141. See, e.g., HARrIs, supra note 6, at 110; Harris, supra note 23, at 122; see also KILNER, supra note 55 , at 9,13 (addressing dilemma of choosing among patients but asserting that whenever possible such dilemmas should be avoided through increased funding).

142. See Mark Sandalow, Report Calls Rationing of Health Care Immoral, S.F. Crron., June 30, 1989 , at A2.

143. In the end, Harris concedes he has no satisfactory solution to this question. See Harris, supra note 23 , at 122 . 
Nor does increasing the budget solve the problem. True, such a budget increase inay avoid an immediate choice between certain health care needs. But at any new spending level, new allocation dilemmas will arise about how to allocate the budget among the remaining health care activities that would provide some positive health benefit. The tendency then will be to increase the budget again, to avoid the new dilemma. The effect is an everrising budget spiral. And however high the budget goes, the dilemma will remain. Unless some beneficial health care is ultimately denied, this moral position amounts to nothing more than a closet version of the absolutist claim. Recognizing this is crucial because the closet absolutism that derives froin a desire to avoid painful choices is probably a far greater cause of overspending on health care than any explicit adoption of the absolutist claim.

We must then face up to the difficult tradeoffs necessitated by a hmited health care budget. To better isolate the relevant concerns, I begin by considering a stylized situation where the only variable is the number of lives we could save with an available resource. Subsequent sections add new variables, such as the years of hife the patients would live and the quality of the life they would have.

\section{Total Lives Saved}

Imagine that we have five potential patients, all the same age and equally likely to live long and healthy hives if they receive a certain drug. One of thein, however, needs 4 ounces of the drug to survive whereas the other four would need just 1 ounce each. If we have only 4 ounces, what should we do?

Formal equality can readily be rejected. If we gave each patient an equal share of our 4 ounces, they would each get 0.8 ounces. But this would not be enough for any of them to survive. Surely moral principles do not require a distribution of medical resources that fails to confer any health benefit to anyone. ${ }^{144}$ The choice, then, would seem to lie between saving the four hives or saving the one. On utilitarian grounds, the appropriate principle seems readily apparent: the number of lives saved should be maximized. ${ }^{145}$

Soine philosophers, however, object to this on the deontological ground that it fails to accord each individual equal concern and respect and requires an interpersonal utility comparison we have no means to make. ${ }^{146}$ They argue that to each person, his or her life is uniquely important, a nec-

144. See KIINER, supra note 55, at 14-16 (collecting sources).

145. At this point, I am abstracting from differences in the particular patients' personal characteristics that allegedly might affect the allocation decision on utilitarian grounds. See infra text accompanying note 221 .

146. MENZEL, supra note 65, at 212; RAKowSKI, supra note 39, at 283-84; John M. Taurek, Should the Numbers Count?, 6 PнII. \& PuB. AFr. 293, 303-08 (1977); Albert Weale, Statistical Lives and the Principle of Maximum Benefit, 5 J. MED. ETrncs 185, 189 (1979); Nora K. Bell, Triage in Medical 
essary prerequisite to enjoy any other goods, and thus incommensurate in value. Because of this incommensurability, we cannot add saved lives in soine social calculus, as if the gains and losses were all experienced by some super-person, to determine what to do. Either choice we make saves something of mcomparable worth-life-to those who have it.

How, then, to choose? Although these philosophers differ on whether any specific inethod of choice is morally required, they recommend, as the best method for equally respecting each individual's right to life, some sort of random chance. ${ }^{147}$ Flipping a com between saving the one life and saving the other four would give everyone a $50 \%$ chance of survival. It thus confers the only equality we can reasonably give under the circumstances: an equal opportunity to live.

On social or utilitarian principle, of course, this is absurd. The principle of maximizing lives saved would save four lives; the principle of random choice would on average save 2.5 lives. The systemic application of the random choice principle would thus result in more deaths. This seems particularly unjustifiable where, as here, the life-saving involves the use of social resources for which everyone has paid.

Even on deontological grounds, the randoin choice position is dubious. Saving the one person may accord proper respect to the incommensurable value that person places on his he, but it demies respect to the incommensurable value four others place on their lives. ${ }^{148}$ Why should avoiding the ultimate tragedy for one person ever be more important than avoiding that ultimate tragedy for four other humans? Such a result defies what iny sense of according equal respect to each hfe means. Indeed, it seems to affirmatively create mequality by devoting (on average) more resources to saving the one life than to saving any of the other four. ${ }^{149}$

Moreover, in deciding which principle best accords equal respect, there seems to be no reason to focus on the time of the principle's applica-

Practices: An Unacceptable Model?, Soc. ScI. \& MED., Dec., 1981, at 151, 152-53; see also KILNER, supra note 55, at 194-95 (collecting sources).

147. See Taurek, supra notc 143, at 303, 307; KHNER, supra note 55, at 194-95 (collecting sources); see also RAKOWSKI, supra note 39, at 285-99 (arguing that this is the best moral position absent $e x$ ante consent to an alternative).

148. For other specific objections to the conelusion that the number of lives does not matter, see GLOVER, supra note 6, at 208-09; Franees M. Kamm, Equal Treatment and Equal Chances, 14 PHIL. \& Pub. Aff. 177, 181-86 (1985); Brian Barry, And Who Is My Neighbor?, 88 Yale L.J. 629, 637 (1979) (reviewing Charles FRIED, Right AND Wrong (1977)); see also Eric Rakowski, Taking and Saving Lives, 93 Colum. L. Rev. 1063, 1105 (1993) (conceding Kantian prineiples could be interpreted to justify maximizing lives saved but arguing that is not the best interpretation).

149. A random selection consistent with this moral intuition would be a lottery with a $20 \%$ chance of selecting to save the one person and an $80 \%$ chance of selecting to save the four. See Kamm, supra note 148, at 180-86; see also John Broome, Selecting People Randomly, 95 Etrics 38 (1984) (advocating a lottery with the odds set proportional to group size). But whenever that $20 \%$ chanee was realized, this method would still save fewer lives than were possible and thus raise the other problems noted in the text. Kamm herself ultimately coneludes that the grcater number should consistently be saved. See Kamm, supra note 148, at 187-88. 
tion rather than the time of the principle's adoption. At the time of adoption, the principle of maximizing lives saved gives everyone the maximum chance of survival-assuming none of them have a particularly high propensity to end up in the position of the single patient-and thus affords all of them a proper and equal respect for their right to life. On similar grounds, we may be able to rely on some version of ex ante consent, ${ }^{150}$ about which I shall have more to say in Part IV.

One objection often raised to the proposition that we should maximize the number of lives saved is that, if so, it would be appropriate to kill a healthy person to take from them the organs necessary to save four others who (through no fault of their own) need organ transplants. ${ }^{151}$ But the two situations are not parallel, as one can readily see by noting that those favoring random choice in saving lives do not suggest we should also randomly decide whether or not to kill a healthy person to save four needing organ transplants. ${ }^{152}$ Many possible grounds, including deontological ones, can be offered for the distinction. ${ }^{153}$ My own grounds for justification would be that the distinction rests on the legitimate fear that allowing humans to select whom among the possible healthy donors will be killed would (1) raise enorinous risks that the selection power would be abused and (2) undermine important moral norins against killing that are imternalized into each of us to make society function better. The possible benefits in isolated cases of well-intentioned killing is hardly worth the risk of abuse and weakening of norms. The absence of these factors explains why in the fanous trolley problem - where the person is faced with a choice of either allowing the trolley to strike and kill four persons or switching to another track that will kill one person-it does seem appropriate for the person to switch tracks even though they are literally killing one person to save four. ${ }^{154}$ The stylized nature of the trolley problem means that the decisionmaker played no role in selecting the person to be killed and makes it unlikely that gen-

150. See, e.g., Wnssow, supra note 132, at 141-42; Kamm, supra note 148, at 181, 189; Rakowski, supra note 148, at 1104-55.

151. See, e.g., Rakowski, supra note 148, at 1063-64. The condition that the persons needing organ transplants not be responsible for their predicament excludes the easy answer to this dilemma: that allowing such involuntary transplants would lessen everyone's incentives to lead healthy lives. Let us also assume, to avoid another easy answer, that those receiving the organ transplants would live just as long, and in just as good health, as the proposed involuntary donor.

152. On the other hand, one philosopher who favors maximizing hives saved has concluded that, as a matter of principle if not practice, there should be a society-wide survival lottery among those who have a sufficient number of healthy organs to save multiple persons needing transplants, who if their number came up would be obhgated to give up their lives to provide organs to others. See Jorn HaRRIS, VIOLENCE AND ResponsibIIITY ch. 5 (1980). But to Harris, the choice whether or not to kill someone to save multiple persons is not random but determinate. In any event, Harris' view does not appear to be shared by anyone else.

153. For a thorough review of some relevant literature, see Rakowski, supra note 39, at 1071-1104.

154. See generally id. at $1064 \mathrm{n} .1$ (collecting sources on trolley problem). 
eral moral norms agamst killing will be undermined. ${ }^{15 s}$ Similarly, in allocating health care resources to maximize hives saved, the decisionmaker has not selected the mdividuals having the fatal illnesses requiring treatment and does not undermine moral norms against killing by treating the greatest number of illnesses she can.

\section{a. More on Random Choice}

The use of random chance to make care allocation decisions deserves separate consideration, im part because it has ramifications beyond the present context. Philosophers and ethicists often rely on random chance when the moral primciples they deem acceptable fail to resolve care allocation

155. Eric Rakowski's ultimate grounds for distinction between the organ transplant hypothetical and the trolley scenario are not entirely clear. Diverting the trolley, he argues, is justifiable where it would be in each individual's ex ante best interest because we may then presume everyone's consent. See id. at 1126-29, 1144-45. One ground offered for distinguishing the life-ending organ transplant hypothetical is that such transplants would not be in everyone's ex ante best interest because then individuals would be encouraged to hive unhealthy lives. See id. at 1083, 1132. However, this ground disappears if we assume needs for organ transplants are unaffected by behavior, and yet Rakowski still seems opposed to presuming consent to the life-ending organ transplants under that assumption. See id. at 1132 n.164. Another argument, which Rakowski extrapolates from Menzel, is that in the trolley example wc are entitled to presume consent to maximizing lives saved because obtaining actual ex ante consent is impracticable, whereas in the hff-ending organ transplants example we could have secured actual $e x$ ante consent from individuals, and thus are not entitled to presume consent. See id. at 1123. This point has some persuasive power, particularly if we add the point that, while those wishing to participate in a life-maximizing organ pool could individually sign up, see id. at 1131-32, efforts to secure actual consent in the trolley problem would likely leave a mixed group of consenting and nonconsenting persons on the same tracks. But Rakowski himself takes great pains to deny that aetual consent has more inherent value than presumed consent, see id. at 1113-22, thus making it unclear why he would not also presume consent to life-ending organ transplants that maximize lives where the cause of organ failure was clearly not behavioral.

In any event, the Rakowski-embellished Menzehan solution, which Rakowski arguably in the end embraces, see id. at 1123, leaves unanswered the questious of (1) why in the real world no individuals seem inclined to give actual ex ante consent to life-ending organ transplants even where the cause of organ failure is not behavioral and (2) why societies would be unlikely to enforce such consent if it were actually given by individuals. My selection-abuse worry explains (1), and the external effect on societal norms explains (2). See text aecompanying notes 150-52. Nor does it explain why affirmative killing to maximize lives saved would not be justified in cases where ex ante consent was impracticable. Suppose, for example, a sophisticated medical team just arrived in a medically unsophisticated island where no one had ever considered the possibility of organ transplants. Would the team then be justified in killing one islander to obtain organs for four others suffering from organ failures (not linked to their past behavior) because securing actual $e x$ ante consent would have been impracticable?

Rakowski's solution also produces some morally counterintuitive results to the trolley problem. He concludes, for example, that there is no distinetion between the classic trolley problem and pushing someone in front of the trolley to cause it to grind to a halt before killing the other four, id. at 1146, a conclusion at odds with that of several other leading philosophers. See F.M. Kamm, Harming Some to Save Others, 57 PHII. STud. 227, 238-39 (1989); Judith Jarvis Thomson, The Trolley Problem, 94 YaLe L.J. 1395, 1409 (1985). (The intuitive result that switching tracks but not pushing someone onto the tracks is morally justified is again explained by the two faetors I cite). He also concludes one is justified in switching tracks only where one knows that the persous on the tracks had an equal risk of being on those traeks. See Rakowski, supra note 148, at 1126-29, 1144-45. Having this level of knowledge seems so unlikely that it will rarely produce the intuitive result that switching tracks is morally justifiable. 
questions. ${ }^{156}$ The grounds are normally that only random chance accords everyone's life or health equal regard by treating them as incommensurable values. Some also believe that random chance ineans no one is responsible for making unpleasant choices. ${ }^{157}$

Yet, to iny mind, randoin chance fails to accord respect to anyone: it dehumanizes each life by making its existence turn on the mere roll of the dice. ${ }^{158}$ This seems justifiable only if one has a faith that God is guiding the dice, which in fact was in many cultures the basis for relying on random chance to guide critical decisions. ${ }^{159}$ Absent such a religious belief, relying on random chance represents merely a throwing up of the hands in the face of a difficult decision, an irresponsible effort to evade or deny the reality that the decision-even if only a decision to throw the dice-is being made by humans. Stooping to random selection also robs each person of a dignified explanation for their death. Would not a patient being denied lifesaving treatment prefer to be told that the resources that would have been necessary to save her life are instead being used to save the lives of four others-that her death has some life-affirming meaning-rather than being told that the only reason for her death lies in the arbitrary luck of the draw?

The effort to avoid human responsibility through random chance is not only misguided, it is also futile. We cannot avoid responsibility for deciding to employ the lottery at all, and when to do so. Moreover, while the operation of lotteries may give the appearance that human choice was not involved, "lotteries do not spring fully formed froin Heaven."160 In particular, some liumans must make the decision about who can enter the lottery and how often. Can I, for example, enter the lottery when I am healthy in case later in life I need the medical treatment being raffled off? If not, how bad does my niedical condition have to be before I can enter the lottery? If I do not win the lottery this year, can I enter it again the next? If I already received the treatment (say an organ transplant) and it failed, can I enter the lottery again? Can I trade any rights I won in a lottery to someone else in excliange for the rights to another medical procedure? The conduct of any lottery would require resolving these questions, and any resolution will effectively make some choice between the health needs of different persons.

Furtherinore, the framing of allocative decisionmaking in a way that allows random choices among patients-while creating fruitful avenues for

156. See, e.g., BeAuchaMP \& CmIDRESS, supra note 138, at 196; WinsLow, supra note 132, at 102; James F. Childress, Triage in Noenatal Intensive Care: The Limitations of a Metaphor, 69 VA. L. Rev. 547, 561 (1983); Al Katz, Process Design for Selection of Hemodialysis and Organ Transplant Recipients, 22 BUfF. L. Rev. 373, 403 (1973); see also KILNER, supra note 55, at 194-95 (collecting sources).

157. See Barbara Goodwin, Justice By LotTery 45-46, $97-99$ (1992).

158. See CALABrest \& BoBbrTt, supra note 8, at 134 ("The arbitrariness of the [lottery] approach makes the losers feel helpless and depersonalized.").

159. See KIINER, supra note 55, at 192 (collecting sources).

160. Williams, supra note 140 , at 9 . 
philosophical analysis - mischaracterizes the actual problem facing anyone trying to devise a workable system for allocating health care resources. Most actual health care allocation decisions run more along the following lines. Should we order the $98 \%$-effective drug or the $99 \%$-effective one? Should we buy the new expensive machinery that somewhat improves our ability to diagnose, or not? It is hard to know what it would mean to make sucli choices in a random way that gives every potential patient an equal chance at having her he saved. Should doctors randomly decide which drug to prescribe, or machinery to buy, if some offer better quality and others lower prices? Such random choices are unlikely to actually give eacli patient an equal chance at life. ${ }^{161}$ Nor are they likely to be workable. Those making health care allocation decisions need some set goal that they can ami to fulfill.

In short, random chance should not and could not evade human responsibility for whatever allocation decision is made, and there are strong utilitarian and deontological grounds to clioose, where the only variable is how many lives are saved, whichever allocation maximizes the total saved lives. This measure also has the advantage of being consistent with the traditional medical practice used during triage. ${ }^{162}$

\section{b. Resources Required and Likelihood of Benefit}

The analysis so far imdicates that, absent any other variable, the basic standard of health maximization should be the total number of lives that can be saved witl the given resource. The answer is no different if we describe the question as whether to allocate resources first to those who need fewer resources for treatinent. We can think of the clioice as using our four ounces of medicine to save either one life or four lives, or we can think of the clioice as allocating the medicine either to patients who need one ounce per life saved or to patients who need four ounces per life saved. In either case, the choice is the same in a world where the supply of medicme is limited. The maximizing-lives-saved standard can thus be alternatively expressed as a resources-required standard, which favors saving those whose lives can be saved with fewer resources. ${ }^{163}$

Though inore controversial, the same logic requires that we allocate resources to those patients more likely to have their lives saved by those resources. Suppose, for example, we had ten ounces of a drug and could give it either to ten people who have a $10 \%$ chance of survival or to ten people with a $40 \%$ chance of survival. Which group should we choose?

161. Indeed, to give every potential patient an equal chance would require a decidedly nonrandom, highly intricate series of purchase decisions across a multitude of illnesses. It would also seemingly require resources to be dedicated first to those with the lowest chances of being saved so that everyone's chanees could be equalized.

162. See supra note 139.

163. See KIINER, supra note 55, at 56-57. 
The statistical likelihood is that we are again choosing between one life saved and four lives saved. I would thus resolve this under the same principle of maximizing the number of lives saved.

Some people, liowever, balk at a likelihood-of-benefit criterion, even though they would accept a lives-saved and resources-required standard. ${ }^{164}$ First, they argue that such a standard is excessively utilitarian, because it gives some patients who have a significant likelihood of benefitting from treatment no chance at all of being treated, and thus denies them the equal regard to whicls they are entitled. ${ }^{165}$ But this argument is no different from the argument against maximizing lives saved, and does not justify denying care to patients who have a greater likeliliood of benefitting froin treatment.

Opponents of utilizing a likelihood-of-benefit criterion also argue that such likelihoods are uncertain and merely statistical, so that "the patient preferred might die even with treatment, while the patient left out might have survived if treated." 166 But that does not justify failing to make the best judgment we can, especially when the alternative is to flip a coin. ${ }^{167}$

Moreover, even those who advocate refusing to consider the likelihood of benefit in allocating liealth care resources agree that such resources should not be expended on those whose probability of benefitting is very low. ${ }^{168}$ But this argument is inconsistent: given the existence of some positive possibility of benefitting, why should the level of probability only matter up to a certain threshold and not thereafter? The refusal to consider differences in the likelihood of benefit beyond some threshold manifests a failure to follow through with the policy grounds for considering the likelihood of benefit at all. ${ }^{169}$ Similar tendencies are not at all uncommon in health care allocation proposals, which frequently advocate allowing certain factors to narrow the field of candidates, but then try to avoid ultimate responsibihty by using randoin chance to select among that final field. ${ }^{170}$

164. See, e.g., id. at 137-40.

165. Id. at 137, 230; Wanslow, supra note 132, at 68-69; John Broome, Selecting People Randomly, 95 Ethucs 38, 48 (1984); see Myron Ebersole, Organ Transplants, in Medical Ethics, Human Choices: A Christian Perspective 103, 110 (John Rogers ed., 1988).

166. KחNER, supra note 55, at 137; see also Lois K. Christopherson, Heart Transplants, 12 Hastings Center Rep. 18, 19 (1982).

167. See KIINER, supra note 55, at 230 (advocating random selection among persons with a significant likelihood of benefitting from treatment no matter how much their likelihoods vary).

168. Id. at 120-21 (advocating a minimal threshold and listing supportive sources).

169. A likelihood-of-benefit threshold also leads to some perverse allocation results. Suppose, for example, that we have a fixed set of resources that we could use to either (1) save five lives (with near certainty) through intensive neonatal care, or (2) provide prenatal care to 10,000 patients, which produces a $0.5 \%$ reduction in infant mortality. A likelihood-of-benefit threshold would foreclose the prenatal care option even though it would save a total of 50 lives, and thus be far preferable to the neonatal care option (even leaving aside quality of life) under a maximizing-lives-saved test.

170. See, e.g., RAKowsKr, supra note 39, at $321 \&$ n.6 (favoring younger people over older but choosing randomly if the gap in age is small or moderate because at that point their situation becomes roughly equal); Childress, supra note 156, at 559 (suggesting that likelihood-of-benefit criterion should only be employcd where difference in likelihood is large and certain); Frances M. Kamm, To Whom?, 24 Hastings Center ReP., July-Aug. 1994, at 29, 30-31 (should favor those who will live longer or are 
This, to my mind, is irrational. If human choice legitimately plays a role in excluding certain candidates, and if the justifications for that choice are valid, then human choice based on those justifications should extend to the ultimate decision as well.

A final argument, employed more frequently against the likelihood-ofbenefit standard, but applicable as well against the resources-required standard, is that these standards discriminate agamst those who are older or in worse health because they will likely have a lower chance of survival or require more resources. ${ }^{171}$ For now, I put aside such discrimination claims, taking them up below in Section C.

\section{Life Years Saved}

\section{a. Life Years Simpliciter}

Let us now agam abstract from probabilities and uncertainties. Suppose we can choose to deploy our resources to achieve one of two certain results: (1) saving the life of a person who will live one year, or (2) saving the life of a person who will live four years. Assume both persons are the saine age and would liave the same quality of life during any extension provided by medical care; the only variable is the number of years. How should we choose?

The total-lives-saved standard does not lielp us because either choice results $\mathrm{i}$ the saving of one hife. But we might by analogy adopt a similar standard: maximizing the total number of life years saved. This would dictate saving the life of the person who would live four years. Again, this seems easy to justify on utilitarian grounds. Assuming utility satisfaction is a product of the length of time lived, maximizing life years will inaximize utility.

But again, the matter is debatable on deontological grounds. All mdividuals, one position asserts, value whatever is left of their life equally. ${ }^{172}$ Their life, however long, is all they have and they have an equal right to keep it. Humans are more than the sum of their life years, and it dehumanizes them to treat thein according to their potential life span. Thus, society cannot morally justify denying soine persons the rest of their life in order to provide a longer term of life to other persons.

One might dispute the premise of this argument. Surely if any individual were asked to choose between a treatment that would give her one year

more likely to be saved and favor larger groups who can be saved, unless the difference [in length of life, probability of benefitting, or numbers saved] is "small"); Katz, supra note 156, at 415 (proposing random selection of individuals to receive care from sub-pool); Nieholas Reseher, The Allocation of Exatic Medical Lifesaving Therapy, 79 Errics 173, 183 (1969) (setting forth five criteria for selecting patients but advocating that they be used to create a pool one-third to one-half larger than will be treated with the final choices made by lot); see also Wnstow, supra note 132, at 143-47 (discussing random selection of patients from a pool of individuals having the same level of neediness).

171. KINER, supra note 55 , at 138-40.

172. See, e.g., id. at 83, 147, 149; RAKowsKu, supra note 39, at 322; Harris, supra note 23, at 118. 
of life and another that would give her four years of life, she would choose the latter. One year of life does not, then, seem to be valued equally to four years by individuals. Why are we not justified in applying the same judgment individuals would make in their own cases across different individuals as well? Doing so does not, rightly understood, constitute a failure to accord equal regard to each individual's views. Moreover, as with the totallives-saved standard, each individual would favor this standard at the time of its adoption. We should thus again be able to obtain or rely on some version of ex ante consent. ${ }^{173}$

It must also once again be recognized that in the end some choice must be inade. The alternative to denying soine persons the rest of their life in order to provide a longer term of life to others is to deny some persons the rest of their life to provide a shorter term of life to others. There is nothing in deontological theory that makes the latter choice more attractive than the former. Thus, opponents of a length-of-benefit test are forced to rely on random chance in choosing among patients who vary only in the length of time they would live, ${ }^{174}$ which has all the probleins discussed above.

Interestingly, those who reject a length-of-benefit criterion for allocating health care resources inevitably do concede that if the length of benefit is short, health care should be denied. ${ }^{175}$ If the threshold were one year, for example, care would be provided to someone who would live one and a half years but not to someone who would hive six months. But if one extra year of life should not matter in choosing between persons who would live two versus three years, why should it inatter here? Again we seem to have an inconsistent failure to follow through with the full implications of the justification for setting a threshold.

\section{b. When Maximization of Life Years Conflicts with Total Lives Saved}

There thus seem sound grounds, where the only variable is the number of life years that could be saved, to allocate resources where it would maximize life years saved. A more difficult problem, however, arises when we have a conflict between the total-lives-saved test and the life-years-saved test. How should we choose when these two health maximization ineasures conflict?

Suppose, for example, that we have the following choice. We can provide health care either to six dying persons who will each gain one healthy

173. See infra Part IV.

174. See, e.g., HARRIS, supra note 6, at 88; KIINER, supra note 55, at 230.

175. KILNER, supra note 55 , at $120-21$ (supporting a minimum length-of-benefit threshold and citing sources proposing thresholds ranging from a few months to several years). Harris suggests an exception for cases where the life saved would be "very short," a matter of "hours or days," but ultimately backtraeks from it, concluding that it is up to individuals whether they want whatever period of remission medicine can give them. See Harris, supra note 23, at 120-21; see also HARrIs, supra note 6 , at 100 . 
life year or to one dying person who will gain seven healthy life years. ${ }^{176}$ If our standard is maximizing life years saved, we would save the one person to gain seven life years instead of six. But do we, in this situation, really regard saving the one life as having greater value than saving six lives? A pure life-years test seems unable to capture inportant concerns about the distribution of health care.

More fundamentally, one might argue that a pure life-year-inaximization test fails to sufficiently respect the sanctity of human life. It is one thing to justify a tradeoff between one life expectancy and a longer one. But a pure life-years test would trade life-expectancy for life itself.

One can thus plausibly argue that the total-lives-saved standard should have absolute priority over the life-years test. Under this position, where a choice must be inade between different life-saving activities, the systein should choose those that save the most lives without regard to how long the individuals whose lives are saved will live. ${ }^{177}$ The life-years test would only play a supplementary role in choosing among allocative options that would save the same number of lives. ${ }^{178}$

I can see no conclusive argument for rejecting this position, which does at least avoid relying on random chance. The following considerations, however, seem relevant and cut agamst an absolute priority for lives saved.

To a pure utilitarian, inaximizing total life years seems more likely (assuming that all generally enjoy smillar utilities per year) to inaximize total utility. True, this would not persuade those who instead favor versions of utilitarianism that emphasize the equal distribution either of utility or of opportunities to achieve utility. ${ }^{179}$ But consider again the distributional implications of a pure livcs-saved test. Suppose treating one person's illness will save his life for now, but we can predict that in a year he will require more life-saving treatment to live another year, and the year after that further life-saving treatınent to live a third year. ${ }^{180}$ On a pure livessaved test, this would count as saving three lives. Treating this person three times would thus be preferred over using the same resources to give two persons each a single treatment that would extend each of their lives by two years. But this furthers neither the maximization nor the just distribution of utility.

Next, consider agam the deontological concerns. If we conceive of life's sacred nature as lying in the experience of life, then arguably a life-

176. The example is taken from Harris, supra note 23 , at 118 .

177. HARris, supra note 6, at 21-22; Harris, supra note 23, at 118, 122.

178. Harris himself would deny the life-years test even this supplementary role, preferring random selection. See sources cited supra note 174.

179. See sources cited supra notes 65-68.

180. For the argument that evaluating the costs of lifesaving requires accounting for the costs of treating all the future illnesses the saved person will likely incur, see CALLAHAN, supra note 3 , at 13234. 
year-maximization test does not disrespect the sanctity of life but rather focuses more on its true essence. A total-lives-saved test, one might say, diverts focus to the act of life-saving itself, giving the test an inevitably short-term orientation. In the long run, it is the life-years test that will tend to maximize the number of people who, in any given year, remain alive because of health care, and that is the true measure of whether the sanctity of life has been respected.

The principle of according each individual equal concern and respect as a separate being is not necessarily hostile to a life-years test. Instead of looking at the question at the time of treatment, suppose that we look to the time of the adoption of a primciple, or to the time when individuals might consent $e x$ ante to be governed by a principle. At those earhier tines, we might expect everyone to prefer a pure maximization-of-life-years test since it would give each individual a longer expected lifetime than would result from giving a priority to total lives saved. ${ }^{181}$ Risk aversion might cut the other way, and lead to a rejection of a pure maximization-of-life-years test, but I doubt it would justify absolute priority for the number of lives saved-especially given the distributive ambiguities noted above.

Finally, one disturbing implication of a test that gives absolute priority to the total lives saved is that it seems to imply that we should allocate medical equipment to those with worse prognoses. Suppose, for example, that we have a limited supply of dialysis equipment. A patient presents himself who is a good candidate to live a long time with dialysis. A pure total-lives-saved test requires denying dialysis to such a patient, and reserving it for future patients who can have their lives prolonged for only a short period by dialysis. Thus, by using the equipment exclusively on patients who have poor prognoses, we can save more human lives during the life of the equipment than we could by using it on patients who have excellent prognoses!

These considerations convince me that the number of life years saved should play far more than a supplementary role. But the matter seems sufficiently debatable, and the precise weight to give each of the two factors seems sufficiently open to judgment, that a wide range of reasonable moral views is possible. This supports my ultimate conclusion that the moral paradigm cannot dictate a uniformly binding moral principle of allocation. Rather, the best we can derive from the moral paradigm is a range of reasonable moral choices among which individuals should be permitted to choose. But before taking up the argument for allowing such a diversity of moral choice, we need to examine some other variables bearing on the question.

181. See, e.g., Dantels, AM I My Parents' Keeper?, supra note 46, at 96-97; Daniels, Just HeAith CARE, supra note 46, at 93. 


\section{Quality-Adjusted Life Years}

Health care does more than save and extend life. It also improves the quality of life by reducing pain and improving the operation of mind and body. Indeed, the bulk of medicine is directed at the latter purposes. What principles should guide us im allocating health care resources between lifesaving and life-enhancing inedicime?

One prominent answer is that resources should be allocated to maximize Quality-Adjusted Life Years, often called QALYs. ${ }^{182}$ QALY analysis assumes health care has two functions: mcreasing the years of life and improving the quality of that life. A year of healthy life is valued at 1.0; being dead is valued at zero. A year of unhealthy life is valued at something $\mathrm{m}$ between, depending upon the degree of impairment, which is where the "quality adjusted" part comes in. ${ }^{183}$ These QALY values do not depend upon who receives the treatınent: an extra year of life or improvement in health is accorded equal value no matter who gets it. Thus, under QALY analysis, a health care system should employ whatever resources it has to maximize the production of QALYs.

To illustrate, assume that a treatınent extending the life of a dying patient by six months with relatively high pain and disfunction has a QALY value of 0.3 , and that the resources necessary for that treatment could instead be expended on shoulder surgery for another patient with a QALY value of 0.4 . Then QALY analysis would indicate that the shoulder surgery must be funded first.

Note, however, that the procedures with the highest QALY values are not always funded first. The key is which procedures have the highest QALY value per unit cost. "A high priority health care activity is one where the cost-per-QALY is low, and a low priority activity is one where the cost-per-QALY is high." 184 If, for example, foot care with a per-case QALY of .01 could be provided to a hundred persons for the same cost as the shoulder surgery, then the foot care should be provided first, because it will deliver a total of 1.0 QALY for the same cost it would take to derive 0.4 QALY from shoulder surgery.

But where do these QALY values come from? Assessments of quality of life by physicians have been viewed with great suspicion, on grounds

182. See, e.g., Alan Williams, The Value of QALYs, Health \& Soc. Service J. (1985); Richard Zeckhauser \& Donald Shepard, Where Now for Saving Lives?, 40 LAw \& ContzmP. ProBs. 5 (1976) (employing use of QALYs to determine efficient health resource allocation). Others using the same concept, but with different terminology, include Robert M. Kaplan \& James W. Bush, Health-Related Quality of Life Measurement for Evaluation Research and Policy Analysis, 1 Health PsYchol. 61 (1982) and George W. Torrance, Measurement of Health State Utilities for Economic Appraisal: $A$ Review, 5 J. Health EcoN. 1 (1986).

183. If the quality of life preserved by medieal treatment would be extremely bad, it is possible for the QALY to be negative, meaning that the individual is better off dead.

184. Williams, supra note 182 , at 3 . 
that they are likely to be both inaccurate and biased. ${ }^{185}$ More favored sources are questionnaires directed at patients themselves. ${ }^{186}$ These questionnaires might, for example, ask individuals to assess the subjective value of various health states. Or they might ask patients with a given condition how inuch shorter a life with perfect liealth they would prefer over a longer life in their current condition. If the answer were $20 \%$ shorter, the QALY value of a year of life in their current condition would be 0.8 .

Again, the utilitarian argument for this is fairly obvious, and the fundamental objection is deontological: that there is no moral basis for sacrificing one person's health (and especially hife) to benefit the liealth of another. It may be true, these objectors argue, that individuals choosing for themselves would choose a shorter, liealthier life over a longer life full of pain and disability, but that does not mean that society is justified in making the same choice between different individuals. ${ }^{187}$ Again, the deontologists assert, all individuals value whatever is left of their lives equally, and society cannot morally justify denying soine persons the rest of their lives in order to provide a longer or healthier term of life to others.

The deontological argument against QALYs is, however, stronger in three respects than the similar argument against a pure life-years test. First, whereas we can plausibly argue that every individual would agree that more years of life are better than fewer years, individuals are likely to disagree both in the assessinent of their quality of life and about the particular tradeoff they would make between the length and quality of life. The miposition of some QALY value formed from the aggregated views of patients thus seems more likely to fail to accord sufficient respect to the value many individuals would put on their own lives. ${ }^{188}$ (Using nonaggregated QALYs is not feasible since eacli patient, once ill, would have cause to exaggerate to increase the odds they will obtain health care.)

Second, the argument that the sanctity of life is being infringed is stronger because here we are trading off life quality against the experience of life itself. The living of some lives is better than others, QALYs imply,

185. The concem about inaccuracy is in part based in theory: physicians have not experienced the health conditions and thus cannot accurately assess the quality of life with them. But this concern is also well-founded in empirical evidence. Studies show physicians differ widely in their assessments of the quality of life of the same patients. See Robert A. Peariman et al., Variability in Physician Bioethical Decision-Making, 97 ANnALs of INTERNAL MED. 420, 424-25 (1982). Physician assessments also differ widely from those of the patients themselves. See, e.g., Norman K. Brown, Clinical Conferences: Quality-of-Life Considerations in Geriatric Care, $31 \mathrm{~J}$. Am. Gerratrics Soc'y 113, 115 (1983); John Collette \& Peter Y. Windt, Medical Decision-Making, Dying, and Quality of Life Among the Elderly, in Shoutd Medical Care Be Rationed by Age? 99 (Timothy M. Smeeding et al. eds., 1987); William M. Sage et al., Is Intensive Care Worth It?-An Assessment of Input and Outcome for the Critically Ill, 14 Crmical CARE MEd. 777 (1986); T. Jolene Start et al., Quality of Life and Resuscitation Decisions in Elderly Patients, 1 J. GEN. INTERNAL MED. 373 (1986).

186. See MENZEL, supra note 5, at 81-86 (citing and summarizing sources).

187. See KILNER, supra note 55, at 149, 156; Harris, supra note 23, at 118.

188. See Kr.NER, supra note 55, at 154-55 (collecting sources). 
and should thus receive better treatment, which might be regarded as deny. ing an essential equahity among humans.

Finally, the possible distributional concerns are somewhat greater here. A QALY-inaximization test might result in health care resources being devoted to allow one person to hive a really healthy, long life, whereas several others are denied even a short period of life in poor health.

However, once one includes both life-extending and life-enhancing medicine into the analysis, what is the alternative method of resource allocation? Opponents of QALYs offer the usual dodges. They assert that any choice other than increasing the budget is immoral or insist that any choice should be made randomly. ${ }^{189}$ These assertions have all the problenis outlined above. A more tenable position is that any health care system should first devote all its resources to life saving, foregoing all health care that is neerely life-enhancing until all hife-saving needs have been niet. ${ }^{190}$ Under this test, absolute priority would first be given to total lives and life years saved, and quality of life would only play a supplenientary role in choosing among options that were neutral under both those ineasures.

Such an approach seems far less attractive once one considers its full inplications. Some services nay lower the chances of death, but by an extremely sinall percentage. For example, we might have weekly, instead of yearly, tests for cancer. Do these weekly tests have to be funded before hip replaceinents and cataract operations, which confer a clear benefit to life quality but not to life span? To the extent that, as argued in Part II, we could expend an infinite amount of resources on lowering the risk of death, a health care system dedicated to maximizing lives saved, or even life years saved, would wind up with no resources to spend on the bulk of health care which iniproves the quahty but not length of life.

Moreover, to the extent one doubts we really could spend an infinite set of resources on lowering the risk of death, consider this: most operations that enhance life quality theinselves involve some small percentage risk of death, usually froin anesthesia. If we follow the absolute-priority position to its logical extreine, it suggests that we should never devote resources to such operations. Indeed, resources should be devoted to stopping them from taking place!

It seenis clear that few wonld want to sign up for a system that accorded only a supplementary role to quality of life. Such a system thus would likely deny respect to the views almost everyone would hold ex ante to finding out how they in particular fared under the systen. But again the inatter hardly seems free from all doubt, and it would be surprising if there were not a broad range of well-founded views about how precisely to trade off quality of life against life years and total lives saved. Again, it seenis advisable to allow a diversity of inoral choice.

189. See HARRIS, supra note 6 , at 88.

190. See Harris, supra note 23, at 120. 


\section{Discrimination, Equitable Baselines, and the'Status Quo}

An objection often voiced against QALYs is that they discriminate against the old. Of course, there is no explicit discrimination: if a treatment would provide more QALYs to a 70-year-old than a seven-year-old, then QALY analysis would give the treatment to the 70-year-old. But because the young have more life years ahead of them, they are, as a class, likely to be favored by QALY analysis. Some object that this makes QALYs "ageist."191 Similarly, some argue that under QALYs the sick suffer "a sort of double jeopardy" because those who already have poor health are punished again by having that poor health quality used to deny them life-saving care. ${ }^{192}$

Such discrimination claims raise particular concerns under modern American statutes that outlaw discrimination against the elderly or the disabled. A discussion of the legal issues raised is beyond the scope of this Article. But it is worth discussing here, more directly than above, the general moral question raised by these allegations of discrimination: what would it mean to distribute health care resources in a nondiscriminatory or "equitable" fashion?

Clearly we do not mean that all persons should receive the same health care. As mentioned above, an equal distribution that resulted im everyone receiving an insufficient dose of medicine would hardly be desirable. Nor does it mean that all persons should receive the saine chance of receiving health care. Even those who otherwise favor random chance in allocating ainong health needs concede that, if a drug could be used either to save one person's life or alleviate another's mild discomfort, it is not equitable to give them an equal chance of getting the drug. ${ }^{193}$ Equity involves both horizontal equity, treating equal cases equally, and vertical equity, treating unequal cases unequally in proportion to the pertinent differences. Here, vertical equity demands giving the drug to the person whose life is at stake because he stands to benefit more from the drug.

But if horizontal and vertical equity are both the operative principles, then what is wrong with using QALYs to direct scarce medical resources to those who would benefit more from them? Why is the resulting direction of resources away from old persons who can benefit less from them any more discriminatory than the direction of a particular drug away from those who can benefit less from the drug?

Further reflection reveals that whether or not one sees "discrimination" depends upon one's baseline of what an equitable distribution of health care would look like. QALY opponents complaim that QALYs discriminate

191. Id. at 119; see also KIINER, supra note 55, at 148; Alwyn Smith, Qualms About QALYs, 1 LANCET 1134, 1135 (1987); Margaret A. Somerville, "Should the Grandparents Die?": Allocation of Medical Resources with an Aging Population, 14 LAW Med. \& Health CARE 158, 161 (1986).

192. Harris, supra note 23, at 119-20.

193. Id. at 121 , 
against the old because the young have more life years ahead of them. But one could just as readily conclude that a position of maximizing the number of lives saved without regard to life expectancy or quality discriminates against the young because the elderly are more likely to be near death. Which position is the discriminatory one depends upon the baseline from which one measures the discrimination.

Often, without reflection, the status quo is employed as the baseline without any critical examination of whether it reflects an equitable distribution. Because we currently employ so many resources on extending the last six months of life, and relatively few resources on prenatal and pediatric care, QALY analysis would divert resources from the old to the young, which is what makes the claim of ageism plausible. But suppose we already spent more resources on prenatal and pediatric care based on QALY considerations. Would we then be "discriminating" against the young if we changed to the system we have now (thus diverting some of these resources to life-saving care for the elderly) because we decided to maximize the number of hives saved rather than QALYs? Unless we grant the status quo a privileged moral status, the existence of "discrimination" cannot turn on whether a group is harmed by a change. It must turn on whether the change takes us further away from what we regard, on independent moral grounds, as an equitable distribution.

But deriving such an independent baseline is quite problematic, for equity has a liost of different possible meanings. QALY analysis, while couched in the language of efficiency, actually represents one possible position on equity: that a given increase im QALYs lias the same value no matter who receives it. The distribution of health care turns solely on individuals' capacity to benefit from the care in life-years and health quality.

However, there are a pletlora of other possible equitable positions. One miglit take the positions noted above: that equity rcquires distributing health care to maximize the number of lives saved without regard to life expectancy or quality on the grounds that everyone values the rest of his life equally, or to maximize life years because everyone values the experiencing of life equally. ${ }^{194}$ Alternatively, one might conclude that society should allocate health care resources in a manner that tends to equalize final health states. Those with the worst health or disabilities slould be treated before others even though their health cannot be improved as much. ${ }^{195}$ Or one miglit believe that allocations should tend to equahize the total years of life

194. See supra Sections III.B.1 \& III.B.2.

195. See Gauthier, supra note 15 , at 194-95 (concluding that Rawls' maximin rule implies this position); $c f$. DeNNIS C. MUELLER, PUBLIC CHOICE II 419 (1989) (arguing that Rawls' maximin principle could lead to enormous expenditures to achieve a modest improvement in welfare for those with severe disabilities). In fact, Rawls' difference principle requires maximizing the welfare of the worst off socioeconomic class, not the worst off individual. See RAwLs, supra note 70, at 97-100. 
each person enjoys, ${ }^{196}$ or bring everyone to some minimal age first. If the choice is whether to provide one year of life to a young person or to an old person, this view of equity would demand giving it to the young because the elderly have already received their "fair innings" or lived a "full life span."197

Note that each of these different positions on equity is associated with maximizing a different measure of health: QALYs, lives saved, life years, the health status of the worst off, or the number of hives reaching some minimum age. Efficiency-liere understood as maximizing health improvements out of a given set of resources ${ }^{198}$-is thus not in "tension" with equity as commonly thought. ${ }^{199}$ Rather, each different measure of efficiency or equity implies a given measure of its counterpart, and any choice of efficiency or equity goals is part and parcel of a single decision: what should our health priorities be?

Moral philosophy can help clarify choices bctween the various positions, but ultimately cannot resolve what our maximization goal, or position on equity, should be. I do not by this mean to rest on an epistemological point. Many philosophers are fond of pointing out that the fact that moral analysis leads different persons to different conclusions does not refute the proposition that one of those conclusions is right and the others wrong. My interest is, however, not that of a moral philosopher arguing for what I consider the right moral solution, but rather that of a health care system designer endeavoring to determine the appropriate role for the technique of moral analysis in making ongoing health care resource allocations. If that technique cannot generate consistent conclusions when used by different decisionmakers, then that is a serious limitation on its effectiveness as a decisionmaking process for allocating resources, even if some of those conclusions (which the technique cannot consistently identify) are riglit.

Recently, some efforts to conduct surveys have begun to find out what positions are held by the general public. So far these surveys suggest that many people believe that, where everyone would benefit by an equal

196. See RAKOWSKr, supra note 39 , at 318,321 (arguing that the younger of two persons should be favored).

197. See Callahan, supra note 3, at 152-53, 156 (defining full life span as late 70s/early 80s); Dantel. Callahan, Settrng Limits: Medical Goats in an Aging Soctety 66, 137-38, 172 (1987) (same); Robert M. Veatch, Justice and Valuing Lives, in LIFE SpAN 197, 218 (Robert M. Veatch ed., 1979); Alan Williams, Ethics and Efficiency in the Provision of Health Care, in PHILOSOPHy \& Medical Welfare 111, 117-18 (J.M. Bell \& Susan Mendus eds., 1988); see also Menzex, supra note 5, at 92-93; MenzeI, supra note 65, at 190-92; cf. Daniers, AM I MY PARENTS' KeEper?, supra note 46 , at $87-93$ (justifying allocation scheme limiting care once over the age of 70 or 75 but on nonfaimess grounds); Fried, supra note 37, at 32 (suggesting that in defining decent minimum of care, preference should be given to treating those illnesses that strike in the prime of life).

198. Alan Williams, Economics, Society and Health Care Ethics, in Prnnctples of Health CARE ETHICs 829, 832-33 (Raanan Gillon ed., 1994).

199. See id. at 829-41; see also CALLAHAN, supra note 3, at 187 (suggesting that one must balance goals of maximum equality and maximum health). 
number of QALYs, the young should have priority over the elderly. ${ }^{200}$ Perhaps most striking, this view is held by the elderly themselves. ${ }^{201}$ From this equity baseline, QALYs are indeed "ageist," but against the young not the old!

A few more points may be added on the discrimination issue. First, any health maximization measure we choose will be potentially vulnerable to the claim it discriminates agamst the old or the sick. Even a pure maximizing-lives-saved test, for example, can be claimed to discriminate against the old and the sick because, as a class, they either are likely to need more resources to save their lives or are likely to have a lower probability of being saved by medical treatment. ${ }^{202}$ Indeed, measured from an absolutist baseline of providing all beneficial health care, any system for allocating resources from a fixed set of resources will necessarily provide less care to, and in that sense disadvantage, the old and sick. Only the absolutist position is invulnerable to such discrimination claims, whicl is why discrimination charges create so mucl pressure to stick to the absolutist position, despite its plam untenability.

Second, once we reject such an absolutist baseline, it is far from clear that QALY analysis, or any measure of health maximization, on balance discriminates agaimst the sick. Those with poor health quality can benefit from QALY analysis if treatment would give them a greater increase in life quality than it would give those who started out with better health. The assertion that QALY analysis on balance disadvantages those who already suffer a low quality of life thus seems overly simple. It disadvantages those with less capacity to benefit from health care, but those who are sick have both inore and less such capacity.

Nonetheless, QALYs contain an important ambiguity that should be addressed because it might lend itself to a claim of discrimination. Suppose, for example, we may perform one operation to unblock an esophagus, and we must choose between two newborns who need the operation. One is normal; the other has Down's syndrome. ${ }^{203}$ Would QALY analysis dictate saving the normal one first on the grounds that the baby with Down's syndrome will have a lower quality of life? My interpretation is that the answer is, or at least should be, no. For a contrary answer would involve

200. Williams, Cost-Effectiveness Analysis: Is It Ethical?, supra note 140, at 10-11; P.A. Lewis \& M. Channy, Which of Two Individuals Do You Treat When Only Their Ages Are Different and You Can't Treat Both?, 15 J. MED. Entrcs 28 (1989); see also RAKowski, supra note 39, at 321-22 (defending this position on grounds that it tends to equalize bad brute luck).

201. Williams, Cost-Effectiveness Analysis: Is It Ethical?, supra note 140, at 11; Williams, Ethics and Efficiency in the Provision of Health Care, supra note 197, at 125.

202. See KINER, supra note 55 , at $137-40$ (rejecting the probability-of-bencfit test as discriminatory on such grounds).

203. The example is derived from the Bloomington Baby Doe casc. For an excellent analysis of this case and the argument that it is impermissible discrimination to deny normal lifesaving procedures to newborns born with handicaps, see Martha A. Field, Killing "the Handicapped"-Before and After Birth, 16 HARV. WOMEN's L.J. 79 (1993). 
discrimination along the lines of a personal characteristic no different from saving a child prone to be happy over another child prone to melancholy. ${ }^{204}$ QALYs do not admit personal characteristics-other than the capacity to have the condition subject to treatment inproved-into the analysis. All life years and health improvements are deemed of equal quality no matter who gets them. Because for both newborns the improvement is the saving of life, the QALY value is the same. The condition of Down's syndromenot being the target of the treatment-is excluded from the quality-adjusting analysis.

This means that the same condition might be excluded as a personal characteristic in some cases but included as a quality adjustment in others. For example, suppose we have two patients with leg problems which we can treat at the saine cost. The leg problems of one can be completely cured; the other will, even with treatment, limp for the rest of his life. The QALY value for the former treatment will thus be higher than that for the latter because the condition requiring treatment can more fully be cured in the former case. Now suppose instead we must choose between unblocking the esophagus of a person with a healthy leg and another person with a limp, and that, if unblocked, both would have the same expected lifespan. Here the QALY values should be the same for botls treatments even though the person with the limp suffers the same condition that results in a quality adjustment in the last example. Not being relevant to the condition under treatment, the limp is excluded as a personal cliaracteristic. ${ }^{205}$

What explains this apparent anomaly? In the former example, the risk of being demed care is equitably distributed $e x$ ante to the condition requiring treatment; we do not know which of us will end up with leg problems that are curable and which will not. In the latter example, on the other hand, the risk of being demed care is inequitably distributed $e x$ ante to the condition requiring treatment: those with linps will suffer a greater share of the risk of being denied the operation to unblock the esophagus. And experimental evidence consistently shows that people prefer risk distributions that are ex ante equitable..$^{206}$

204. For the argument that such personal characteristics should be excluded from consideration, see infra Section III.D.

205. Of course, sometimes one illness might also mean one has lower capacity to benefit from the treatment of other conditions. Someone on dialysis might, for example, have a worse prognosis from a heart transplant. There the state of being on dialysis is properly taken into account because it relates to the likely success of solving the heart problem whose treatment is being considered. If, on the other hand, the person on dialysis has the same prognosis as another from the heart transplant, the state of being on dialysis should not make the QALY value from her transplant any lower.

206. For an excellent analysis and collection of studies, see Donald T. Homstein, Reclaiming Environmental Law: A Normative Critique of Comparative Risk Analysis, 92 CoLum. L. REv. 562, 59596 (1992). 
Even more worrisome, in the latter example we must be concerned that those with limps will be discriminated against as a class. ${ }^{207}$ The value of their lives might thus be undervalued by others without this disability. There being no objective measure to tell us which lives are more worth living than others, the clioice thus depends on subjective judgments by potentially biased decisionmakers. In the first example, on the other hand, those with leg problems do not know in which class they will wind upthose remaiming with a limp or not. We can thus trust the survey answers given by those with leg problems about the tradeoffs they would make between various liealth outcomes because they have no incentive to exaggerate either way. Moreover, considering their relative capacity to benefit from treatment merely takes into account an objective scientific fact about the treatment: it helps some more than others with the problem under treatment. Being objective, this fact is less susceptible to manipulation by biased decisionmakers.

If instead a person's medical disability were taken into account in determining that person's right to treatment for all other illnesses, then the claim of a form of double jeopardy would have considerable force. For then, having suffered the first illness, the person's claim to all future inedical treatment of other illnesses would be discounted. There is no reason QALY analysis need be interpreted to include such a result, especially given the resulting inequity im risk distribution and concern about discriminatory abuse.

A third point to remember about the claims that care allocation standards are discriminatory is that we all grow older and all are vulnerable to falling ill. Thus, unlike discrimination based on race or sex, discrimination based on age and health status does not involve discrimination against persons in whose position we would never potentially be. As Nonnan Daniels put the poimt regarding age discrimination:

If we treat the young one way and the old another, then over time, each person is treated both ways. The advantages (or disadvantages) of consistent differential treatment by age will equalize over time. An institution that treats the young and the old differently will, over time, still treat people equally. ${ }^{208}$

This is slightly overstated. Some of us inay die young and never see old age. Nonetheless, we probably all do imagme ourselves reaching an old

207. In the United States, such concerns about prejudice against the disabled prompted the Americans with Disabilities Act. See 42 U.S.C. $\$ 12101$ (Supp. V 1993); Note, The Use of Quality-ofLife Measures to Ration Health Care: Reviving a Rejected Proposal, 93 Colum. L. Rzv. 1985, 19972004 (1993) (collecting legislative history); Note, The Oregon Health Care Proposal and the Americans with Disabilities Act, 106 HARv. L. REv. 1296, 1298-99 (1993) (summarizing statute and administrative action under it).

208. Dantels, AM I My Parents' KeEper?, supra note 46, at 41; see also id. at 63; DanIels, Just Health Care, supra note 46, at 96-97; Peter H. Schuck, The Graying of Civil Rights Law: The Age Discrimination Act of 1975, 89 Y ALE L.J. 27, 33, 64 (1979). 
age, unless when young we are (and know we are) likely to die prematurely. But in that case we would likely fall into the second category-the unhealthy with poor prognoses-that is supposedly discriminated against by health maximization standards. To the extent we care about our future, then, few of us would be motivated to discriminate against the old and sick simultaneously. ${ }^{209}$

A more serious question is whether or not we care about our future selves as much as we care about our present selves. As Derek Parfit has persuasively argued, unless we each have some mental substance separate from our brains and bodies that makes us a person, our only motive for concern about our future selves lies in our sense of psychological connectedness with the persons we will become. ${ }^{210}$ But because that sense of connectedness is inevitably far less than $100 \%$, to a significant extent any individual's future self is a different person than he is today. It may thus be just as rational for iny present self to care more about its well-being than about the well-being of my future self as it is to care more about myself than about other individuals. ${ }^{211}$

We shall return to Parfit's point in Section IV.A, when I discuss the legitimacy of binding persons to their past consent and the frequency with which to require consent. For now it perhaps suffices to make a couple of observations. To begin with, even if Parfit's point is true, we still have more motivation to care about our future selves than we do to care about those belonging to another sex or race we will never jom. Parfit's point thus does not so inuch eliminate the distinction between age discrimination and sex/race discrimination as it softens it. His point also puts the selfinterested motive to have regard for the elderly on solnewhat similar footing as the motive to have regard for the sick. In both cases, the regard is neither identical to that we have for our present selves, nor to that we have for perfect strangers, but is related to the probability and degree to which we see our present selves being in the other state in the future.

Next, Parfit offers the cleavage between our present and future selves not as grounds for denying the possibility of imtrapersonal utility comparisons, but rather as grounds for denying that the problem of intrapersonal

209. An exception might be persons who risk their lives in activities, like hang-gliding or violent crime, that have a significant likelihood of producing sudden, often untreatable injuries leading to premature death. But even these people must take into account the significant likelihood that they will survive to need serious medical treatment and rcaeh old age.

210. Derek Parfit, Reasons and Persons 202-17 (1984).

211. This goes far beyond the usual economic point about discounting the future, for that point rests on the observation that, given some normal rate of return, any amount of money invested today will produce greater wealth in the future. Such discounting would make perfect sense even from the perspective of someone who equally valued the utility of our present and future selves. Parfit's point, in contrast, is that an even greater discount will be used because to a large extent we regard money enjoyed by our future selves as similar to money enjoyed by another person. To put it another way, we not only discount the value of money in the future, but also discount the value of future utility itself. Id. at 32939. 
utility comparisons differs in kind from the problem of interpersonal utility comparisons. If this is so, then the deontological stress on a sharp moral boundary between separate persons is unfounded, ${ }^{212}$ and moral theory can more justifiably trade off one person's utilities against another's. Thus, Parfit's theory bolsters the argument for utilitarian theories of justice, which if anything provide stronger grounds for the group health maximization measures under consideration.

\section{Allocations Based on Personal Characteristics}

Utilitarian theories of justice might be thought to justify allocative measures that do not just maximize some ineasure of group health, but also take mto account personal characteristics of patients, such as their individual contribution to social utility or the likelihood they will be happy. These personal characteristics differ from the variables considered so far because they do not bear on the extent to which treatment can help the individual's illness. $^{213}$

I reject allocation systeins based on personal characteristics. ${ }^{214}$ In analyzing the argument against such care allocation, it is useful to begin by sorting the personal characteristics into three categories: (1) characteristics one cannot control; (2) improper conduct that bears no relation to health care costs; and (3) behavior that imcreases health risks. I conclude that characteristics in none of these categories offer good grounds for altering care allocation standards. However, the third category might, under certain cir-

212. Id. at 339 .

213. See supra text accompanying notes 200-05 (distinguishing between personal characteristics and capacity to benefit from treatment). The Clinton Plan generally would have avoided exclusions based on personal characteristics except for the exclusion of illegal aliens. See Proposed Health Security Act, supra note 54, $\S 1005$ (a). This exclusion seems quite unjustifiable. The purported purpose for it was curbing free riding by those who do not contribute to the health care system. But many illegal aliens work and pay their taxes, and many citizens do not, so this criterion correlates poorly with its purported justification. The Clinton Administration seemed to tacitly recognize the unjust nature of this legislative exclusion when it annoanced it would adopt what amounts to (yet another) "Don't ask, don't tell" enforcement policy: any employee for whom an employer made a contribution would have been assumed not to be an illegal alien and given a hcalth security card, and no inquiries would have been made to test the assumption. See Sam H. Verhovek, Health Proposal Could Leave Aliens in U.S. Without Care, N.Y. Trmes, Oct. 25, 1993, at A1.

214. However, this rejection of allocation systems based on personal characteristics is based not only on moral paradigm analysis but also on market paradigm analysis. Allocative schemes based on personal characteristics are likely to be particularly vulnerable to adverse selection problems given the high asymmetry of much of the relevant information and the difficulty of making risk adjustments. See supra note 83; infra Part IV.B. As long as some individuals follow their incentives to pick schemes that favor, or do not disfavor, their own personal characteristics, adverse selection will probably lead everyone to do the same. Moreover, allowing health care plans to allocate resources taking into account personal characteristics unrelated to treatment responsiveness would significantly increase the information costs consumers face in assessing different plans. Thus, even if an allocation scheme based on personal characteristics were morally justifiable, it does not seem feasible or advisable under any system that allows individual choice among care-allocating plans, and allowing such individual choice seems highly advisable on both market and moral grounds. See infra Section III.E and Part IV. 
cumstances, justify extra financial levies to offset the externalities imposed on others.

\section{Uncontrollable Characteristics}

Consider, first, personal characteristics beyond one's behavioral control. Suppose, for example, we had to choose between saving the life of Charlie Cheerful and Murray Melancholy, who each have the emotional dispositions suggested by their last names. On pure utility-maximization grounds, it might seem we should favor giving the care to Charlie Cheerful because he will gain more utility from life than Murray Melancholy.

Of course, a series of standard objections imight be made. One can argue, for example, that the societal goal should be an equitable distribution of utility, not a maximzzation of it. ${ }^{215}$ This would suggest that, smce Charlie Cheerful has enjoyed more utility in his life, Murray Melancholy should be favored in the health care allocation. But this would simply change the implication of the personal characteristics admitted into consideration, not exclude them from consideration entirely. Or one can say that all life has incommensurate value, so that any choice (other than a random one) is deontologically illegitimate. But that argument proves too much, for it would undermine all purposeful care allocation standards. ${ }^{216}$ And neither of these objections would persuade soineone philosophically committed to utility maximization.

A more persuasive rationale for rejecting care allocation based on personal characteristics, fully cognizable within the utilitarian framework, is that application of a general utilitarian standard would be unworkable and susceptible to discriminatory abuse. To begin with, consider the task of trying to apply a general utility-maximization (or utility-distribution) test on a case-by-case basis to guide health care resource allocations. The information-gathering process alone would be unfeasible because of the quantity of infornation required and because patients will not have imcentives to be as forthcoming as they do about health information. ${ }^{217}$ Moreover, the persons who will inevitably have intimate involvement in allocative decisionmaking-physicians-have no training or expertise in inaking such utility measurements. ${ }^{218}$ Nor is there any common metric by which such measurements could be traded off against health maximization goals. Other

215. See supra Section I1.B.

216. See supra Section III.B.

217. Note that even a pure health maximization measure might sometimes have the unfortunate side-effect of chilling doctor-patient communications if the patient fears the truth will cause the doctor to think the patient has a poor prognosis even with treatment. See KrnNER, supra note 55, at 139. But the chilling effect will likely be reduced because the patient will have difficulty determining whether communications will make his capacity to benefit from health care seem greater or lower, and because much medical information is obtainable from tests and direct observation.

218. Indecd, professional norms have historically condemned criteria based on the social value of the patient. See id. at $32 \mathrm{nn} .52-53$ (citing sources). 
than making arbitrary ad hoc judgments, how would we figure out what to do in the inevitable case where one person is more socially useful (assuming we know what that means) but the other would receive more QALYs from treatment?

More fundamentally, even if workable, the view that there should be just one conception of what constitutes the good life (seemingly necessary for such a utility function to work) is at odds with the pluralistic traditions of liberal deinocratic societies. The risk is high that whoever applies the utilitarian standard will impose her view of the good life on others. Moreover, even if she is acting in perfectly good faith, she may naturally devalue those who are different than she is.

These problems of discriminatory abuse and workability are real and costly even under a utilitarian framework. A nonutilitarian argument might instead simply stress the unfairness of punishing persons for characteristics beyond their control. For example, to the extent an individual's lower "social value" results from a lack of talent or intelligence, it merely compounds his undeserved misfortune to hcap upon him a denial of health care as well. Note also that for many of these characteristics there is no poimt in the person's life when he would have knowingly consented to such a tradeoff being made. Those born melancholic would not, for example, enroll in a plan that disfavored unhappy dispositions. Or, even if they developed melancholy later in life, they certainly would not have knowingly consented to such a tradeoff being made at the time they signed up with a care-allocating plan. On the other hand, those enrolling with a plan might well consent to a care allocation standard that tried to maximize aggregate health improvements (under soine ineasure) because at the time of enrollinent such standards can benefit all enrollees. ${ }^{219}$ For similar reasons, personal characteristics are more likely to result in an inequitable distribution of ex ante risks that people find morally objectionable in and of itself. 220

A narrower version of a utilitarian criterion favors those who have special responsibihities to third parties. For example, many people believe that those raising children (and, to a lesser extent, those looking after elderly relatives) should get medical priority over those without dependents. ${ }^{221}$ Such a test would be easier to apply than an open-ended social value test. But it too is problematic. How closely, for example, would physicians have to check into how well the patient was treating his dependents? What if recovery will not leave him as able to care for them as in the past? What if the would-be widow or widower seems likely to remarry? More generally,

219. See supra text accompanying note 181 . For a fuller analysis, and many cavcats, regarding relying on ex ante consent, see infra Section IV.A.

220. See supra text accompanying notes 204-05.

221. See, e.g., Avery Russell, Applied Ethics: A Strategy for Fostering Professional Responsibility. 28 CARNEGIE Q. 1, 5 (1980) (noting that subjects of case study gave care preference to subjects with most vulnerable dependents regardless of any other considerations); Williams, supra note 140, at 10-11; see also KILNER, supra note 55, at $64 \mathrm{nn} .1-6$ (collecting sources). 
once one considers the interests of third parties, it is hard to see where to stop. Should it matter that one person has more friends that will miss him? That the dying person's family or other dependents do not like him much? That another person has employees who depend on her? That the person is a great artist, revered religious leader, or popular politician? Again, such a system does not seem very workable, least of all when managed by physicians who must make quick medical judgments. And again it seems susceptible to discriminatory abuse. Those with traditional families, for example, might be biased by their disapproval of alternative hifestyles.

Another problem with such a standard is that, by disfavoring care to the childless, it punishes individuals for conduct that may be beyond their control (if, for example, they are infertile) or that, even if within their control is perfectly proper (declining to have children). Such persons are unlikely to knowingly consent to such a tradeoff at the time of enrollment, and many will find the inequitable distribution of ex ante risks itself morally objectionable.

\section{Improper Conduct}

What about improper conduct one can control? Suppose, as in a recent case I heard about, a hospital had one heart to allocate between two persons needing a heart transplant, one of whom had been convicted of child molestation. Can the hospital properly take that child molestation conviction into account in allocating the heart?

My answer would be no. The child molester is, no doubt, generally less deserving as a hunian being and has inflicted enormous harm on others. But he has presumably received the punishment society has already judged appropriate to inflict on child molesters. To add a demal of care would be to impose an additional-and here capital-punishment that is not prescribed in the child molestation statutes. Moreover, it would impose that additional punishment by happenstance on those child molesters who happened to need heart transplants. If additional punishment for child molestation is required, it should be mcluded within the criminal statute and applied evenly to all those who violate it.

\section{Self-Inflicted Ilness}

Another view often voiced is that those who cared for their health (by, for example, not drinking, smoking, overeating, or driving fast) should get priority to care affording a given health benefit over those who did not. ${ }^{222}$ Note that the issue here is not whether those who failed to lead healthy hives

222. See, e.g., KILNER, supra note 55, at 165-66 nn.24-26, 31-33 (collecting sources); RAKowsKr, supra note 39, at 75, 293 n.18. See generally RaAnan Gilon, Philosophical Medical. Ethrcs 86-99 (1986) (discussing various theories of justice for allocation of medical resources, including the principle that relevant inequalities should be considered and thus a patient's merits and demerits should be included in the allocation criteria). 
should be denied care because their prognosis is worse than others'. Rather the issue is whether-where their prognosis is identical ${ }^{223}$ - they should be denied care because they are less deserving. Where, for example, both a smoker and nonsmoker need a heart transplant and have the same prognosis, should the nonsmoker receive the only available heart?

Those favoring the nonsmoker note that he has suffered a misfortune that is truly undeserved, and thus worthy of social compensation, whereas the smoker has deliberately engaged in conduct he knew increased his risk of the ilhress lie is suffering. ${ }^{224}$ Altlough this argument is not without force, the arguments to the contrary seem more powerful.

To begin with, it is not at all clear that the sinoker imposes greater financial burdens on society througli his conduct. Nonsmokers live longer but this means they probably end up requiring treatment for a greater number of ilhiesses, and (at the end of their life) more expensive ones, than smokers. ${ }^{225}$ The supposition that smokers impose costs on the rest of us may thus reflect more prejudicial lostility toward smokers than raw facts-

223. Studies have shown, for example, that alcoholic patients receiving liver transplants lave survival rates better than those of many types of nonalcoholic patients and perhaps no lower than those of nonalcoholic patients generally. See KILNER, supra note 55, at 168 (collecting sources).

224. See id. at $165 \mathrm{nn} .24-25$ (citing sources); cf. RAKowsk, supra note 39, at 75, $293 \mathrm{n} .18$ (arguing that equal treatment may not be appropriate where blame can be assigned unequally, as in the case where a person knowingly aggravated a liver ailment through excessive consumption of alcohol while others suffer from the same ailment through no fault of their own).

225. See Robert E. Leu \& Thomas Schaub, Does Smoking Increase Medical Care Expenditure?, 17 Soc. ScT. \& MED. 1907, 1910-11 (1983) (finding that overall the expected lifetime medical expenditures for a 35-year-old male are almost scven percent lower if that person smokes); see also Comment, Blowing Smoke, supra note 30, at 7. See generally Menzel, supra note 5, at 58-59, $75 \mathrm{n} .4$ (citing literature debating this conclusion and suggesting that overall effects of smoking on total health carc costs are unclear). The reduction in financial costs from smoking is even greater if we take into account the additional pension payments that are avoided by smokers' early demise. Id. at 58-59.

Additional complications arise if one discounts future costs by a normal discount rate. One important study showed that smoking reduced extemal costs if one assumed no discount rate but increased external costs if one assumed a discount rate of five percent. See Willaro G. Mannino et. AL, The Costs of Poor Health Habits 14-15, 62, 79, 85, 127-28 (1991). Discounting has this effect because the medical and pension costs saved by smoking arise later, and thus are more discounted, than the costs inflicted by smoking. There are a number of reasons, howcver, to doubt this proves smoking imputes net negative externalities.

First, the conclusion of the Manning study is sensitive to the precise discount rate chosen. If one assumes a real (inflation-adjusted) rate of $3.5 \%$ or less, which is more in line with the historic ratc of return on relatively risk-free investments, see Joseph Bankman \& Thomas Griffith, Is the Debate Between an Income Tax and a Consumption Tax a Debate About Risk? Does It Matter?, 47 TAx L. REv. $377,387 \& \mathrm{nn} .28-29,390 \&$ n.39 (1992) (average riskless rate of return just $0.5 \%$ in the past 60 years), then smoking does reduce lifetime external costs even under the Manning study. See ManNino at AL., supra, at 79-80. Second, not all studies lave reached the same conclusion. One study found that smoking reduced external costs even if one took discounting into account. See Robert Leu and Thomas Scliaub, More on the Impact of Smoking on Medical Care Expenditures, 21 Soc. ScI. \& MED. 825 (1985). Third, while the Manning study correctly discounts future costs, it excludes the effects of medical inflation. See MANNINa ET AL., supra, at 82-83. If one assumes medical inflation will continue, as it generally has, at over fivc percent per year, then it would offset the discounting effect. 
the very sort of discriminatory bias that makes allocations based on personal characteristics suspect. ${ }^{226}$

Next, especially in light of the above, the fact that smokers suffer a greater likelihood of illness seems punishment enough for their behavior. What grounds do we have for adding an additional punishment by depriving them of care toward which they have contributed equally, if not more than equally? However heinous smoking might be, it certainly is less heinous than child molestation. ${ }^{227}$ Even if smoking - or some other category of activity - could be shown to inpose net societal costs, a more proportionate response would be to impose greater cigarette taxes rather than adopting an allocation scheine that imposes potential capital punishment. ${ }^{228}$

Finally, taking behavior that increases health risks into account in allocating health care raises serious administrative problems. Individuals who know their prior behavior will adversely affect their health care will have incentives to withhold information about that behavior from their physicians, thus undermining the accuracy of diagnosis and treatment generally. Moreover, even if we were prepared to give preferences to those who took better care of themselves, how would we trade off this factor agaimst others? Assuming that at some point a better prognosis would outweigh a history of smoking, the grounds for determining what that point should be seem far from clear.

Although unhealthy behavior should not affect health care allocations, perhaps it should affect financial contributions. Suppose, for example, an activity (say coal mining) does statistically result im greater lifetime medical expenses than other occupations and that the amount of these additional medical expenses exceeds any societal savings from lower pension or other payments. Under those circunistances it seems both appropriate and feasible to inpose a surcharge tax on the coal industry (or require it to pay inore to cover its workers) to offset this externality. Indeed, a failure to do so could appropriately be dubbed an unwarranted subsidy of the coal industry. But it would be inappropriate-instead of imposing such a tax-to give coal miners a lower preference in care allocation than others with the same prognoses.

226. The fear of discriminatory bias seems even greater in some cases than others. Consider, for example, the claim that practicing homosexuals should get a lower priority in AIDS treatment because they engaged in conduct that increased their risk.

227. Nor is it clear the extent to which smoking reflects inborn addictive tendencies rather than behavior fully within individual control.

228. In fact, even studies concluding that smoking imposes external costs have concluded that those costs are less than half the amount of the current cigarette tax. See MANNING ET AL., supra note 225, at 18-19. The argument for increased cigarette taxes is even weaker than this data might suggest because such taxes are meant to offset the cost to the public fisc of smoking, and whatever doubt there is about whether smoking imposes net external costs, it almost certainly saves the government money, for nonsmokers tend to subsidize the private health insurance costs of smokers while smokers subsidize the medical and social security costs of nonsmokers. See id. at 127. 
One interesting feature of the self-inflicted-illness criterion is how views about it differ between physicians and the general public. Although some in both groups believe a nonsmoker should be favored, this belief is far more popular among physicians. ${ }^{229}$ Indeed, some evidence suggests that physicians actually do allocate hearts and other organs in a way that favors those who had good health habits. ${ }^{230}$ I suspect that this difference in views arises because those dedicating their career to fighting disease find it a particular affront that anyone would deliberately risk it. In any event, this schism in views between physicians and nonphysicians highlights that simply delegating moral choices to professionals is unlikely to produce decisions in line with the moral beliefs of the community. Thus we arrive back at the point with which we began this Part: allocating scarce health care resources among a group cannot simply be left to medical judgment.

\section{E. Coping with Moral Diversity}

Even if we put aside allocations based on personal characteristics, we remam faced with the fact that moral analysis leaves us with a relatively broad range of reasonable views about the best measure of health maximization or equitable care distribution. How can any health care system hoping to employ the moral paradigm cope with this diversity of moral views? For Alan Williams, a leading proponent of QALYs, the answer is the same as that used by QALY analysis to cope with the diversity of opinions on the extent to which individuals would trade off life-expectancy for life-quality: survey the various views, and aggregate them into the view most representative of the general public. ${ }^{231}$

An imitial problem with this approach is that there are a multitude of methods for aggregating positions. In deriving QALY values, for example, one might use an "arithmetic mean" of responses, or (if one is concerned about "overweighing" extreme opmions) the "Inedian or modal values."232 As Alan Williams recognizes, the choice of measurement is critical, even on this seemingly technical issue, because it determines what weight different policy views receive. But he offers no explanation for choosing one measure over another.

229. See Williams, Cost-Effectiveness Analysis: Is It Ethical?, supra note 140, at 10-11; Williams, Ethics and Efficiency in the Provision of Health Care, supra note 197, at 119, 123-26. Physicians are also more likely than patients to favor allocation criteria based on the social value of the patients. See KINER, supra note 55, at 28-29.

230. See KIINER, supra note 55, at 163; John A. Robertson, Supply and Distribution of Hearts for Transplantation: Legal, Ethical, \& Policy Issues, 75 CIRCULATION 77, 81 (1987); see also Robert H. Blank, Rationing Medicine 199-200 (1988); William J. WINSLade \& Judith W. Ross, Choosing LIFE OR DEATH 196 (1986).

231. Williams, Cost Effectiveness Analysis: Is It Ethical?, supra note 140, at 10-11; Williams, Ethics and Efficiency in the Provision of Health Care, supra note 197, at 113.

232. Williams, supra note 140 , at 10 . 
Further, in determining whether to use QALYs at all, or instead soine other allocative formula for trading off different health care benefits, policy views can be aggregated in inultiple ways. One can use the plurality view, the view that survives a series of majority rule votes, the view that wins a Borda count vote (where voters get to reflect the intensity of their views by ordering the various options froin their first to last choice), or inany other aggregation inethods. ${ }^{233}$ Since different methods will lead to different conclusions about the community's collective nnoral view, we often cannot say there really is one collective noral view. ${ }^{234}$

The more critical problem with aggregating health-1naximization views is the assumption that different valuations should be coinbined to inake one collective moral judgment. If people disagree about how to allocate resources among different health care needs, and there are a diversity of reasonable inoral positions about the issue, what justifies imposing the aggregated view on everyone? Such an aggregation may be the best we can do if we insist on one uniform system. But if we instead assume a system where individuals could sign up with different care-allocating plans-each of which might have its own mechanism for inaking health care tradeoffsthen the systein could encompass a diversity of moral choice.

The desirability of accommodating such a diversity of moral views, particularly in pluralistic countries, should be plain. Not only do different individuals reach different personal conclusions, but different cultures and religions hold sharply divergent views. Consider, for example, the difficulties that Christian Scientists have had with inainstream medicime. No uniform moral judgment can accommodate all these differences. Ultimately, the problem with QALYs, and other inethods of allocating scarce health care resources according to set formulas of moral justice, is not the particular formula chosen, but the assumption that one formula of moral justice must be imposed on all persons. ${ }^{235}$

233. See generally MUELLER, supra note 195, at 112-47 (comparing aggregation methods).

234. Indeed, even if one uses a single method, such as pairwise majority votes, the aggregation process can lead to multiple conclusions, which produces an opportunity to determine the result by ordering the agenda. See Einer R. Elhauge, Does Interest Group Theory Justify More Intrusive Judicial Review?, 101 YaLE L.J. 31, 101-05 (1991).

235. More immediately, permitting a diversity of moral choice might prevent the derailment of health care reform in the United States by a highly contentious issue: abortion coverage. As the U.S. debate is currently framed, any national health care system must adopt one uniform schedule of insurance benefits for the entire country, and it either will or will not include abortion coverage. It seems quite clear that a majority of the Congress is unwilling to include abortion coverage because they do not want government funds used to pay for abortions. But there is another sizeable bloc that might vote against any plan that excludes abortion coverage. As long as the impasse persists, any effort to adopt national health insurance is likely to be doomed. Allowing individuals to sign up with the careallocating plan of their choice might help evade this impasse, however, beeause individuals who do not want their share of government funds being used for abortions could sign up with plans that do not provide them, and individuals who do want access to abortions could sign up with other plans. (This would not impose an extra "tax" on those choosing abortion coverage because in fact abortions save medical expenses by avoiding the costs of pregnancy.) Abortion opponents may still complain about 
Allowing individuals to sign up with the care-allocating plan of their choice has the additional advantage of empowering imdividuals with soine immediate ineans of responding to efforts to discriminate agamst their personal characteristics. Thus, if a plan discriminated agamst those with limps, or those without children, one would expect those persons to disenroll from such plans and enroll in ones more hospitable to their conditions.

And we have not yet even reached the most powerful reason for designing a health care system that permits a diversity of moral choice: the inoral significance of respecting mdividual autonomy. It is to that topic that we turn next.

\section{IV \\ Actual or Presumed Prior Consent}

A theory of moral justice that offers more potential for accomınodating a diversity of moral judgment focuses on the importance of individual autonoiny and consent. ${ }^{236}$ Denying soine persons health care in order to preserve societal resources or to attend to the health needs of other persons will always be morally problematic because it sends the message that society considers those resources or other persons inore important than it does the person denied care. ${ }^{237}$ Relying on the prior consent of those denied care, in contrast, draws moral force froin individual free will and sends the inessage that society considers each individual's choices important. Rather than showing a lack of respect for mdividual life, ratioming by prior consent dennonstrates respect for imdividual autonomy. This, consent-based theorists argue, inorally justifies a policy of denying excessively costly care whenever a person consented or would have consented to the policy. 238

However, prior-consent arguments inevitably raise four questions. First, at what time (and how often) should we require consent? Second, what are the legitimate conditions for that consent? Third, where actual consent at the proper time is not feasible, should we presume whether or not consent would have been given? Fourth, if we presume consent, how do we determine what an individual would have consented to? These are not mere technical questions, for the answers radically alter the policy conclusions drawn froin a prior-consent argument. And, as we will see, the answers depend on policy conclusions that inust be derived from outside the concepts of autonoiny and consent.

Consensual theories of justice thus seem imcapable of providing a complete answer to moral questions regarding what to allocate to and among

others' share of government funds being used on abortion, but at this point the claim that they are being associated with an activity they deem immoral seems attenuated.

236. See, e.g., MeNzEL, supra note 5, at 10-15; Gauthier, supra note 15, at 204; Gibbard, supra note 37 , at $171-74$.

237. See, e.g., MENZEL, supra note 5, at 10-11, 16-17.

238. See, e.g., id. at $10,14-15$. 
health care services. But if we can derive a basis for these consensual parameters independent of the consensual framework, then consent-based systeins can both help legitimate ${ }^{239}$ subjecting individuals to particular allocation inethods and allow a diversity of moral views on what those methods should be. By combining the lessons of the previous Parts with the lessons of this one, in short, perhaps we can establish a workable role for the moral paradigm in ongoing decisions of health care allocation.

\section{A. Timing and Frequency of Consent}

The question of when to require consent is important because whether an individual will consent to a given policy turns critically on timing. For example, Paul Menzel assumes that the time of consent should be not after the onset of illness but rather at the point when individuals subscribe to an insurance plan. ${ }^{240} \mathrm{He}$ argues that enforcing an individual's commitments made at the time of subscription respects her autonomy as a "whole person" to choose at an earlier point in time to control her later desires. ${ }^{241}$

But autonomy alone does not produce this result because the question here is whether an individual's past exercise of autonoiny should constrain her present autonomy. We have a choice between two exercises of autonomy, and we do not always give priority to whichever came first. ${ }^{242}$ For example, individuals cannot enter into enforceable contracts to sell themselves into slavery or even to have themselves physically bound to stay at a fat farm..$^{243}$ And the law generally denies enforcement to contracts a person niakes with himself. ${ }^{244}$ Circumstances may have changed im unforeseeable ways, or the person's preferences, values, or character traits may have changed, making his prior choice inappropriate. ${ }^{245}$ Indeed, to the extent Parfit's point is valid, 246 the choice between the two exercises of autononiy is even inore difficult on purely consensual grounds because the person exercising autonomy at the subscription stage is to a significant extent a different person froin the one being bound at the treatment stage.

239. See generally Kim L. Schepple \& Jeremy Waldron, Contractarian Methods in Political and Legal Evaluation, 3 YALE J.L. \& HUMAN. 195, 202 (1991) (arguing that hypothetical consent can confer legitimacy but not create obligations).

240. See Menzet, supra note 5, at 10-15.

241. Id. at 11 .

242. See generally Donald H. Regan, Paternalism, Freedom, Identity, and Commitment, in Paternalism 113, 127-34 (Rolf Sartorius ed., 1983) (arguing in favor of later exercise of autonomy); Richard Thaler, Precommitment and the Value of a Life, in THE VAIUE, OF LIFE AND SAFETY 171 (M.W. Jones-Lee ed., 1982) (discussing individual choice and cxamining the poticy implications of the timing of exercising that choice). Indeed, if anything, a pure concern for autonomy would look to present consent because the further back we go the more likely that we will have to rely on presumed consent rather than actual consent.

243. See Thomas C. Schelling, Choice And Consequence 96 (1984); see also Regan, supra note 242 , at $116-17$.

244. See Scheling, supra note 243 , at 99.

245. Daniels, AM I My Parents' Keeper?, supra notc 46, at 152-53.

246. See supra text accompanying notes 207-08. 
Thus, even if one were legitimately afraid that one's future self would spend a lifetime of savings on heroic medical treatment, a contract purporting to forbid one's future self from spending on some particular health care would, if one's future self were competent, be legally unenforceable. Nor is this himitation easy to evade by contracting with others, for one's future self always has the right to renegotiate. For example, even if I signed contracts with all health care providers barring them from selling my future self some particular health care, my future self would be free to renegotiate that contract with a provider if he (I?) wanted to buy that care. An ordinary insurance contract is not an exception to this principle, for it does not restrict the autonomy of my future self to buy care; it only limits the obligation of the insurer to pay for it. To be sure, one could certainly say that one's future exercise of autonoiny is affected by the obligations one's past self negotiated with others. But that merely gets us back to the normative question: when should we respect the exercise of past autonoiny over the present?

Menzel's justification for respecting the earlier exercise of autonoiny is that, once insured, the patient will have an incentive to overuse care. Thus, he concludes, the "decision is likely to be better" at the subscription stage than at the illness stage. ${ }^{247}$ Now this nornative judgment certainly strikes me as sound. But it is not a judgment derived from the principle of consent and autonomy. If one instead adhered to the absolutist position, one might conclude that the decision is likely to be "better" if consent is required right before treatment is denied. My point is not that the absolutist position is preferable to enforcing a consent given at the time of subscription. Rather my point is that the reasons for rejecting the absolutist position have less to do with a respect for autonomy than with the arguments outlined in Part I.

Coupling the consent framework with the need for some tradeoff established im Part I does not, however, suffice to settle the timing question. For one does not have to go so far as the absolutist position to dispute the assertion that consent at the subscription stage will produce "better" decisions. Individuals at the subscribing stage, one might argue, are likely to underestimate the risk of illness and discount the value of their health and life. This claim draws support from psychological, philosophical, and economic sources.

Kahneman and Tversky's famous psychological experiments, ${ }^{248}$ for example, demonstrate that individuals tend to systematically misweigh small-probability events, are unduly influenced by easily available informa-

247. MeNZEL, supra note 5, at 11,32 .

248. See Amos Tversky \& Daniel Kahneman, Judgment Under Uncertainty: Heuristics and Biases, in JUDGMENT UNDER UNCERTAINTY: HeURISTICS AND BIASES 3 (Daniel Kahneman et al. eds., 1982); Daniel Kahneman \& Amos Tversky, The Psychology of Preferences, 246 Sc1. AM. 160 (1982); Daniel Kahneman \& Amos Tversky, Prospect Theory: An Analysis of Decision Under Risk, 47 EconometricA 263 (1979). 
tion and their own past estimates, and falsely take small samples derived from present experience as representative of future probabilities. ${ }^{249}$ Philosopher Derek Parfit argues that we undervalue our future selves because they are to some extent different persons from our present selves. ${ }^{250}$ If so, then even if we do accurately evaluate the relevant information, we may consent to allocation methods that are not in our long-term best interests.

Even pure economic analysis casts doubt on whether individuals will adequately value their long-term interests. Suppose, to put aside the problems of the last paragraph, we assume perfect foresight and continuity of identity over time: i.e., individuals accurately gauge the risks and also care as much about their future selves as they do about their present selves. It would still be true that the amount of money a rational individual would pay up front to have her hife saved, on the $1 \%$ chance it is endangered by illness, will likely be far less than $1 \%$ of the amount that same mdividual would pay to have her life saved once ill. The reason is simple: the opportunity costs differ at the two moments. When the individual faces the $1 \%$ risk, the opportunity cost of spending money on lifesaving equals the cost of foregoimg all she could buy and enjoy in the $99 \%$ likelihood she does not fall ill. However, when the individual has contracted the illness, the opportunity cost of not buying the treatment equals (assuming she has no strong wish to leave her money to others) zero: if she does not buy the treatment, she will not live to buy and enjoy anything else anyway. ${ }^{251}$ As a result, the person once ill will be willing to pay far more in other goods for treatment than the same person facing the $1 \%$ risk would be willing to spend. Neither valuation of the opportunity costs is "correct": both reflect an accurate assessment at the time. ${ }^{252}$

These concerns about individual ability and incentive to judge the future accurately relate to the other major timing question: how frequently should the system require consent? Upon reflection, the assertion that consent should be at "the" subscription stage masks an important ambiguity. Is

249. See Kahneman \& Tversky, The Psychology of Preferences, supra note 248; see also Kenneth J. Arrow, Risk Perception in Psychology \& Economics, 20 Econ. INQUIRY 1, 5-6 (1982) (showing people have tendency to underestimate uncertainties and generally do not recognize the importance of sample size); Richard Nisbetr \& Lee Ross, Human INFEREnCE: Strategies AND SHORTCOMings OF SOCIAI JUDGMENT 55-59 (1980) (information is weighted in proportion to its vividness).

250. See supra notes 207-08 and accompanying text.

251. This is the economic explanation for Calabresi and Bobbitt's famous conundrum. See CalABresi \& BobBrtT, supra note 8, at 116-17.

252. On utilitarian grounds, we may want to favor the first valuation, because under these assumptions it is most likely to maximize the joint utility of the present and future selves, or more accurately the summation of daily utilities over the person's lifetime. But once again we are importing a normative concept outside the principles of autonomy and consent. If we instead favor an equal distribution of utility over our lifetimes, then the latter valuation may deserve more deference, because once ill the individual has far lower utility. Indeed, to the extent we conceptualize my future self as a different person, 1 may have a trusteeship duty to leave my future self as well off (taking resources and health into account) as I was, akin to the trusteeship duty some philosophical writers say a present generation owes to future generations. See ACKERMAN, supra note 68, at 203-04. 
there really to be only one subscription stage per lifetime (occurring perhaps when individuals reach the age of coinpetency), or rather many subscription stages over the course of a lifetime?

Several arguments can be inarshalled on behalf of more frequent subscription choices. To begin with, the smaller the gap between the subscription choice and the treatment decision, the less the concern about our cognitive ability and present incentives to decide what we will want in the future. A clioice made at the age of majority is likely to bias choices toward allocation schemes that favor young adults over the elderly. ${ }^{253}$ Moreover, frequent subscription decisions will likely be necessary for a coinpetitive insurance inarket to flourish.

On the other liand, allowing frequent changes in allocation schemes does have significant disadvantages. The more frequent the allowed changes are, the 1nore likely they will occur after the onset of any illnesses we inay contract. This eliminates any advantage that choice at the subscription stage has over choice at the illness stage. Moreover, while the young 1nay not have sufficient knowledge and incentives to take into account the interests of the elderly, they have even less incentive when their choice only lasts a year. ${ }^{254}$ And what incentives have the elderly, choosing among the allocation scliemes that will govern the liealth care they receive, to take into account the interests of the young?

The importance of these problems, and of lingering concerns about our cognitive ability to picture ourselves in need of health care, turn in signifcant part on the conditions under which any consent is obtained. Questions of consent timing cannot be separated froin questions of consent conditions. But I hope I have said enough so far to show that questions regarding the timing and frequency with which to obtain consent require answers that cannot be derived froin the autonoiny framework itself.

\section{B. Conditions of Consent}

The content of consent turns not only on its timing, but on the conditions under which that consent was obtained. Some, for example, assume that individuals who are unwilling to consent at the subscription stage to greater health risks will have to pay nore. ${ }^{255}$ This presumes it is appropriate to rely on a consent determined in part by ability and willingness to pay. ${ }^{256}$ But to inany, any consent to the demial of care by those with less wealth would be "coerced" and thus illegitimate and nonbinding. The absolutist might insist that individuals have a right to any beneficial health care,

253. See Daniels, AM I My PARENTs' KeEper?, supra note 46, at 55-56.

254. Yearly changes in insurers would have been allowed under the Clinton Plan, Proposed Health Security Act, supra note 54, $\S 1323(\mathrm{~d})(\mathrm{I})$, and are allowed by most employer-provided insurance schemes in the United States.

255. See, e.g., MENZEL, supra note 5, at 29, 45-46.

256. Menzel is willing to defend this point. See id. at 116-28 (arguing against targeting redistributions toward health care); see also MENZEL, supra notc 65, at 66-70 (same). 
and should not have to pay to retain it. Others might conclude that consent is only valid when obtained under conditions where everyone had equal resources. 257

The decision about which conditions to require for consent requires an independent normative justification. If the argument in Part II is accepted, then everyone has a right not to any beneficial health care, nor to only that health care their wealth can provide, nor even to fully equal resources which might allow thein to trade off their desire for health care against other desires. Instead, everyone has a right to an adequate level of health care, defined roughly as that level of health care enjoyed by the middle class, regardless of their inabihty to pay for it or even their willingness to trade the right for inoney. ${ }^{258}$ The consent required, then, is only consent to one of the different care allocation plans that can be offered with a roughly middle-class funding level.

Although this conclusion cannot be derived from the consent framework itself, this definition of the conditions for consent does help alleviate some of the concerns about the problematic nature of individuals' cognitive ability and personal incentives to judge their future interests. A persistent underestimation and underweighing of the risks and harms of becoming ill, and a relative lack of concern for our future selves, might lead us each to underspend at the subscription stage, thus shortchanging our future interests. If, however, our choice is simply among different allocation methods, with similar levels of aggregate spending, such underspending will not be possible. We may not care as inuch about our future selves as about our present selves, but we will have no bias among the different states of ilhress in which we might find ourselves at a given future time. ${ }^{259}$ Further, while our cognitive biases might lead us to prefer allocation scheines that undertreat low-risk illnesses, such biases would be minimized if, as Section III.E suggests, the choice is among different measures of health maximization. Our ability to perceive and judge accurately the level of risk does not matter so inuch if the assessinent of health benefits per resource spent is professionally determined, with the individual consent going only to the question of what measure of health maximization the professionals should employ.

A more problematic question is the degree to which one's health status can be a relevant condition of consent. There is a strong tradition of saying health status should be irrelevant. Indeed, even some who otherwise favor making ability and willingness to pay relevant consent criteria assume that consent would be illegitimate if produced because society charged higher

257. See Ronald Dworkin, Will Clinton's Plan Be Fair?, N.Y. Rev. Books, Jan. 13, 1994, at 20, $22-23$.

258. See supra notes $122-27$ and accompanying text.

259. If our consent lasts a long time, we may of course be biased toward treating those illnesses we are likely to suffer in the near future over those in the more distant future. This counsels toward requiring frequent consent. See supra text accompanying note 250. 
(and perhaps unaffordable) premiums to persons with known illnesses. ${ }^{260}$ The conclusion that those with worse health should not have their access to health care determined by their ability or willingness to pay extra is, of course, a necessary implication of the analysis in Part II. But it is not a conclusion that flows from the concept of autonomy itself. Nor is it at all clear why those willing to countenance consent influenced by differences in wealth are unwilling to countenance consent influenced by differences in the cost of treating known illness. Why shouldn't those with poor health pay inore if others must suffer the costs of being less talented or having less earning potential?

Part II rejects both conclusions on grounds unrelated to consensual theory. But to say that one's health status should not result in one having to pay inore for access to health care is not to say that it can or should be rendered irrelevant to consent to a particular health care schemc. Any health care scheme that refrains from adopting the absolutist position will necessarily have to allocate its scarce rcsources ainong health care needs in a way that leaves soine needs unmet. If it is a proper condition of consent that individuals must choose froin among the available schemes for allocating fixed health care resources, then soine health statuses will inevitably affect consent because treatment of thein will not be advisable under any feasible health maximization measure.

A contrary conclusion about the proper conditions for consent is drawn by Paul Menzel, who concludes that a person "who coines to the issue of whether or not to consent to rationing policy already knowing his or her illness need not be exposed to the same limitations on costworthy care that the rest of us willingly accept."261 Under this view, those with known poor health at the subscription stage cannot be subjected to any budgetary limitation. They are entitled to society-funded care for that illness even though the same care is demed to others struck by the same illness after the subscription stage. Those who at the subscription stage know they have a failing heart are thus entitled to a heart transplant even though those who developed a failing heart after subscribing would be denied transplant with the same prognoses.

But Menzel offers no explanation why the former persons should be allowed to withhold consent under conditions that ignore scarcity, while the latter are bound by consent given under conditions that require thein to confront scarcity. ${ }^{262}$ His conclusion regarding those with known health

260. See MENZEL, supra note 5, at 139-40 (advocating a government subsidy to compensate highrisk individuals for their greater premiums); cf. RAKowsk, supra note 39, at 90-92 (suggesting various schemes to compensate for variation in health status within insurance system where every individual had equal resources).

261. MeNzer, supra note 5, at 16.

262. In a market-based system, which Menzel advocates, there may be no way of requiring actual consent for those with known health problems that both confronts those persons with scarcity and does not charge them higher premiums than those without known health conditions. For if the same 
problems seems to presuppose that they start with a right, which they must consent to waive, to unbounded societal funding of any health care services that might help them. But if those without known health problems got to start with that same right, they would not have consented to any rationing either. Why assume that some begin with this right and not others?

Imposmg different consent conditions for different individuals does not follow froin concepts of autonomy. Nor does any other conception of justice seem served by denying one person the care given another suffering the same illness solely because the illness struck after, instead of before, the subscription stage. People with known illnesses should perhaps be treated no worse than those who develop those illnesses later, but it is hard to see why they should be treated better. The consent required need merely be consent to a particular version of the many possible regimes for rationing health care under scarcity.

Although those with known illnesses should not be able to elect health care under conditions that ignore scarcity, those conditions cannot ignore the fact that those in worse health, or with greater likelihood of becoming ill, need inore care. Otherwise any consent-based system will unravel in adverse selection or a related self-selection phenomenon. Adverse selection can cause a market-based system to result in insurance offered only at rates so high that only the least healthy individuals would find the insurance worth the price. ${ }^{263}$ Here the result is somewhat different. Those who are young or otherwise have lower health risks are likely to enroll in care-allocating plans that allocate resources toward routine health care needs away from the sort of expensive medical treatment required by those in poor health or near death. The old or unhealthy are likely to self-select into plans with the opposite allocation priorities. The result is that, if the amount of funding that follows enrollment decisions is equal for everyone, then those who are old or unhealthy will find that the care-allocating plans it makes sense for them to join will have just as much money per enrollee as the others, but far less money relative to their health needs. The more frequent the subscription decisions, the greater the problein. This problem cannot be solved without devismg some method to counterbalance this self-selection phenomena.

Forbidding plans froin barring enrollment based on age or health status will not eliminate this problem, because the old and sick will find themselves naturally drawn away from allocation inethods that are not congemal

premiums must be charged to all (or if any premium difference is government subsidized), then those with known health problems will always choose the "high" (in terms of coverage and premiums) option because the costs of the extra care they know they will receive will come almost entirely out of insurance funds (or the government subsidy). True, one might instead presume that, if they did not know about their illnesses, these persons would have chosen the regular option, and thus bind them to all the limitations on care imposed on those who consented to the regular option without knowing the health problems they would have. But this is to rely on presumed rather than actual consent.

263. See supra note 83 . 
to their needs. It would thus seem necessary, under any scheme guaranteeing everyone equal access to adequate care, to risk adjust the societal payments received by care-allocating plans.

In any event, one of the conditions of consent that would have to be set is whether, and how, to risk adjust the premiums received by insurers. But setting this condition raises serious problems for a consent-based theory. For, assuming some limit on health care spending, any choice of riskadjustment formula (or choice not to adopt one) necessarily involves some central nonconsensual decision about how those limited resources should be allocated among health care needs. Someone will, for example, have to decide the extent to which the risk adjustment for enrolling elderly persons will include the cost of heroic efforts to resuscitate them at the end of their lives. Only if the system were committed to the absolutist approach would this risk-adjustment question be a mere technical one of judging the costs of treating the relevant health conditions. ${ }^{264}$ Any other system will have to make normative choices about which conditions should be treated and to what extent. ${ }^{265}$

The setting of the risk-adjustment condition will thus, to some significant extent, constrain the moral diversity in allocation methods that otherwise seeins desirable. Individuals will not be able to exercise an autonoiny to choose whatever allocation method comports with their moral views, for some may not be feasible given the risk-adjustment formula. ${ }^{266}$ But a broad range of feasible allocation methods will probably exist under any riskadjustment formula, and this should provide enough diversity of moral views to legitimate binding the individual to his choice among them.

Finally, inost would agree that a necessary condition for consent to be meaningful is that it be informed. This suggests an inportant governmental role in seeing that the relevant information is collected and disseminatcd to those consenting to particular health care rationing plans. It also bolsters

264. The Clinton Plan would have delegated risk-adjustment decisions to a politically appointed National Health Board, with the advice of a Risk Adjustment Advisory Committee consisting of representatives from affected interests, including health plans, providers, and consumers. See Proposed Health Security Act, supra note 54, $\S 1501,1541,1543$. Interestingly, the Clinton Plan would have provided that Board members should have expertise in one of many fields, including medicine, health financing, or law, but did not include medical ethics or moral philosophy among those fields. See id. $\S 1502$. This helps confirm the impression that the Plan's commitment to providing all "medically necessary and appropriate" care embodied a refusal to deny any beneficial care. See supra note 54. How the government could have maintained such a commitment once the Act's global budget limitations kicked in was an issue left unresolved by the Act.

265. One could of course adopt a budget limitation but say that the allocation of that budget will be proportional to the allocation that would be made under an absolutist system. But that too would represent a normative choice, and a rather bad one since it would freeze into place the current misallocation of resources toward health care with low marginal benefit.

266. Of course, even without the self-selection and risk-adjustment phenomenon, individuals would be unable to sign up for an allocation scheme that did not attract cnough other subscribers to make the plan feasible. But that would be a condition imposed by the voluntary choices of those around them and not by a central authority. 
the argument, made above, that consent should be required with some frequency. The currently popular frequency of once a year is probably too short-it invites subscribers to discount the risk of untreated serious illnesses because they will often have timc to switch plans if such an illness develops. But more than say, a five year stretch, and individuals' ability and incentive to inake the future tradeoffs grow weak. ${ }^{267}$ And even if able and properly motivated, the further away are the matters to which one is consenting, the less likely one's present judgment can be truly informed about them. I would suggest three years as an appropriate period. However, no matter what the period, fully informed consent may often, as discussed in the next section, be unfeasible.

\section{When to Presume Consent}

Often we cannot reahstically obtain actual consent to specific allocation decisions. Individuals cannot possibly consider all the health problems they might have, and even if they could consider them it would be unreasonably expensive to obtain their consent. Menzel thus concludes that presumed consent should be used whenever obtaining actual consent is either "impossible" or "prohibitively costly," defining prolnibitive costs as "what the actual individual, with his or her actual values, would agree is too high a cost for upgrading from presumed to actual conscnt."268 This test has a certain circularity, since one must presume what individuals would have agreed was too high a cost. And Menzel seems surprisingly quick to presume consent on scanty evidence. ${ }^{269}$ But even if one avoids these pitfalls, the point remains true that the high costs of obtaining actual consent will often force those looking for prior consent to use presumed consent instead.

To others using the prior-consent framework, the need for relying on presumed (or hypothetical) consent is even more fundamental. Those who beheve that consent is legitimate only under conditions where everyone enjoys equal resources must, for example, rely on hypothetical consent since currently conditions of equal wealth or health care resources do not exist. Even greater reliance on presumed consent is required for those who beheve that consent is valid only if the consenting parties are behind a veil of ignorance, where none knows the state of health or wealth they will have in their lives. Arguments based on what imdividuals would choose in such mythical ex ante states are a common staple of medical moral philoso-

267. See generally Section IV.A.

268. MENZEL, supra note 5, at 31, 33.

269. He presumes, for example, that British individuals have consented to the British National Health Service's denial of kidney dialysis for certain older patients because the patient "probably supported" the government policy as a voter. Id. at 14; see also id. at $45-46$ (presuming consent to "somewhat greater health risks" if as voter, taxpayer, or subscriber, individual chooses a "leaner plan"); id. at 89 (presuming consent to QALYs, even though the actual patient has not agreed to them, if the survey used to obtain the QALY results was well done). 
phy. ${ }^{270}$ More generally, any consent-based theory must rely on presumed consent to the timing and conditions under which actual consent is obtamed.

Although at least partially necessary within the prior-consent framework, the introduction of presumed consent is problematic in two senses. First, it expands the range of possible timings for consent, with a corresponding effect on possible policy outcomes. Menzel, for example, argues that society cannot restrict beneficial care to a baby born with a congenital illness, no matter how expensive the treatment and poor the prognosis, because there is no point in the baby's life when she would have consented to the restriction of care. ${ }^{271}$ If an adult demands care with the same cost and prognosis, however, we can presume consent (where actual consent was not feasible) and deny care. ${ }^{272}$ By restricting society's unlimited health care spending obligation to newborns, Menzel also implies that children who develop illnesses after birth but before the age of competency are also presumed to consent, perhaps via their parents, to denials of excessively costly care. In effect, Menzel assumes that one cannot go before birth to presume consent. 273

But if the consent is hypothetical, why shouldn't we go back before birth and even conception, at least in the sense of excluding knowledge of health problems acquired after that poimt? John Rawls, and others who go behind some variation of a veil of ignorance where none of us knows what health condition we might be born with, effectively do. ${ }^{274}$ One need merely conclude that behind this veil (or suspension of health knowledge) we would agree to forgo care in the event we are born with certain difficult-totreat conditions because the expected benefits of that care are exceeded by the expected costs in resources that could instead service our needs in the far more likely event we are born without those conditions.

The reasons for going back before birth would be the same reasons Menzel cited for going back from the onset of ilhiess to the subscription stage: after birth, persons born with illnesses will (at least under Menzel's scheme) have an imcentive to overuse resources. Pre-birth consent is, to be

270. See, e.g., Dworkin, supra note 257, at 22-24; Gauthier, supra note 15, at 204; Gibbard, supra note 37 , at 171-74.

271. Menzet, supra note 5, at $16,99-100$.

272. See id. at 99 .

273. On related but different grounds, Eric Rakowski draws a similar line at the age of majority instead of birth. He concludes that humans are entitled to full societal compensation (unless the costs are "excessive" in proportion to the benefits) for any illness while minors but not once they reach adulthood because then they have had the opportunity to buy insuranee. Rakowski, supra note 39, at 98-100, 323-24.

274. See, e.g., Gibbard, supra note 37, at 165-69, 171, 175; cf. Dworkin, What is Equality? Part 2, supra note 68, at 297-99 (declining to use Rawls' veil of ignorance but in effect using hypothetical prebirth consent to derive extent of coverage for those born with handicaps who had no chanee to exercise actual consent). 
sure, a thoroughly artificial construct. ${ }^{275}$ But that is also the case when we presume consent for adults and children. In either case, actual consent is not feasible and, if we are to use the concept of consent, it must be presumed. ${ }^{276}$ Why should it be considered fair or just to presume consent to restrictions on health care because poor health struck at age three instead of in the womb? ${ }^{277}$

The second problem with presumed consent is that it lacks the moral force of actual consent. Our conclusions about what care to deny actual patients will turn not on the past exercise of their autonomy, but on our presumptions about what we think they would have consented to had they been asked. And any presumption that an individual would have consented to the denial of treatment will almost surely conflict with the imdividual's present views (now that she is ill) about what she would have consented to in the past. It is hard to see how this shows respect for individual autonomy and will. Unless we can confidently determine when and to what individuals would have given consent, the fact that obtaining actual consent is too costly (or for other reasons inappropriate) indicates not that we should use presumed consent but that the prior-consent framework is, by itself, inadequate.

The system should thus do all it can to make actual consent more feasible and meaningful. One way would be to structure consent decisions as a choice among various possible ineasures of health maximization, along the lines suggested in Part III. Although hardly uncomplicated, this miglit make the alternatives sufficiently clear, and the costs of understanding them sufficiently low, that actual consent would be ineaningful and practicable. At a minimum, even if not a model of easy understandability, structuring

275. We can, of course, make it somewhat less artificial by suppressing only knowledge of the health conditions obtained at birth, admitting knowledge about the other personality features that arguably give the individual that personal identity that makes their autonomy worth respecting. See Dworkin, What is Equality? Part 2, supra note 68, at 344-45 (criticizing Rawls for suppressing too much such information); Rakowski, supra note 39, at 231-32 (same). But I doubt any of these other personality features would be likely to alter the consent presumed, at least not in any way an administrable system could take into account.

276. If we are looking for actual consent, we might look to the same sort of proxy consent we normally use for children: decisionmaking by a parent in the best interests of the child. Parents effectively exercise this authority, and consent, by deciding whether or not to insure before the baby's birth against the costs of treating any illnesses with which the baby might be born. The point is not that the unborn child should be bound by a parent's decision not to insure them (indeed parents would have no right to waive the child's right to adequate care under Section IV.B), but that notions of consent seem to provide no convincing grounds for distinguishing between the case of the child who became ill before birth and the one who gets the same illness after birth.

277. Rakowski's position that, until they are adults, humans need not be confronted with social scarcity, but are rather entitled (with a minor exception) to full compensation for any illness, see supra note 273 , suffers a similar flaw. Why should the seventeen-ycar-old have a greater right to health care than the nineteen-year-old has (or could afford) for the very same illness? The solution of Dworkin and Fried, giving children the same level of insurance coverage adults normally buy for themselves or their children, seems a more sensible source for presuming consent under parallel conditions. See CHARLES FRIED, RIGHT AND WRONG 127 (1978); Dworkin, What is Equality? Part 2, supra note 68, at 297-99. 
the choice in this manner seems more likely to be understandable at an acceptable cost than a choice among different schedules of coverage and services. The latter, after all, requires a complicated understanding not only of what those services are but also of the chances each will be needed and what the associated health improvements would likely be. It is hard enough to get meaningfully informed consent to particular treatments for known problems after the onset of illness. ${ }^{278}$ Trying to obtain informed consent to the denial or coverage of all the possible medical procedures for all possible problems at the time of subscription exacerbates the problem exponentially.

\section{What Consent to Presume}

When we are forced to make presumptions about when individuals would have given consent, what should we assume regarding their decisionmaking process? As it turns out, the arguments about this issue replicate many of the same arguments made outside the prior-consent frainework.

This is particularly true for those who feel such consent must be established behind some form of veil of ignorance where individuals are not aware what their wealth and health condition will be. To soine, we should presume that individuals behind the veil would establish a right to a decent minimum of health care because of its special importance. ${ }^{279}$ Others assume that they would choose QALYs modified by equity considerations as the method of distributing health care resources. ${ }^{280}$ Rawls argued that individuals would choose those principles that maximize the minimum share of primary social goods enjoyed by the worst-off class. ${ }^{281}$ Some have used similar maximin logic to conclude that health care resources should be spent to maximize the health of the least healthy first. ${ }^{282}$ Menzel presumes that individuals would reject pure efficiency or utilitariamism. ${ }^{283}$ In contrast, utilitarian philosophers have argued that behind a veil of ignorance individuals would want to maximize their expected welfare and would thus choose to adopt utilitarian primciples. ${ }^{284}$

The range of plausibly presumable consents is somewhat more limited if the question is whether to presume consent by real persons, with identifiable interests and preferences, who did not think about the issue at some point in the past. We can, for example, presume that they would not have

278. See generally Peter H. Schuck, Rethinking Informed Consent, 103 YALB L.J. $899-959$ (1994).

279. See generally DANIELS, AM I My PARENTS' KeEPER?, supra note 46, at 68-73; Gibbard, supra note 37, at 171-74; Ronald M. Green, Health Care and Justice in Contract Theory Perspective, in Ethics and Health Policy, supra note 75, at 111.

280. See Williams, supra note 198.

281. Rawls, supra note 70 , at $75-83,150-61$.

282. See supra note 195.

283. MENZEL, supra note 5, at 15-16.

284. See, e.g., Richard B. Brandt, A ThEORY of the Good and the Rught 213-23 (1979); R.M. Hare, Rawls' Theory of Justice, in REAdino Rawts 93-97 (Norman Daniels ed., 1974); John C. Harsanyi, Morality and the Theory of Rational Behaviour, in UtILITARIANISM AND BEYOND 39, 45-48 (Amartya Sen \& Bernard Williams eds., 1982). 
agreed to consent to some rationing scheme that deliberately discriminates against their personal characteristics. But the range remains wide because the disagreement about what to presume behind the veil of ignorance reflects a deep disagreement about what rational individuals would try to maximize in making tradeoffs among different health states. And that basic disagreement about the nature of rational decisioninaking continues even once the personal characteristics and interests of the individuals are taken mto account. Moreover, the mere fact that we are presuming consent means we are going beyond — or even against - the currently available evidence of what the individual's preferences actually are. ${ }^{285}$

Given the above, it is not surprising that the conclusions derivable from presumed consent are often quite vague. Gibbard, for example, concludes that under the ex ante pareto principle "the best known treatment for a serious ailment might not be worth the cost," but he is unable to say how we determine when this is true or even whether it is true for any ailment today. ${ }^{286}$ Menzel ultimately argues only that we can presume "[i]ndividuals' prior consent to less than maximum health security for their futures."287 But how much less than this inaximum should we presume individuals have, or "would have," consented to? Rakowski presumes virtually everyone would consent to a plan denying treatment to someone who had "a paltry chance of recovery or was likely, if he survived, to lead a very restricted, painful, or otherwise miserable existence."288 But how paltry and how miserable do the chances and existence have to be? And to what allocation policy should we presume people have consented once those cases are excluded? ${ }^{289}$

The nebulous nature of, and limited guidance provided by, the consent one can reahstically presume is particularly problematic for those who, like Menzel, propose to use presumed consent to persuade physicians operating within the current system to reinterpret their ethical commitment to individual patients. ${ }^{290}$ A charge to deny care when the costs are so high that a reasonable patient "would have" consented to bemg denied care is far too vague to alter seriously physicians' ethical commitınent to do anything that

285. Arguably, doing so necessarily requires us to abstract significantly from what makes them a separate human being, whose separate consent we need, rather than part of a larger social being that can trade off gains and harms to different persons. The methodology of presumed consent may thus undermine the justification for requiring consent at all.

286. Gibbard, supra note 37, at 169.

287. MENZEL, supra note 5, at viii; see also id. at 45-46 (presuming consent to "somewhat greater health risks").

288. RAKowsK, supra note 39 , at 316 .

289. Rakowski himself conjectures that, once cases involving extremely bad prognoses are excluded, individuals would consent to a random selection procedure such as first-come, first-serve. Id. at 317,323 . But such a random process seems to be one allocation mechanism we can be sure no one would consent to since it does not maximize their expected outcome under any conceivable health measure. See supra Part III.

290. See MenzeL, supra note 5, at 18-19. He also proposes giving somewhat greater weight to patient's assumption of risk in tort law. See id. at 157-61. 
might benefit the health of their patients. That commitment is too deeply embedded in medical culture, has too long a history, and is too closely aligned with plrysicians' financial interest, for it to change without severe resistance, especially when there is nothing intelligible to repace it with. We would also be losing something valuable if we clianged physicians' ethics in this fashion, for it would cast an element of doubt on the patientphysician relationship, undermining the trust essential to make that relationship work.

Nonetheless, althougl not as robust as one might like, presumcd consent does offer significant moral gnidance. In particular, although inquiries into presumed consent do not by themselves seem capable of producing any single choice among various health maximization measures, they do seem useful in excluding some choices. For example, as discussed in Part III, presumed consent seems capable of rebutting the claim that the only way to give equal respect to everyone's interests is to choose randomly among allocation options, even when such random allocation would result in fewer lealth benefits on any measure of aggregate health. We can also presume that one would not consent to allocation plans that discrimmate against their personal characteristics, such as race, sex, or whether they have children. We can further presume, for the reasons discussed in Part $I$, that everyone would reject the absolutist position and want some tradeoff made between the benefits and costs of care. Finally, while presumed consent does not suffice to generate any specific risk-adjustment formula, we can presuine that individuals considering the allocation of resources over their own lifetimes would want soine method of risk-adjustment to avoid an irrational misallocation away from the times in their lives when they will need health care most. ${ }^{291}$ We can also presume that they would not want the riskadjustment formula to reflect the expected costs of expensive heroic ineasures that do no more than postpone death in an unconscious, painful, or temporary state near the end of life. ${ }^{292}$ Leaving these matters aside, the

291. Cf. Daniels, AM I My Parents' KeEPER?, supra note 46, at 63-64 (using similar reasoning to conclude that individuals would allocate resources so that at each point in their lifetimes they could pursue whatever their life plans at that time happen to be); Daniels, Just Health Care, supra note 46, at 96-97 (articulating a theory of prudent allocation of resources over a lifetime).

292. Cf. Dworkin, supra note 257, at 23 (assuming under his hypothetical consent model that individuals would not want insurance coverage for trcatment that would sustain a vegetative or demented state or that would provide only four to five months of additional life to someone who had already reached old age). Unlike Dworkin, I would not presume consent to the exclusion of these matters from coverage because I disagree with his conclusion that mandatory coverage is appropriate, see id. at 23-24, and would thus seek actual consent to coverage tradeoffs. But because mandatory riskadjustments are necessary, the consent to those risk adjustments must be presumed. Although differing from Dworkin's actual conclusions, my conclusions are perfectly consistent with his model of hypothetical consent in a world of equal resources, general medical knowledge, but no knowledge about personal hcalth conditions. One need only conclude that in that world individuals would want health care funding to be equally distributed, but would want to accommodate the likely diversity of preferences and protect themselves from monopoly, distant centralized decisionmaking, and the likely agency costs of governmental decisions by allowing choice among multiple rationing plans with 
system should try as much as possible to secure actual consent to allocation policies by framing the issue in the manner most congenial to common understanding.

\section{E. The Limited Implications of Consent-Based Theory}

In sum, on all the issues critical to drawing conclusions from a prior or ex ante consent framework - the timing of consent, the conditions under which consent should be obtamed, whether and when to presume consent, and what to presume imdividuals would consent to-we are forced to rely on normative justifications independent of any consent framework. We must determine which timing is better, which conditions are more just, when presuming consent is desirable, and what tradeoffs rational imdividuals would want to make. Solving these fundamental issues requires resort to normative judgments not drawn from the autonomous choices of the imdividuals in question.

Autonomy and prior consent are thus far from complete answers to the question of how we should allocate our health care resources. Autonomy arguments do, however, have some important lessons. Whatever process or primciples we use to decide when scarcity requires the denial of health care, we are certainly better positioned to morally justify demals of care if individuals have consented in some fashion to those denials in advance than if they have not. Moreover, if we couple consent theory with the conclusions reached in Parts I-III, we can create a framework for morally and practically tenable consent to specific allocation methods.

\section{CONCLUDING REMARKS}

The potential role ascribed to the moral paradigm in this Article is large. But it far from suffices to guide all health care decisions that any system must make. It is, after all, of no help in encouraging productive efficiency or im assessing scientific issues about what benefits (if any) various treatments have. Nor should it have escaped attention that the moral paradigm has still left us with no answer to the question of how precisely to

appropriate risk adjustments for health conditions. Thus, it seems to me that Dworkin's conclusions go further than required by his model and are insufficiently sensitive not just to preserving moral diversity but also to matters outside the moral paradigm, such as the advantages of competition and decentralized professional deeisionmaking and the special disadvantages of relying on governmental decisionmaking where information costs are high. See infra text accompanying notes 292-93 (summarizing those matters). His model also offers no explanation for why this should be a right to health care rather than a general redistributive right. Indeed, he advocates that all goods be similarly distributed. See Dworkin, supra note 257 , at 25 . But it seems plain that such a general redistribution of all goods would undermine productive incentives, and that actors in his hypothetical consent world would be sufficiently concemed about these productive incentives to want to trade them off against redistribution. 
make tradeoffs between health care and other social goods. That matter remains largely "incorrigible to moral reasoning."293

To address those issues, we must rely on market, professional, and/or political paradigms for making resource allocation decisions. But why should we have any more faith in those decisionmaking processes, and what role should we ascribe to which process? Clearly, a full justification for the health care system I advocate requires more than an assessment of the strengths and weaknesses of the moral paradigm, which is all this Article offers. It requires a comparative assessment of the strengths and weaknesses of the other paradigms. The details of a full comparative paradigm analysis will have to await another day, ${ }^{294}$ but a sketch of the argument is probably necessary to provide context to this Article's analysis of the moral paradigm.

As I see it, the strengths of the market paradigm are the standard ones: if consumers are knowledgeable, have similar resources, and have incentives to trade off the benefits and costs of each product, then market competition promotes productive efficiency, accommodates varying consumer preferences, and achieves allocative efficiency. The problem of unequal resources is largely external to the market paradigm and potentially remediable through vouchers. But the more fundamental problem of the health care market flows from an inherent division between knowledge and incentives. Unlike other markets, no decisionmaker exists who has both the knowledge and the incentives to decide when the costs of supplying a particular good or service exceed its social value. Patients lack the knowledge and, given the fact that others (sucli as insurers or employers) cover much of the social costs, also generally lack the necessary incentives. Physicians and other health care providers are knowledgeable about medicine but not about social benefits and costs. Moreover, under current American market systems they either have incentives to provide too much care (if paid on a fee-for-service basis) or incentives to provide too little (if paid on a capitation basis). Insurance plans generally lack the information to make caseby-case cost-benefit decisions and have incentives to provide too little care, or to select for low-risk enrollees unlikely to need mucli care, because the imsurers pay the costs of health care but do not enjoy its benefits.

These problems with allocating health care according to market signals likely played a role in the success of physicians in establishing a professional paradigm for allocating resources using medical criteria. The strengths of this paradigm are that it offers a scientific basis for assessing

293. Paul Ramsey, The Patient as Person: Explorations in Medical Ethics 240 (1970). Dworkin asserts that his hypothetical consent approach can resolve the question of what to allocate to health care versus other social goods, but in the end he concedes that, because different persons would apply his approach differently, it is important that the decision be made by entities who represent the affected groups after consultation of public opinion, see Dworkin, supra note 257, at 24, which is, of course, to rely on a form of political process.

294. It will be provided in a forthcoming book on which I am working. 
what care is beneficial to the patient's health and what care is harmful and a professional commitment to provide only the former. The main weakness is that it provides no means for trading off the benefits of care against its costs. This paradigm is likely to offer net advantages in a world, which arguably existed a number of decades ago, where the benefits of that care which is beneficial are large compared to its costs and the amount of harmful and unnecessary care eliminated through professional self-discipline is high. Of course, it is a cominonplace observation that such a world no longer exists because new technology has spawned much care that offers only marginally greater benefits at disproportionately larger costs. What is less commonly appreciated is that, by dictating the purchase of whatever offered greater health benefits than the alternatives, it was inevitable that the professional paradigm would spawn innovation of technology with low marginal benefits. Under such a paradigm, for reasons similar to those discussed in Part $\mathrm{I}$, researchers see no poimt in developing a product that confers slightly lower benefits at far lower costs because such a product wonld be impossible to sell. Instead, they focus on developing any margimally more beneficial product, no matter what the additional cost, because that they can sell. This is what we might call the "Field of Dreams" problein of health policy: if we'll pay for it, it will come. Thus, even though probably the optimal paradigm during one period of history, the professional paradigm carried with it the seeds of its own demise.

Where markets and self-regulation fail, it is natural to turn to the pohtical process. The main advantages of the political paradigm are (1) that it can make the open-ended tradeoffs between health care and other social goods that do not lend themselves to objective scientific analysis and (2) that, unlike decisionmakers under the market and professional paradigms, political decisionmakers have incentives to weigh benefits against costs because both are experienced by the polity. The disadvantages are that the political process is inevitably too centralized to effectively trade off the benefits and costs of health care in individual cases, and is susceptible to problems of majoritarian bias, intransitive choices, and interest-group politics. ${ }^{295}$ These weaknesses counsel for limiting the political process to one global issue: how high to set the national (or state) level of health care spending and associated tax. This avoids the political process' inability to make operational decisions, and lessens the concern of majoritarian bias because funding levels are more likely to affect everyone equally than decisions about which treatments to fund. This way of framing the political decision is also more likely to produce both "single-peaked" preferences resistant to intransitivity problems ${ }^{296}$ and, more important, low political

295. See generally Elhauge, supra note 234, at 31.

296. Preferences are single-peaked only when the options can be laid along a continuum such that, for every individual, the options are less preferable the further away they are from his peak preference. 
information costs that render the process less susceptible to interest group dominance.

The combination of these strengths and weaknesses, when coupled with the potential and limitations of the moral paradigm, support the more specific system I set forth im the Introduction. Indeed, I believe that the developed nations of the world are slowly evolving toward such a system from different directions. But one need not accept these specific normative and empirical conclusions to accept the wider methodological point: that it is often, if not always, more useful to analyze issues of health law policy from the perspective of one who does not assume all the answers will come from any given paradigm of decisionmaking or scholarly analysis. Rather some, indeed a great many issues, should frankly be recogmized as beyond the ken of any one paradigm.

Of course, it is generally a defining mark of legal scholarship that, however theoretical, it must ultimately relate to law by answering a concrete question: what, given current knowledge, should be the current legal framework? The legal scholar thus does not have the luxury of stopping once she has drawn the limited conclusions that can be generated by a single nonlegal scholarly discipline. To perform meaningful legal scholarship, she must stand sufficiently astride each paradigm to permit comparative paradigm analysis. Luckily, this is a mode of analysis in which legal scholars, as cross-disciplinary generalists, have some plausible claim to coinparative scholarly advantage. Unluckily, it is hard and arduous. Nevertheless, it offers the promise that health law scholars will provide insights into health policy that so far have been missed. In a field as intellectually new as modern health law, it should hardly be surprising that this task has only begun.

Whenever individual preferences are not single-peaked in this fashion, majority rule can experience pervasive intransitivity and cycling. See MUELLER, supra note 195, at 64-82. 